

\title{
INVESTIGATION OF ACOUSTIC EMISSION COUPLING TECHNIQUES
}

\author{
FINAL REPORT \\ Contract NAS8-34649 \\ Southwest Research Institute \\ Project No. 17-7445
}

\begin{abstract}
Prepared for
National Aeronautics and Space Administration

George C. Marshall Space Flight Center

Marshall Space Flight Center, Alabama 35812
\end{abstract}

September 1988

Prepared by

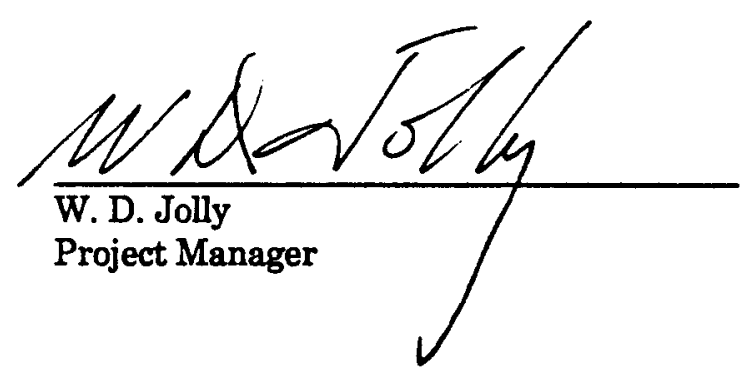

Approved by

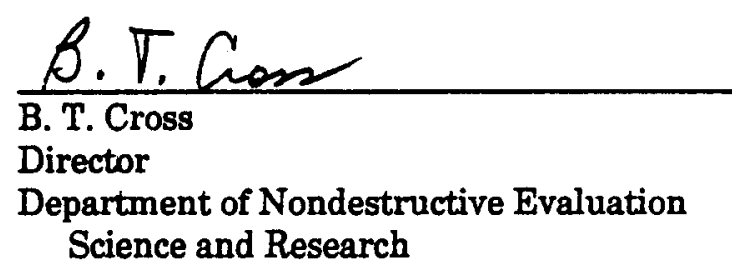


Page

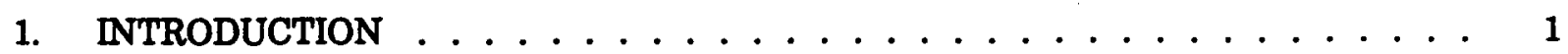

2. TECHNICAL DISCUSSION ....................... . 2

2.1 Prototypes and Tests at MSFC . . . . . . . . . . . . . . . . 2

2.1.1 BMT Configuration . . . . . . . . . . . . . 2

2.1.2 Test Results ..................... 3

2.2 Fabrication of Four ACPs .................... 3

2.2.1 Design Review . . . . . . . . . . . . . . . . . 3

2.2.2 ACP Assembly . . . . . . . . . . . . . . . . . 3

2.2.3 ACP Installation . . . . . . . . . . . . . 6

2.3 Functional Tests at SwRI . . . . . . . . . . . . . . . 6

2.3.1 Acoustic Signal Source . . . . . . . . . . . . . . . . 6

2.3.2 Test Setup . . . . . . . . . . . . . . . . 6

2.3.3 Preamplifier Tests ................... 6

2.3 .4 ACP Tests ......................... 9

2.4 Calibration of ACP Units . . . . . . . . . . . . . . . 11

3. CONCLUSIONS AND RECOMMENDATIONS . . . . . . . . . . . . . . . . 14

APPENDIXES

A Phase I Final Report - Investigation of Acoustic Emission Coupling Techniques

B Phase II Final Report - Development of an Acoustic Monitor to Detect Incipient Bearing Failure 


\section{LIST OF FIGURES}

Firure

Page

1 Acoustic Coupler Probe Mounted on BMT . . . . . . . . . . . . . . 4

2 Cross Section of Acoustic Coupler Probe ................ 5

$3 \quad$ Block Diagram of Test Setup for Functional Tests of ACP-preamplifier Units . . . . . . . . . . . . . . . . . . 7

4 Gain-phase Response of Five Preamplifiers . . . . . . . . . . . . . . . . 8

5 Spectral Amplitude Response of Five ACPs Showing Effect of Damping on Coupler Rod. . . . . . . . . . . . . . . . . . . . . 10

6 Spectral Amplitude Response of ACP No. 4 Showing Effect of Damping on Piezoelectric Element. . . . . . . . . . . . . . . . . . 12

7 Calibration of the Original Prototype and the Four New ACP-preamplifier Units - Spectral Amplitude Response and Waveform Data . . . . . . . . . . . 13

\section{LIST OF TABLES}

Table

Page

1

Preamplifier Performance Data . . . . . . . . . . . . . . . . 9

2

ACP Performance Data . . . . . . . . . . . . . . . . . . . 


\section{INTRODUCTION}

Liquid-fueled rocket motors depend on turbopumps to deliver fuel and oxygen to the combustion chamber at a very high but finely controlled mass flow rate. The bearings in certain types of turbopumps are lubricated and cooled by the flow of liquid axygen through the bearing assembly. The bearings on the turbopump shaft are open cage ball bearings of specially selected alloys designed to meet the load requirements of turbopump service at speeds of up to $35,000 \mathrm{rpm}$.

If the surface of a bearing ball or race is subjected to excess wear, the stresses on the bearing become irregular and the lubricating film of oxygen cannot support the uneven load. Deterioration of the bearing begins when the lubricating film breaks down. The heat of friction increases, stress irregularities increase, damage to the bearing becomes more severe, and the increase in frictional heat continues until the kindling temperature of the metal is reached. The turbopump is then consumed by fire. Therefore, integrity of the turbopump bearings is very important to the operation of a liquid-fueled rocket motor.

To ensure the integrity and reliability of turbopump bearings, the alloys and surface treatments used in the turbopump bearings are tested for durability under simulated rocket motor service on the bearing materials tester (BMT) at Marshall Space Flight Center (MSFC). However, further assurance of bearing integrity and reliability could be realized by continuously monitoring the turbopump bearings on a rocket motor to detect and record any changes in surface condition that may indicate the onset of bearing failure.

A three-phase research program was initiated by NASA in 1983 to investigate the use of acoustic monitoring techniques to detect incipient failure in turbopump bearings. Two prototype acoustic coupler probes were designed and evaluated, and four units of the final probe design were fabricated and delivered to MSFC. Success in this program could lead to development of an on-board monitor which could detect bearing damage in flight and reduce or eliminate the need for disassembly after each flight.

This final report reviews the accomplishments of the first two phases and presents the results of fabrication and testing completed in the final phase of the research program. 


\section{TECHNICAL DISCUSSION}

The acoustic coupler probe (ACP) was designed to monitor the average noise level from the bearing balls in rolling contact with the outer race. The probe contacts the bearing race on the outer radius. The point of the probe in contact with the bearing race couples the sound to a piezoelectric element. The piezoelectric element has a primary free resonance at about $640 \mathrm{kHz}$ due to cross coupling in the element between the radial and the thickness vibration modes. This cross coupling is strong because the thickness-to-diameter ratio is near 1 .

The output of the probe is conditioned in a preamplifier to remove frequencies below $200 \mathrm{kHz}$ and match the high sensor impedance to a $50-93 \mathrm{ohm}$ coaxial cable. The preamplifier is battery powered in the prototype configuration to provide isolation from power supply noise and eliminate the possibility of a ground loop between the sensor and the preamplifier power supply. The preamplifier drives up to 1500 feet of coaxial cable. The cable must be properly terminated at the data acquisition station.

The system is designed to use low frequency variation of the RMS voltage output of the preamplifier as the primary analysis parameter. Trends in the RMS output are correlated with the bearing condition at a given coolant flow and rate of rotation of the bearings. With all four bearings of the BMT instrumented, direct comparison from bearing to bearing will increase the sensitivity to detection of bearing wear or surface deterioration.

The acoustic response of the probe over the frequency range of $200-800 \mathrm{kHz}$ is used to monitor the bearing noise. The total noise monitored includes the noise generated by high velocity coolant (liquid nitrogen) flow through the open cage of the bearing. This flow noise usually includes high-level turbulence and may include cavitation under extreme conditions. Cavitation noise is particularly intense and rich in the same frequencies as the expected noise from bearing damage. This may be due to the fact that the collapse of cavitation bubbles near the metal surface can cause fracture and erosion of the metal. In any event, the bubble collapse is a sharp impulse of pressure sufficient to produce yield or fracture in the steel.

The technical accomplishments of the first two phases of this program are detailed in Appendices 1 and 2. A very brief summary is given here.

\subsection{Prototypes and Tests at MSFC}

The first phase of the research program was directed toward the development of an acoustic probe to monitor the performance of liquid axygen (LOX) cooled and lubricated bearings which were being evaluated by MSFC on the BMT.

\subsubsection{BMT Configuration}

Bearing performance could be monitored by the acoustic probe if other noise sources could be screened out. The high velocity flow of the LOX around the bearing balls and the mechanical noise from the BMT drive system were the primary sources of interfering noise. During Phase I, an acoustic probe was developed for access through a special port in the BMT to make acoustic contact with the edge of the outer bearing race on the number 1 bearing. This design was judged to be unsafe because the severe turbulence of the LOX flow around the probe could cause the probe to vibrate and possibly break off, damaging the bearings. Details of Phase I accomplishments are included in Appendix A. 


\subsection{Test Results}

An alternative acoustic coupler probe (ACP) design was developed and evaluated on the BMT in Phase II of the research program. For this design, access to the bearing race surface was through existing instrument ports which were shielded from the LOX flow. Figure 1 illustrates the installation of the ACP on the BMT.

The ACP prototype was evaluated on bearing number 3 during bearing tests on the liquid nitrogen BMT. Figure 1(a) shows the BMT prior to a test run with the ACP installed in port number 29. The BMT is extensively instrumented, making it difficult to distinguish the ACP from other sensor probes mounted on the BMT body. Figure 1(b) is an enlargement of the section of the BMT around the ACP. The ACP is indicated by a pointer on the picture.

The BMT tests showed that the level of RMS noise from the probe during initial run-up to maximum flow of liquid nitrogen and bearing rotation of $30,000 \mathrm{rpm}$ was less than 1 millivolt RMS at the sensor. This measured level of noise was a factor of 50 below limit of linear dynamic range of the preamplifier, and the variation of the flow/rotation noise level was sufficiently low that it would be possible to detect a sustained increase above the initial background level of as little as 20 microvolts RMS. This means that the sensitivity to bearing damage noise is adequate to detect an increase in roughness due to wear during the test. The results of monitoring bearing tests on the BMT showed that the background noise due to LOX flow and the drive mechanism could be suppressed sufficiently to detect a small change in the noise contribution due to bearing surface noise. A detailed report of the accomplishments of Phase II may be found in Appendix B. The following sections address the design review, probe fabrication, and laboratory testing of a set of four ACP units based on the prototype design tested in Phase II.

\subsection{Fabrication of Four ACPs}

The final phase of the research program addressed the fabrication and testing of four additional ACPs which could be used to monitor all four bearings of the BMT. Monitoring all four bearings simultaneously would enhance the sensitivity for bearing damage detection by bearing-to-bearing comparison of noise signatures. This section reviews the design and assembly of the ACP.

\section{Design Review}

The ACP was designed to fit into the ball pass or thermocouple ports on the liquid nitrogen version of the BMT (materials used in probes are not rated for liquid oxygen). The performance of the prototype ACP during testing on the BMT was satisfactory. Inspection of the disassembled ACP indicated no damage to internal components. Design review resulted in selection of the prototype design for fabrication of a complete set of ACPs for further testing on the BMT.

\subsection{ACP Assembly}

The ACP is shown in cross section in Figure 2. Acoustic pressure waves from the bearing are coupled by the rod through the anvil to the piezoelectric sensing element. The piezoelectric sensing element converts the pressure wave to an alternating electrical voltage. The voltage is coupled to the coaxial cable connector at the top of the assembly through the compliance/force spring and the rod through the packing gland. The electrical circuit is completed through the anvil and the coupler rod to the body of the assembly by means of a conical 


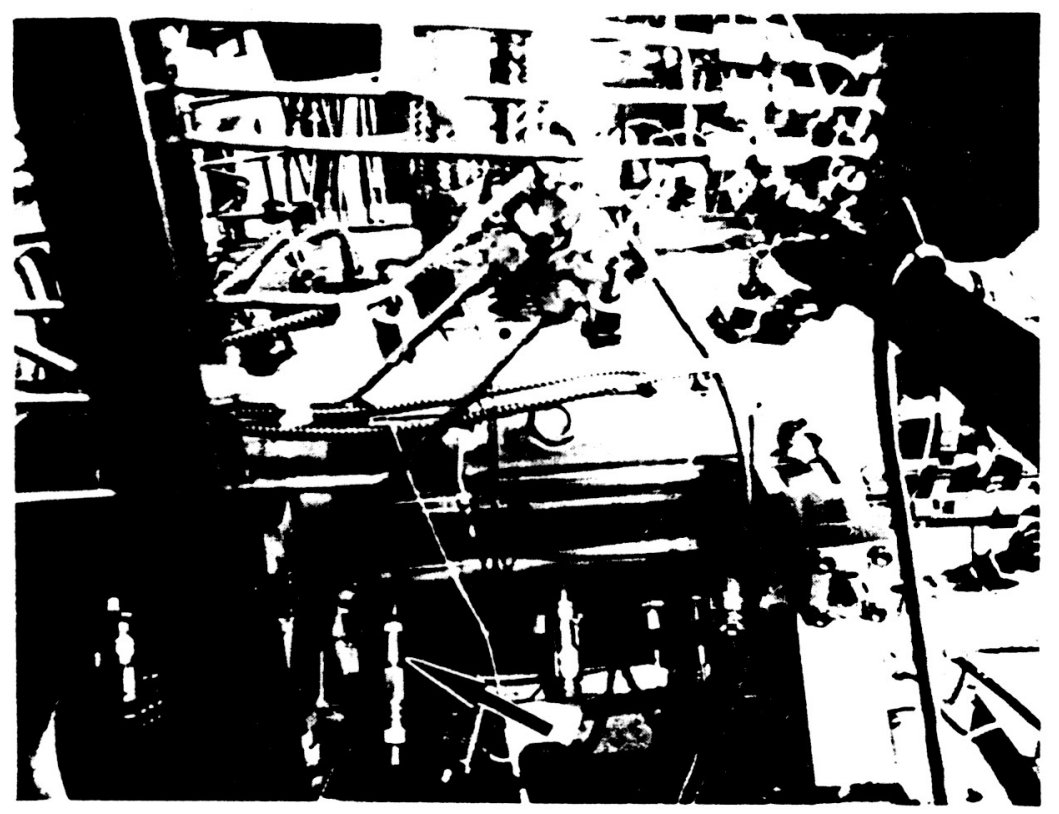

a. Bearing Materials Tester Showing Location of ACP on Bearing No. 3

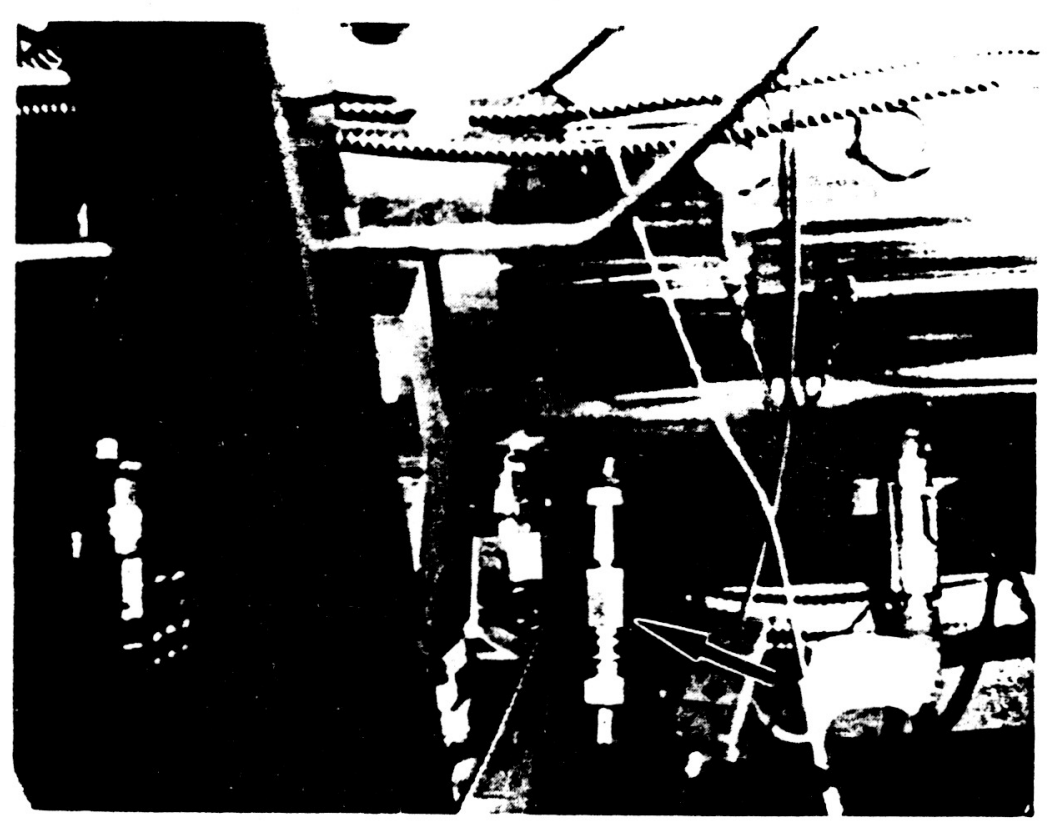

b. ACP Mounted on BMT

Figure 1. Acoustic Coupler Probe Mounted on BMT 


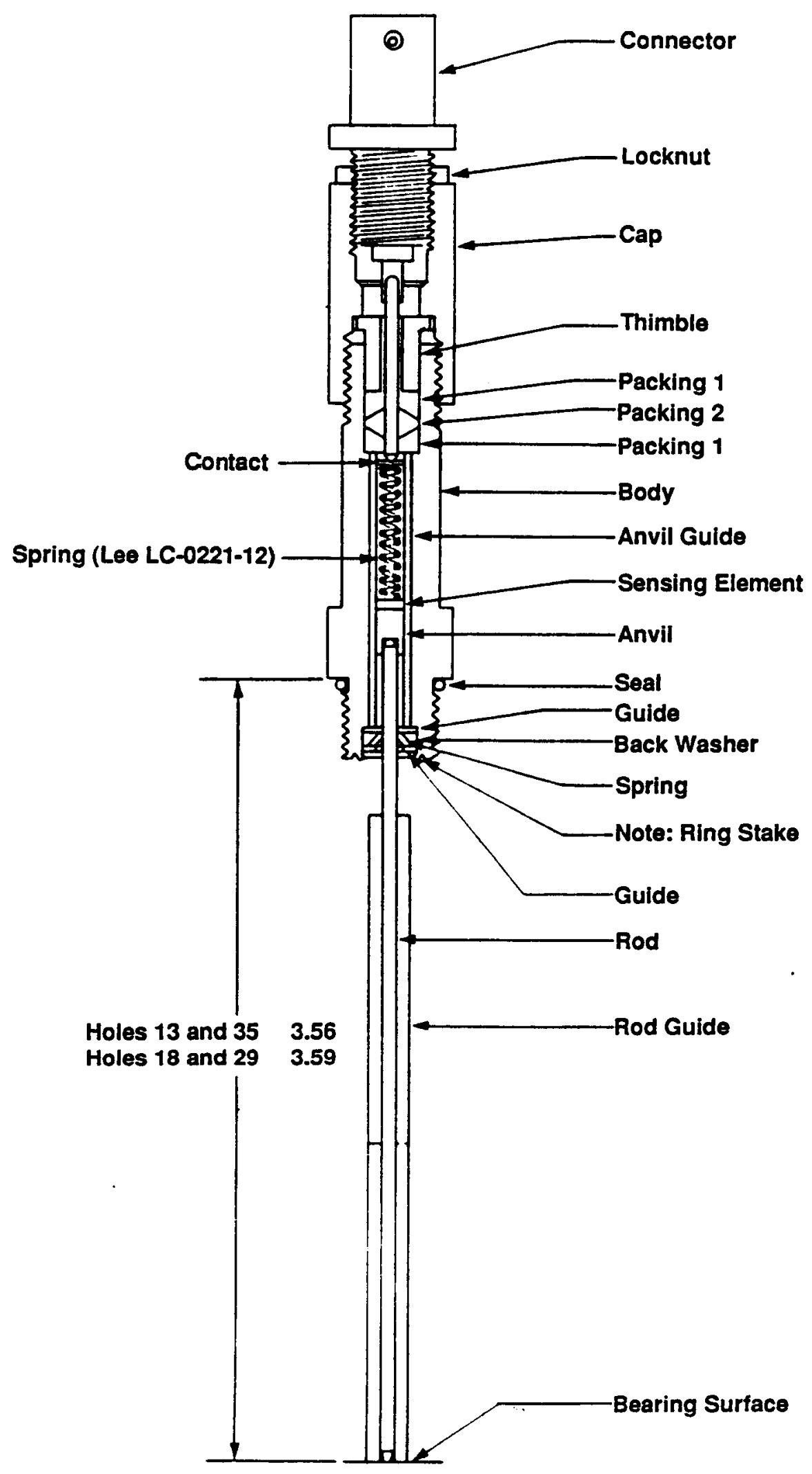

Figure 2. Cross Section of Acoustic Coupler Probe 
spring located where the coupler rod enters the body of the assembly. Acoustic isolation and electrical insulation of the piezoelectric sensing element from the body of the assembly is provided by the teflon anvil guide tube.

\subsection{ACP Installation}

Installation of the probe on the BMT requires that the depth of the port be measured. It is necessary to adjust the spring pressure on the tip of the coupler rod against the bearing outer race to obtain a contact force of 2 to 5 pounds. The contact force depends on compression of the spring above the piezoelectric element. The spring compression can be adjusted when the packing gland is not sealed by turning the rear nut on the coaxial cable connector after loosening the lock nut. When proper compression of the spring is achieved, the lock nut on the coaxial cable connector is tightened, and the packing gland is sealed by tightening the cap to the body.

\section{$2.3 \quad$ Functional Tests at SwRI}

Three types of functional tests were conducted to characterize the ACP preamplifier units. First, the gain-phase response of the preamplifiers was characterized. Second, the acoustic couplers were evaluated under two specific conditions of damping on the coupler rod. Third, the effect of damping on the piezoelectric element was evaluated. The signal source used for characterization of the ACP units is described below.

\subsection{Acoustic Signal Source}

The pencil lead break signal is a standard source for acoustic emission sensor and systems testing. This standard source was developed by the National Bureau of Standards and adopted by ASTM (E976-84). The pencil lead, extended $1 \mathrm{~mm}$ from the pencil tip and held at an angle of 45 degrees to the test surface, is used to apply a gradually increasing stress normal to a test surface. The bending load thus applied to the extended pencil lead suddenly fractures the pencil lead, releases the load on the test surface, and produces an elastic wave in the test piece. A pencil lead $(0.5 \mathrm{~mm}, 2 \mathrm{H})$ break was the broad band impulsive signal source used for the spectral characterization of each acoustic coupler.

\subsubsection{Test Setup}

The functional tests on the ACP units were carried out using the instrumentation setup shown in Figure 3. The gain phase characterization of the preamplifiers was performed on a Hewlett-Packard HP-4194 Gain/Phase analyzer.

\subsubsection{Preamplifier Tests}

The preamplifier used with the ACP is a standard SwRI-developed acoustic emission preamplifier modified to operate on external battery power at a gain of $22 \mathrm{~dB}$ into 50 -ohm termination. The gain/phase response of five preamplifiers is shown in Figure 4. The preamplifier design includes a high pass filter with a sharp cut-off at $200 \mathrm{kHz}$ to reduce the ACP response to lower frequency mechanical and fluid turbulence noise. The gain plots show that the preamplifiers are not band limited below $5 \mathrm{MHz}$, and the phase plots indicate that the high pass filter introduces a phase rotation in the cut-off region, but the phase shift varies slowly through the amplifier in the pass band. Further data on the preamplifier performance including gain, maximum input/output voltage, and input impedance are listed in Table 1. 


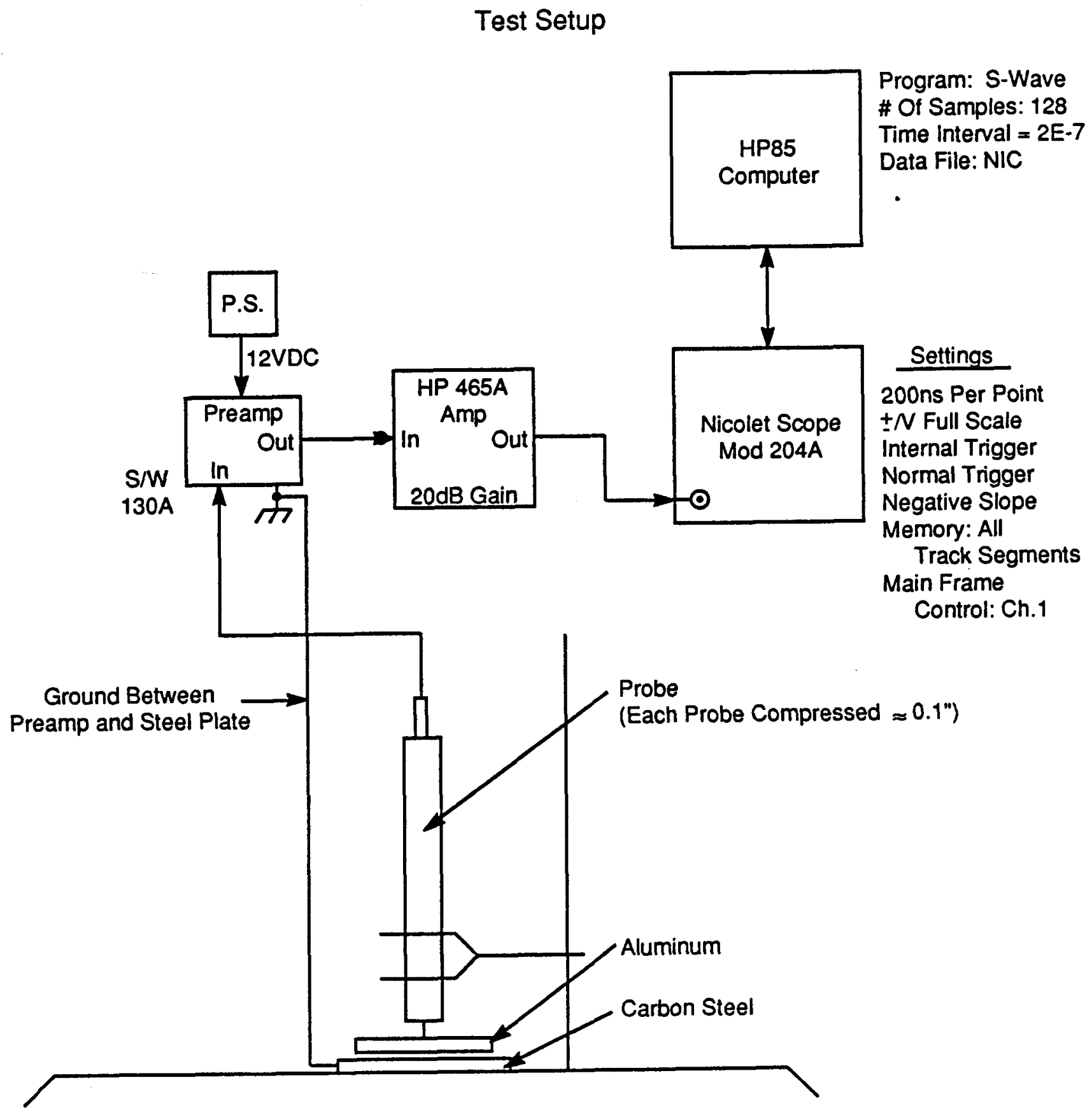

Figure 3. Block Diagram of Test Setup for Functional Tests of ACP-preamplifier Units 
ORIGINAL PAGE IS

OF POOR QUALITY

AE PREAMP MOIEL GZGTT: $54 A$

A:TRCDEJB: B

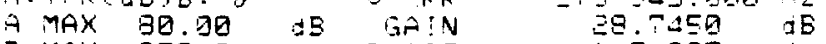

B MAX 250.0 teg PHASE -113.887 deg

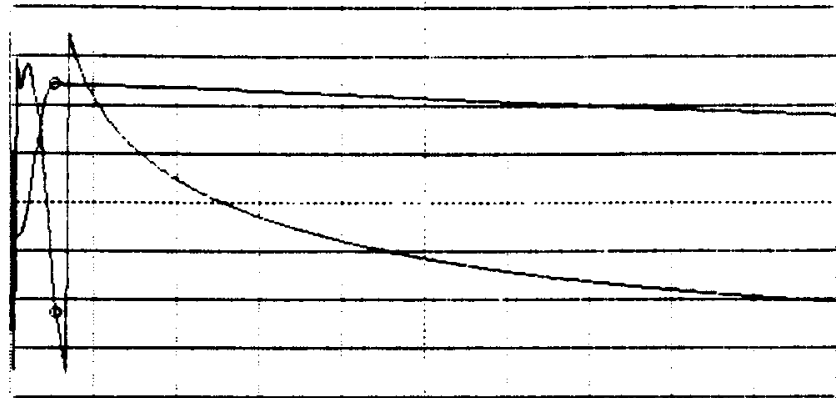

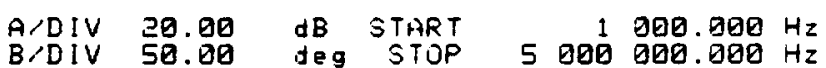

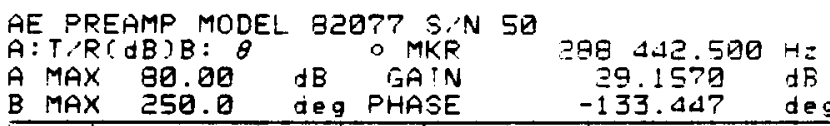

$B$ MAX 250.0 deg PHASE -133.447 deg

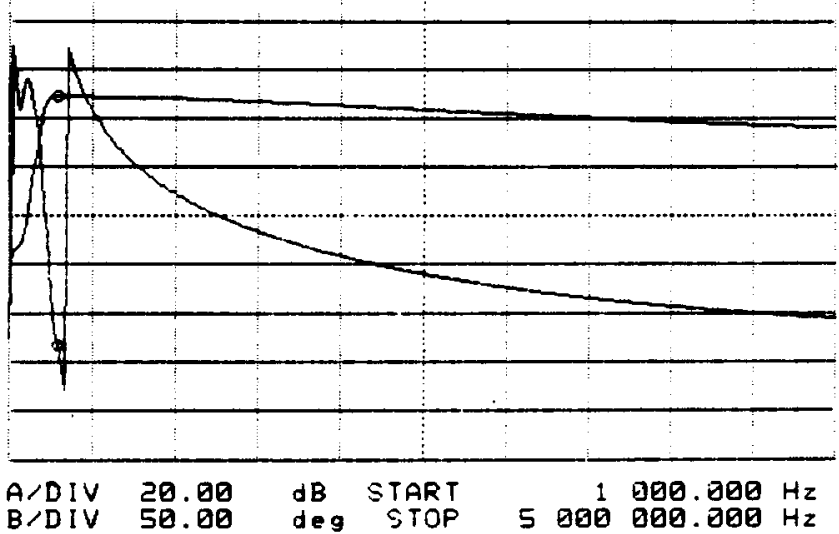

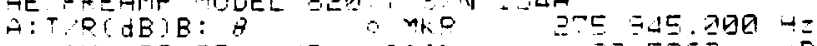

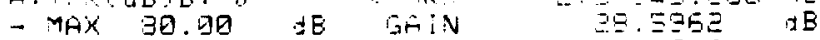

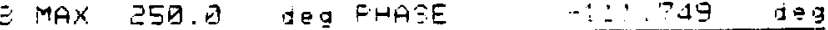

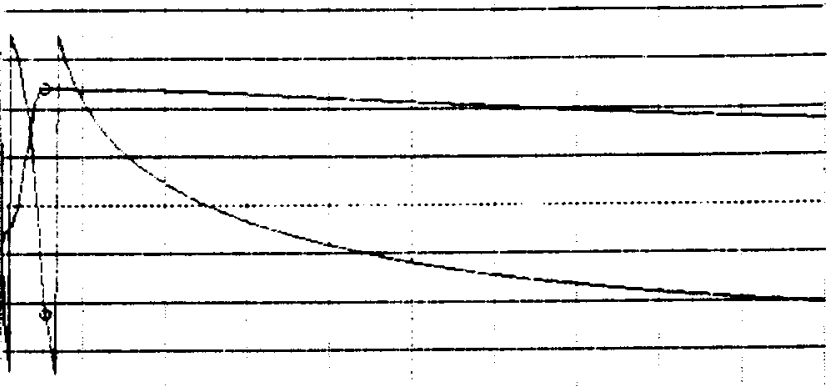

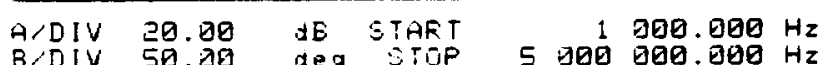

AE FREAMP MODEL $3207 T$ S $57 A$

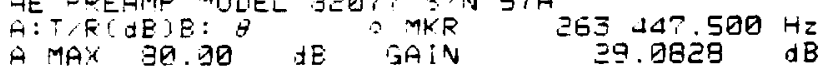

B MAX 250.0 deg PHASE -1077.145 deg

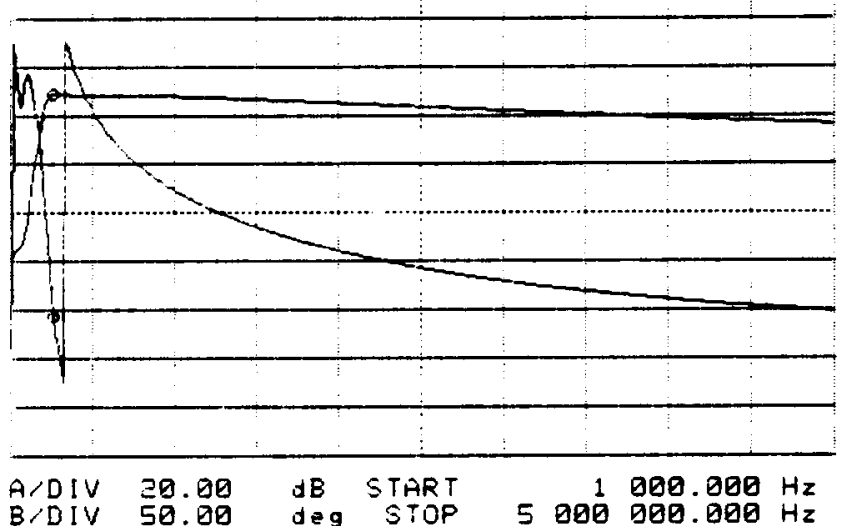

AE PREAMP MODEL B2077 S,N 115

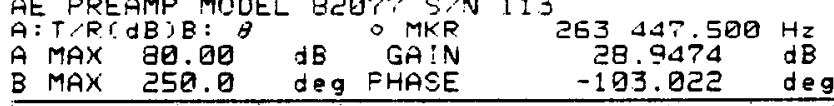

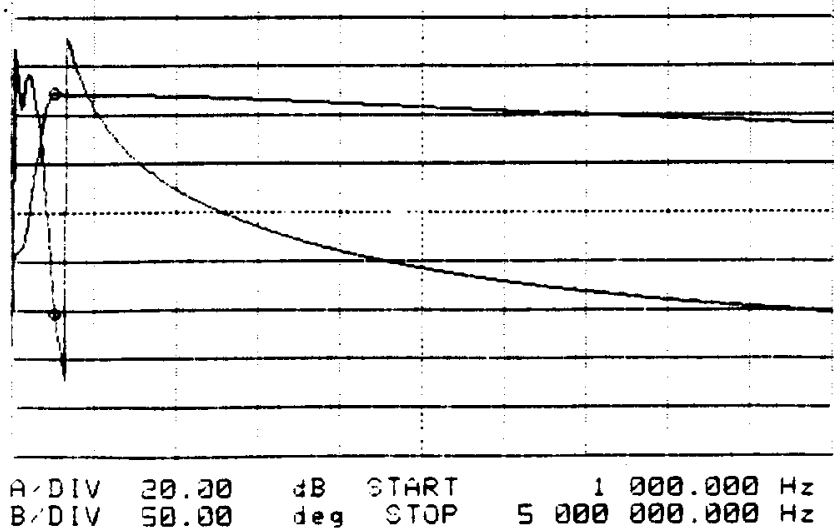

Figure 4. Gain-phase Response of Five Preamplifiers 
Table 1

PREAMPLIFIER PERFORMANCE DATA

$\mathrm{f}=500 \mathrm{kHz}$

\begin{tabular}{cccc} 
Serial No. & $\begin{array}{c}\text { Input } \\
\text { (millivolts } \\
\text { peak-to-peak) }\end{array}$ & $\begin{array}{c}\text { Output } \\
\text { (volts } \\
\text { peak-to-peak }\end{array}$ & Gain $\left(\frac{V_{\text {out }}}{V_{\text {in }}}\right)$ \\
\hline $54 \mathrm{~A}$ & 148 & 4.69 & 31.6 \\
$134 \mathrm{~A}$ & 146 & 4.58 & 31.0 \\
50 & 135 & 4.59 & 34.0 \\
$\begin{array}{c}\text { (unit returned } \\
\text { from MFSC) }\end{array}$ & 138 & & \\
$57 \mathrm{~A}$ & 141 & 4.61 & 33.4 \\
113 & 4.51 & 31.9
\end{tabular}

NOTE: Input is adjusted until output just begins to clip; then output is measured. All readings are with no load.

\subsection{ACP Tests}

The ACP design subjects the coupler rod and the piezoelectric element to wetting by the liquid nitrogen or LOX in the BMT chamber. Wetting of the coupler rod and the piezoelectric element could change the sensitivity of the ACP due to acoustic damping. Two types of tests were conducted to evaluate the effects of damping the couplant rod and the piezoelectric element on the sensitivity and the spectral response of the ACP. One test series was designed to evaluate the effects of damping on the acoustic coupler rod, and the second test series was designed to determine the effect of damping material applied to the back surface of the piezoelectric element. Both series of tests were analyzed by comparison to the response of the ACP in normal configuration as indicated by the performance data listed in Table 2. Table 2 documents the input impedance, center frequency, bandwidth, and sensitivity in terms of response to a standard lead break signal.

The results of the coupler rod damping test series are shown in Figure 5. In Figure 5(a), the coupler rod was clean and dry in order to minimize the damping of acoustic waves at the rod surface. In Figure 5(b), the rod surface was coated with DC-4 silicone compound in order to maximize the coupling of the rod surface to the teflon guide tube. Some variation in the maximum amplitude between damped and undamped rods was evident. The sensitivity with damping tended to be higher than the sensitivity without damping. Damping tended to reduce the lower frequencies in the $200-$ to $400-\mathrm{kHz}$ range and enhance the frequencies above $400 \mathrm{kHz}$. 

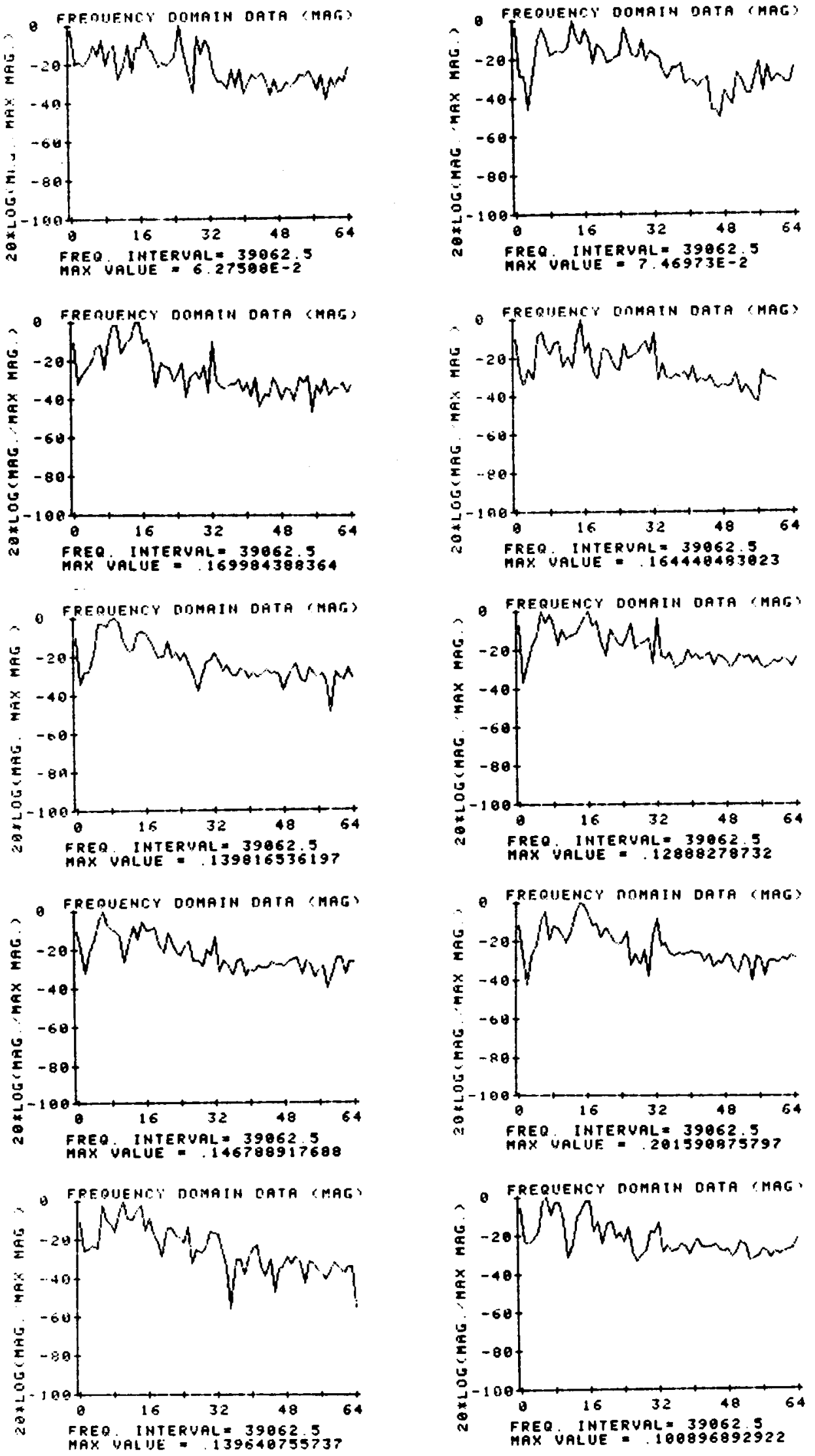

a. Coupler Rod Normal

b. Coupler Rod with Damping

Figure 5. Spectral Amplitude Response of Five ACPs Showing Effect of Damping on Coupler Rod 
Table 2

ACP PERFORMANCE DATA

\begin{tabular}{ccccc} 
ACP No. & $\begin{array}{c}\text { Output } \\
\text { Impedance } \\
\text { (k-ohm) }\end{array}$ & $\begin{array}{r}\text { Bandwidth } \\
( \pm 10 \mathrm{~dB})\end{array}$ & $\begin{array}{c}\text { Center } \\
\text { Frequency } \\
\text { (kHz) }\end{array}$ & $\begin{array}{r}\text { Load-Break } \\
\text { Peak-to-Peak } \\
\text { Amplitude } \\
\text { (millivolt) }\end{array}$ \\
\hline 0 & 16 & 820 & 566 & 3.2 \\
1 & 15.7 & 700 & 508 & 5 \\
2 & 16.1 & 546 & 430 & 12 \\
3 & 15.9 & 469 & 390 & 3.9 \\
4 & 14.5 & 664 & 527 & 5.1
\end{tabular}

Effects of damping on the piezoelectric element were evaluated by insertion of DC-4 compound into the probe against the back of the piezoelectric element. Comparison of the damped and undamped piezoelectric elements is shown in Figures 6(a) and 6(b). The effect of the damping is measurable but not detrimental to the function of the ACP. The evaluation of damping effects indicates that wetting of the rod and the piezoelectric element do not seriously change the sensitivity or spectral response of the assembly. The wetting condition would begin as the BMT is cooled down to operating temperature, and the condition would persist throughout the test.

\subsection{Calibration of ACP Units}

The five ACPs were calibrated using the test setup detailed in Figure 3. The lead break acoustic source was used to excite the ACP through a test block. The ACP coupler rod tip was compressed into the housing by 0.1 inch to produce adequate coupling pressure. The waveforms were recorded on a transient recorder, digitized, and analyzed by a fast Fourier transform to obtain the spectral response of each probe. Figure 7 documents the spectral response and the waveform sample used for calibration of each ACP. Table 2 contains a summary of the performance data on each ACP. This calibration test or other performance measurement procedure should be repeated at 6-month intervals to assure continued performance of the ACP units. 

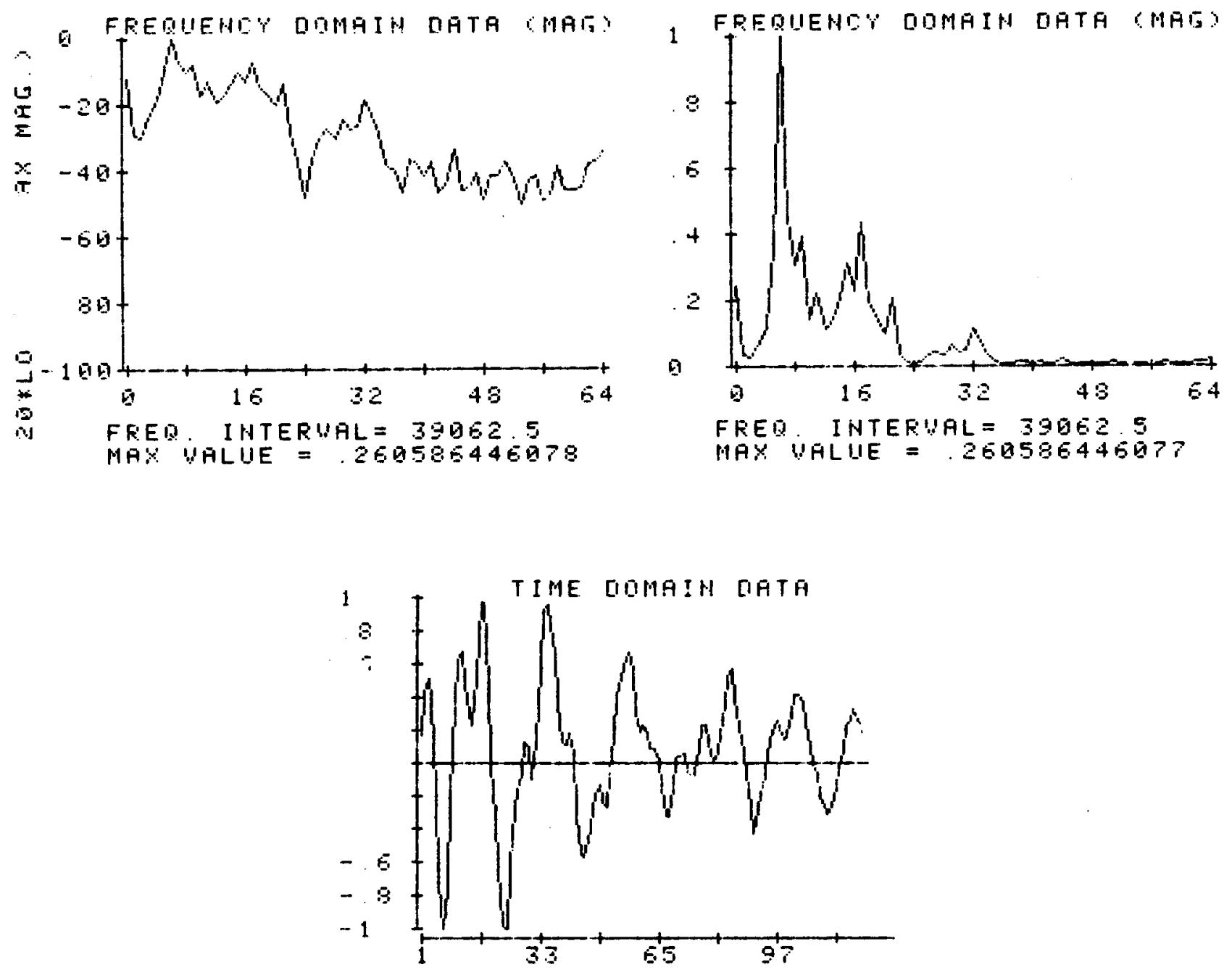

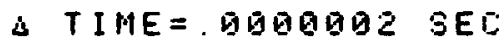

AESCMAX) $=.71999999998$

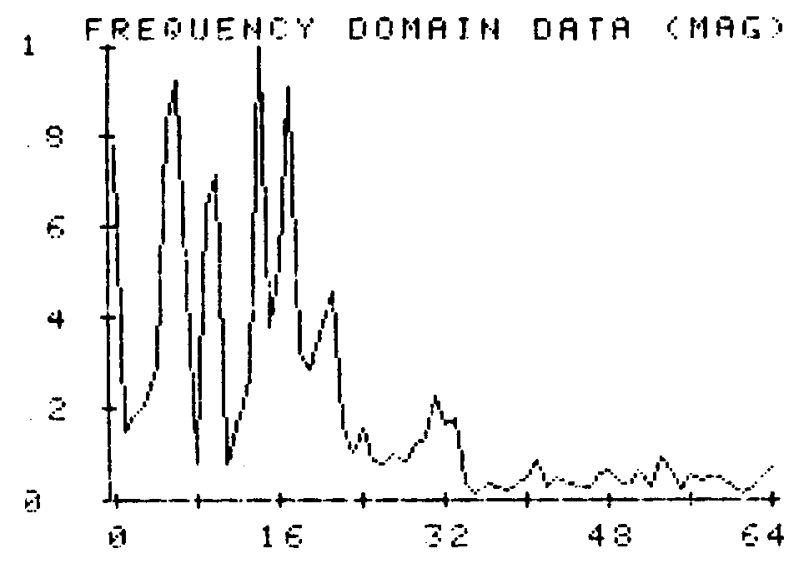

FFED. IHTERUAL = $30 E .5$

$M A X Y A L U E=E .2 Q 3 B S E-2$

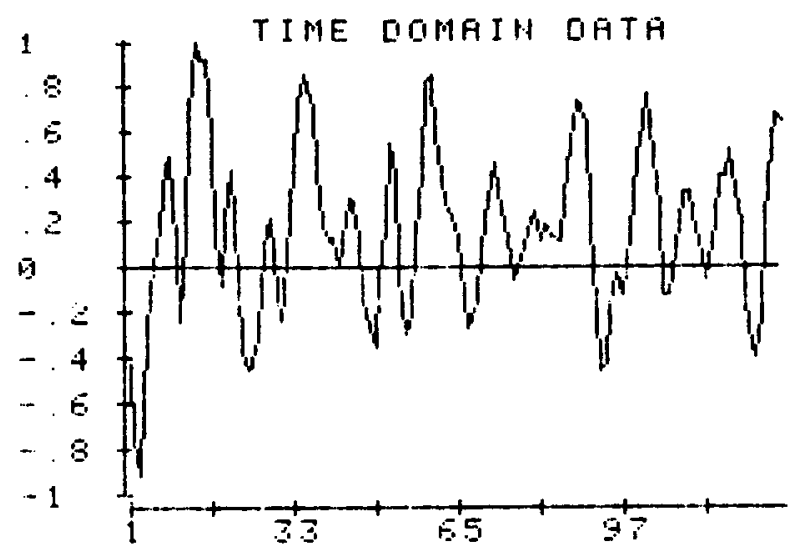

$\therefore$ TIME = GOMOQD2 SEL AESCHAX) $=296$

Figure 6. Spectral Amplitude Response of ACP No. 4 Showing Effect of Damping on Piezoelectric Element 

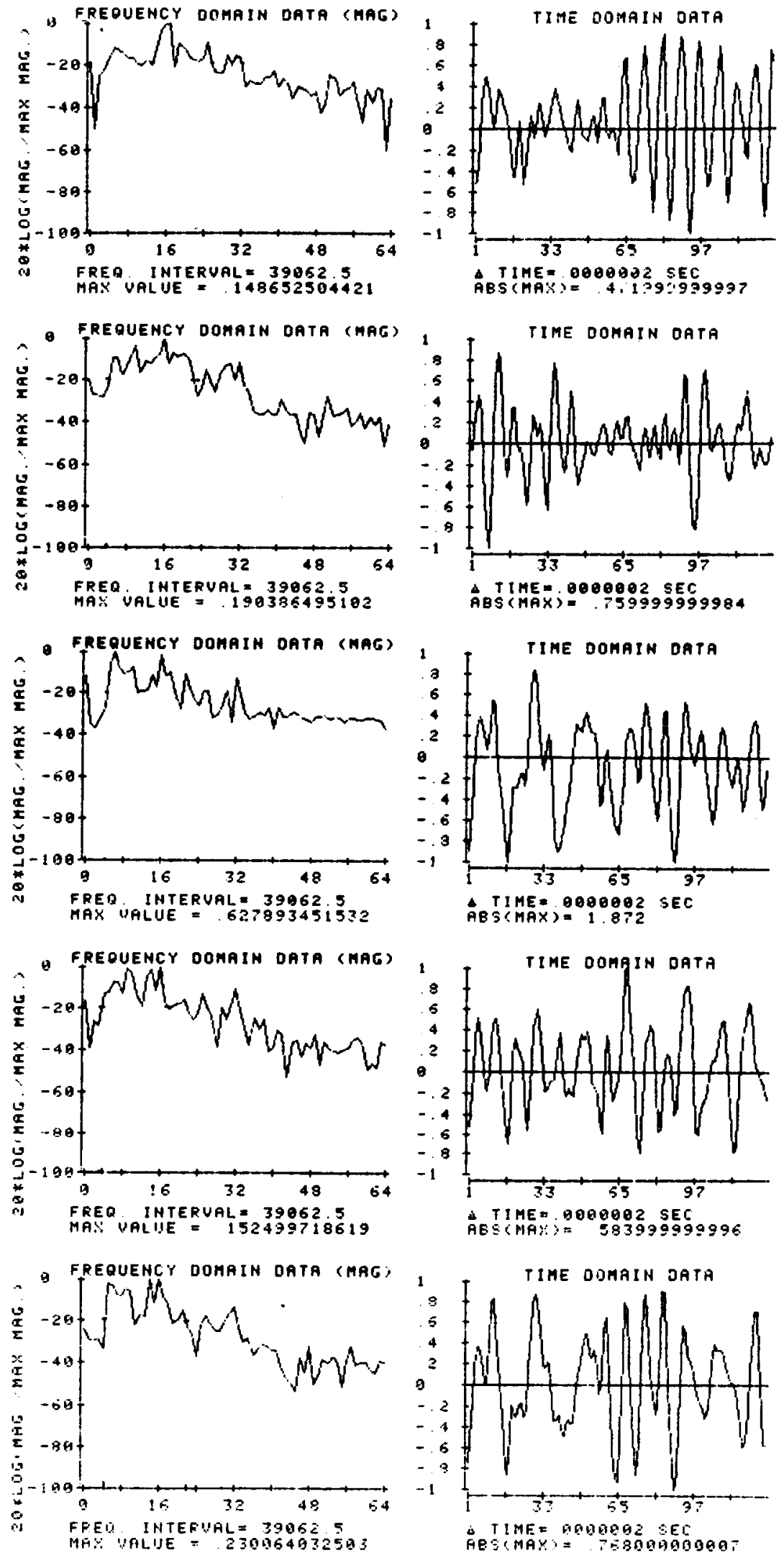

Figure 7. Calibration of the Original Prototype and the Four New ACP-preamplifier Units - Spectral Amplitude Response and Waveform Data 


\section{CONCLUSIONS AND RECOMMENDATIONS}

The development of an acoustic coupler probe for monitoring the change in bearing noise due to wear or bearing damage was completed. Tests on the Bearing Materials Tester at MSFC showed that the dynamic range and the sensitivity of the ACP were sufficient to detect changes in the bearing noise during full flow at maximum rotational speed of the BMT. Four production units and a spare were delivered to MSFC, and instrumentation staff were instructed in procedures for installation and checkout of the ACPs.

It is recommended that the ACP units be used on the BMT to acquire data from several types of bearing materials under varying loads and conditions of damage to the bearing ball and race. It is further recommended that the ACP design should be upgraded for on-board monitoring of bearings in turbopumps during earth-to-orbit flights. 


\section{APPENDIX A \\ PHASE I FINAL REPORT \\ INVESTIGATION OF ACOUSTIC EMISSION \\ COUPLING TECHNIQUES}




\title{
INVESTIGATION OF ACOUSTIC EMISSION COUPLING TECHNIQUES - PHASE I
}

\author{
FINAL REPORT \\ SwRI Project 17-7445 \\ NASA Contract NAS8-34649
}

\begin{abstract}
Prepared for
National Aeronautics and Space Administration

George C. Marshall Space Flight Center

Marshall Space Flight Center, Alabama 35812
\end{abstract}

Prepared by

Quality Assurance Systems and Engineering Division

June 1984

Written by

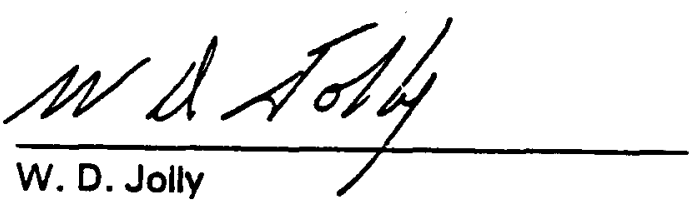

Technical Consultant

Department of Nondestructive

Evaluation Research
Approved by

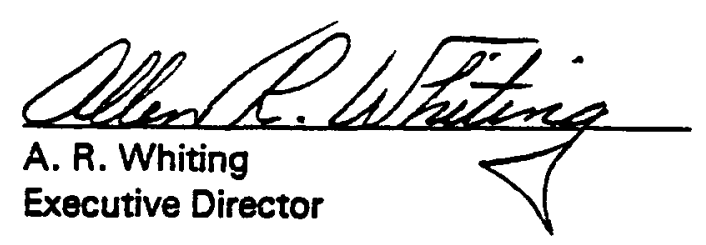


In January 1983, this project was initiated with the objective to develop conceptual designs for one or more mechanisms capable of coupling acoustic intelligence from bearings in the National Aeronautics and Space Administration (NASA) "bearing materials tester" (BMT) to an externally mounted acoustic emission sensor.

This project was Phase I of a program directed to the larger problem of developing a device to detect incipient bearing fallure in the BMT. Bearing failure in the liquid oxygen environment of the BMT can have catastrophic results.

Southwest Research Institute (SwRI) suggested three designs for the acoustic coupler for the BMT. The first design, called the hooked acoustic coupler waveguide, was developed to meet the specifications of the Request for Procurement. The acoustic coupler entered the BMT housing through a designated port, negotiated a 10-degree offset, and then the hooked end of the coupler contacted the side of the outer race of bearing number 4. Two alternative designs were suggested: mounting of a sensor on the outside of the BMT housing; and installation of a straight acoustic coupler in either a ball pass counter port or a thermocouple port.

Evaluation of the hooked design by NASA engineering showed that severe vibration of the hooked coupler would be caused by coolant flow turbulence in the cavity where the acoustic coupler contacted the side of the bearing race. Analysis of the housing-mounted sensor configuration showed that the sensor would be exposed to extraneous nolses which would mask the lowlevel notse from bearing damage. Therefore, the straight acoustic coupler design was selected by NASA engineering.

This report describes the development and analysis of the acoustic coupler designs and recommends an instrumentation system for use with the straight acoustic coupler design to monitor bearing noise on the BMT. 
TABLE OF CONTENTS

$\underline{\text { Page }}$

LIST OF ILLUSTRATIONS . . . . . . . . . . . . . . . . . iv

1. INTRODUCTION . . . . . . . . . . . . . . . I 1

2. TECHNICAL DISCUSSION . . . . . . . . . . . . 5

2.1 Initial Design Concepts .............. 6

2.2 Onsite Evaluation of the BMT ............. 7

2.3 Design of Hooked AE Coupler Waveguide . . . . . . 7

2.4 Evaluation of Hooked AE Coupler Waveguide . . . . . 9

2.5 Alternative Design Concept............. 10

3. CONCLUSIONS ....................... 15

4. RECOMMENDATIONS . . . . . . . . . . . . . 16 APPENDICES

A Hooked AE Coupler Waveguide Design Sketches

B Straight-Through AE Coupler Waveguide Design

Sketches 


\section{LIST OF ILLUSTRATIONS}

Figure

Page

1 Photo of the Bearing Materials Test Facility Located at the George C. Marshall. Space Flight Center in Huntsville, Alabama . . . . . . . . . . . .

2 A Cross-Sectional View of the Bearing Materials Tester Showing the Shaft and the Location of the Four Bearings and Their Carriers ................

3 The Hooked Acoustic Coupler .............

4 A Cross-Sectional View of the Acoustic Emission Sensor on the Hooked Acoustic Coupler . . . . . . . . . 8

5 Block Diagram of the Acoustic Coupler Analysis Setup . . 9

6 Time Domain Presentation of the Lead Break Signal from the SwRI Acoustic Coupler Output . . . . . . . . . II

7 Frequency Response of the SwRI Acoustic Coupler . . . . . 11

8 Time Domain Presentation of a Lead Break Signal from a Commercially Avallable Broadband Acoustic Sensor . . . . 12

9 Frequency Response of a Comercially Avallable Acoustic Emission Sensor . . . . . . . . . . . . 12

10 The Straight-Through Acoustic Coupler Assembly . . . . 13

11 Block Diagram of the Acoustic Coupler Test Setup . . . 16 


\section{INTRODUCTION}

Acoustic surveillance of rotating element bearings goes back to the time when man first learned that if he stopped and greased the squeaking wheel on his wagon, the axle and the hub would not catch fire. The problems now being experienced with rocket engine turbopump bearings have taken us full circle. Now it is the liquid oxygen that ignites the exotic steels in the turbopump bearings when a bearing begins to fail. There is little resemblance between the exotic device illustrated in Figure 1 and the hub of a wheel on a prairie schooner, but the problem is the same. Friction produces heat, and heat in the presence of fuel and oxygen causes fire. The purpose of this project is to develop a method to hear the squeaking of the wheel before the bearing begins to burn.

This project is Phase I of a program aimed at development of a method of detecting incipient fallure in the bearings of the NASA bearing materials tester (BMT) with sufficient warning to shut down the BMT and prevent a catastrophic failure due to ignition of the steel in the bearings by combination with the liquid oxygen. The BMT is a facility which tests new materials and new bearlng designs for the bearings of turbopumps which are used to supply liquid oxygen and fuel to rocket engines. The turbopumps and the bearing materials tester use liquid oxygen as both a lubricant and a coolant for the bearings. In order to provide cooling and lubrication, the liquid oxygen is pumped through the bearing assemblies at a pressure of $500 \mathrm{psi}$. This environment provides severe operating conditions for the bearings as well as for acoustic surveillance of the bearings.

The specific objective of Phase I was to develop design concepts for mechanisms capable of coupling the acoustic noise from the bearings in the BMT to an externally mounted acoustic sensor. Figure 2 , a cross-sectional view of the BMT, shows the location of the shaft and the bearings and illustrates the problem of access to the bearing race through the housing and the bearing carrier.

Phase I specifically addressed the problem of developing an acoustic coupler for the 57-mm bearing test faclilty using an access port located adjacent to the number 4 bearing. The channel from the access port to the outer race of the number 4 bearing was narrow and angled from the access port into the bearing. This required the design of an acoustic waveguide which had a bend and then a sharp hook at the end of it, as illustrated in Figure 3 .

Since the overall objective of this project is to detect the incipient fallure of the bearing in the BMT with sufficient early warning that the BMT can be shut down before the liquid oxygen and the steel of the heated bearings ignite, it is important that the detection device be sensitive to very small amounts of damage in the bearing; that is, low-level noise must be detected. One inherent problem is that noise from sources such as turbulent flow of the liquid oxygen and possible cavitation of the liquid oxygen could mask the low-level signals. A secondary problem is with the designated access port. It was necessary for the acoustic waveguide to 
ORIGNAL PRCE IS

OF, POOR QUALITY

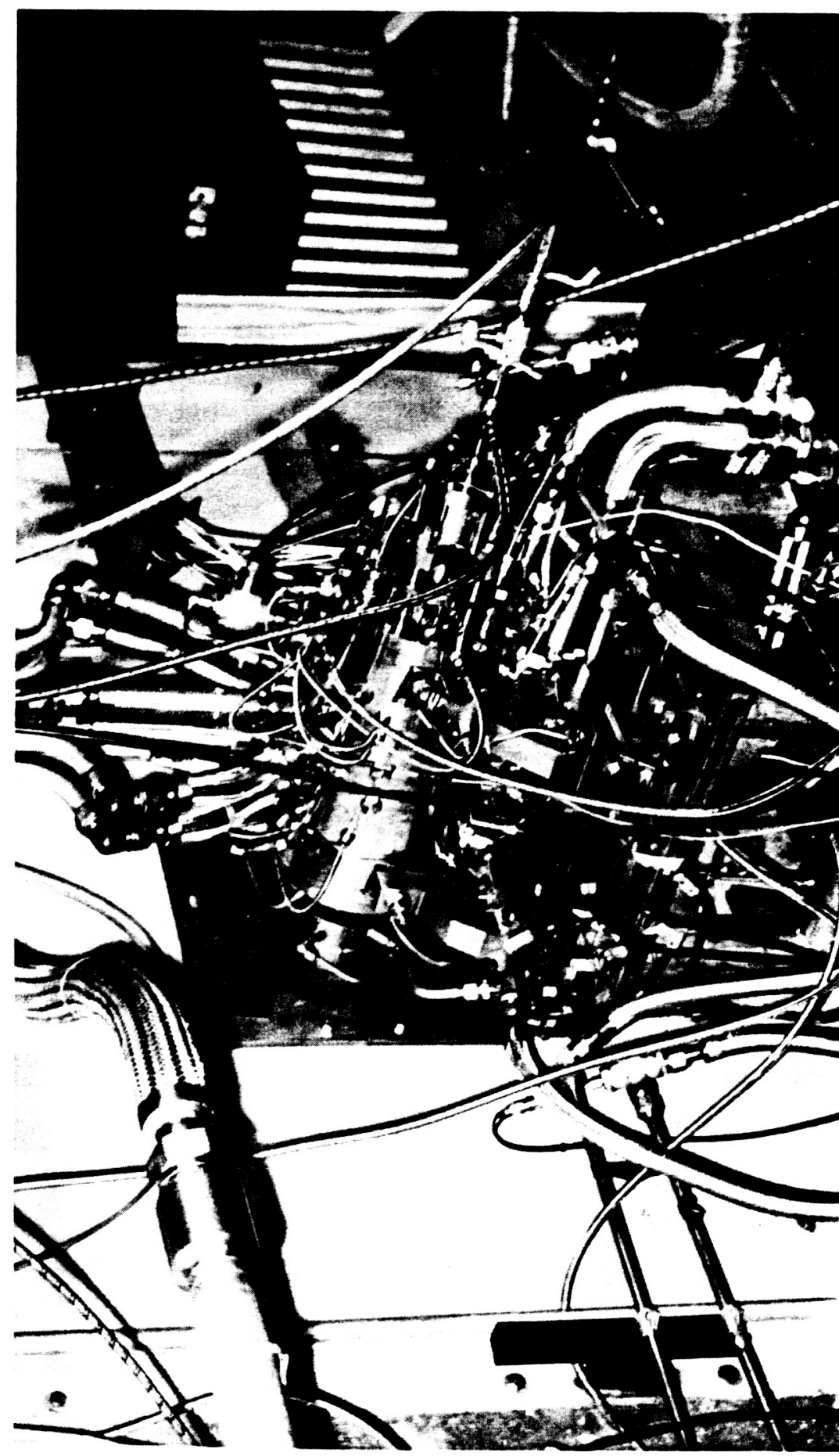

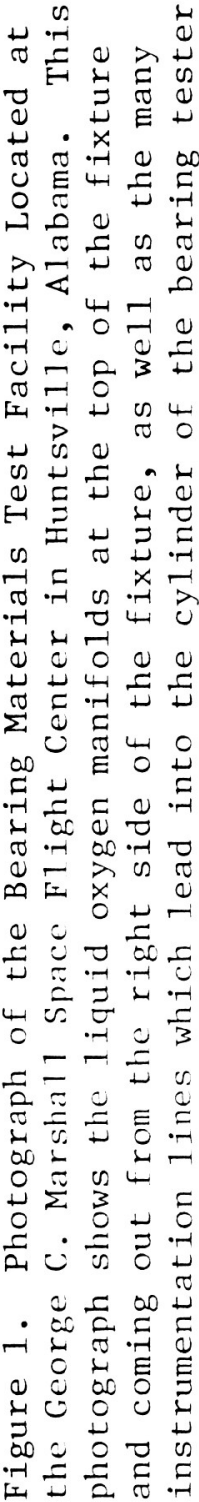




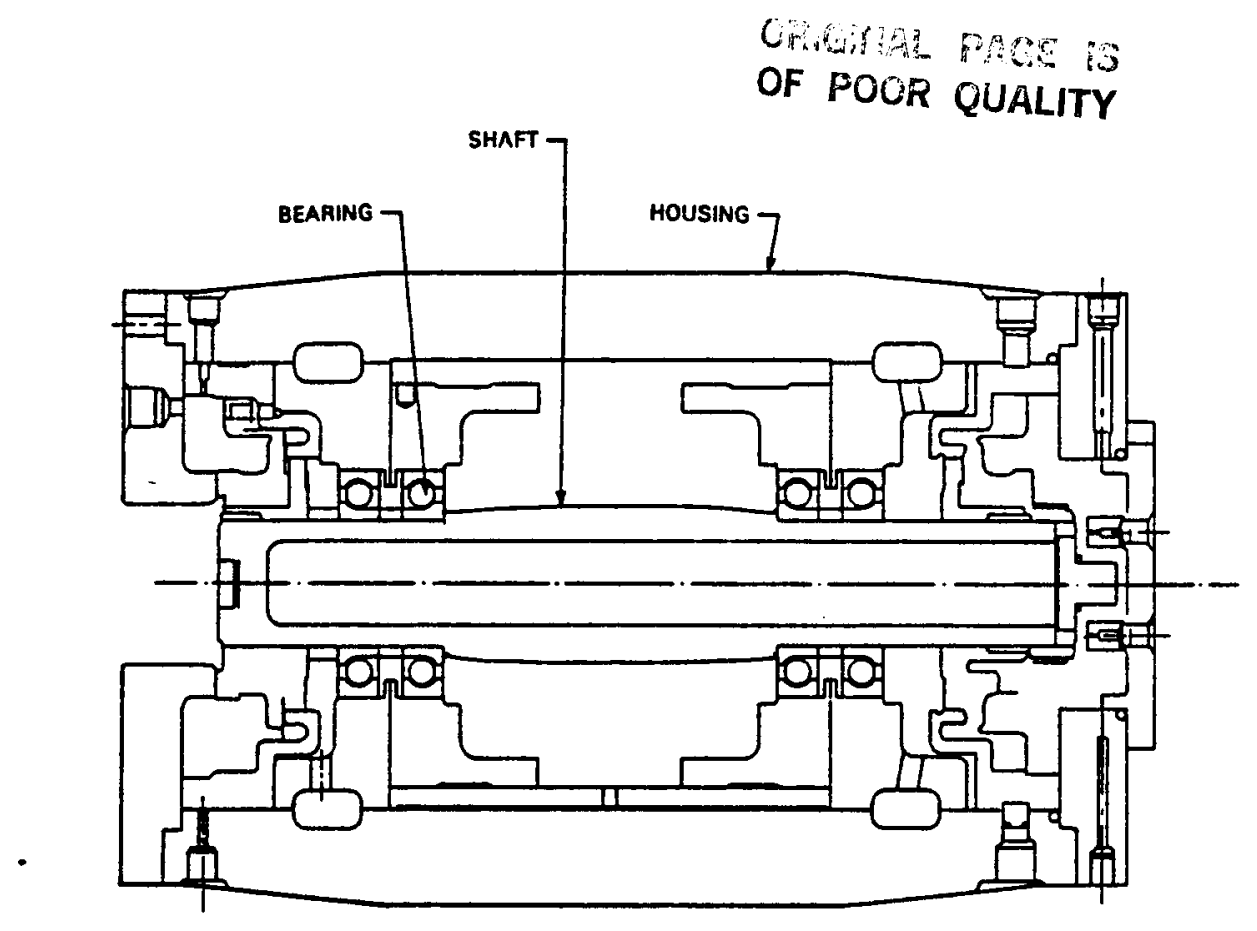

Figure 2. A Cross-Sectional View of the Bearing Materials Tester Showing the Shaft and the Location of the Four Bearings and Their Carriers.

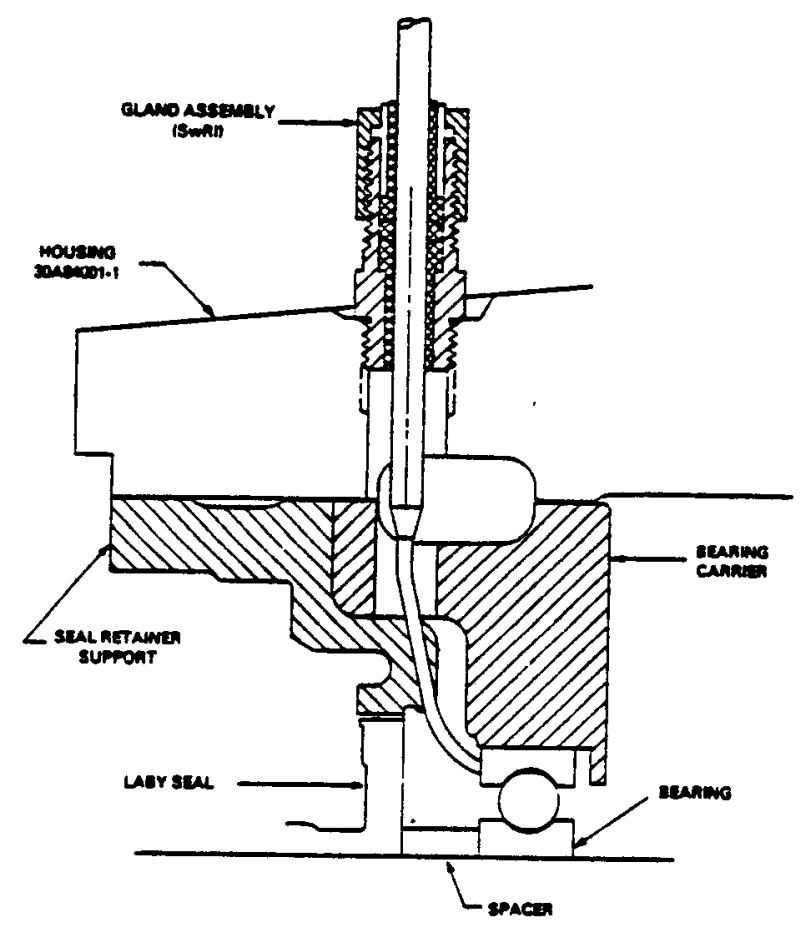

Figure 3. The Hooked Acoustic Coupler. The coupler is shown installed in the bearing materials tester. The smail end of the coupler is in contact with the outer race of the number 4 bearing. This sketch shows the direction in which the coupler enters the housing and angles through the access channel to the number 4 bearing. 
pass through the stream of oxygen flow, unshielded, on its way from the outer housing of the BMT to contact the race of the number 4 bearing. This exposure to the flow of the liquid oxygen and, in particular, the turbulence in the area could lead to vibrations and perhaps even $\mathrm{J}$ iftoff of the contact point of the acoustic coupler, which would interfere with the detection of nolse from the bearing.

This report discusses the acoustic waveguide design concept and describes the development and evaluation of the acoustic coupler design concepts used in this program. Recommendations are given for an instrumentation system to be used with the selected acoustic coupler design to monitor bearing noise on the BMT. 


\section{TECHNICAL DISCUSSION}

Acoustic survellance of rotating equipment bearings is in general use today. Motors and pumps for critical applications are commonly supplied with acoustic bearing monitors in place. Application of acoustic survelllance to the BMT facility to detect incipient failure in the bearings is unique only in that the liquid oxygen and its high flow rates provide a severe environment in which to detect acoustic noise due to bearing damage.

The detection of bearing noise due to damage or overheating of the bearings in the BMT would be straightforward except for the fact that the liquid oxygen flowing through the bearing assemblies generates noise due to turbulence and cavitation. Turbulence noise is usually in a frequency range below $100 \mathrm{kHz}$, while cavitation noise may extend to frequencies as high as $1 \mathrm{MHz}$. Another source of noise is mechanical noise in the system--noises from other bearings, valves, actuators, and solenoids. These mechanical noises also are in the frequency range below $100 \mathrm{kHz}$.

Based on our experience, we decided to concentrate on a frequency range for our acoustic monitoring above $100 \mathrm{kHz}$ and below $1 \mathrm{MHz}$ on the assumption that most of the information we need would be in that frequency range. The solution to the basic problem of turbulent flow lies in the selection of a frequency band where the turbulence noise is minimized and the bearing damage noise is maximized. Usually the desired frequency band lies above $100 \mathrm{kHz}$ and below $1 \mathrm{MHz}$ because turbulent flow noise, being related to the flow velocity and the physical dimensions of the mechanical components, resides in the lower frequencies below $100 \mathrm{kHz}$.

Cavitation, on the other hand, involves the formation and violent collapse of tiny vapor bubbles which generate acoustic transients having broad frequency spectra extending to more than $1 \mathrm{MHz}$. Cavitation in the BMT could be of sufficient intensity to mask the changes in bearing noise we seek to detect. The bearing noise signature will change because of a damaged bearing ball or overheating of the bearing due to general surface damage. Initially, the change in bearing noise will be on the order of a few percent, but as the damage to the bearing accumulates, the noise will increase to a few hundred percent of the noise of a normal bearing. Cavitation noise, however, may be on the order of 500 to 1000 percent of the normal bearing noise.

It is fortunate that an acoustic bearing monitor detects and identifies cavitation because cavitation can be a major source of bearing damage. Cavitation can cause erosion and pitting in both the bearing race and the bearing balls. The first order of business for the acoustic bearing monitor would be identification of the conditions of bearing operation under which cavitation would occur. The acoustic bearing monitor would be able to perform its primary function of detecting bearing damage only when cavitation is not present. 


\subsection{Initial Design Concepts}

Based on analysis of NASA drawings of the 57-mm bearing materials test facility, SwRI considered three possibilities for coupling the acoustic noise from the bearing to the environment outside the BMT housing. The first concept was the hooked acoustic emission (AE) coupler waveguide which contacted the surface of the side of the outer race of bearing number 4 and coupled the sound from that point directly to a sensor mounted on the opposite end of the waveguide outside the BMT housing. The second concept was to examine the possibility of using the BMT housing itself as the acoustic coupler. The drawings indicate that the outer race of the bearings is in intimate mechanical contact with the BMT housing through the compressed spring washers which are used to set up the preload on the side of the bearing. The third concept was that of a straight waveguide passing through a counter port or a thermocouple port, but this was rejected because there was not enough room for another port to be added. Accordingly, SwRI proceeded with development of the hooked AE coupler design and evaluation of the BMT housing-mounted sensor.

\subsubsection{Hooked AE Coupler Waveguide}

The hooked AE coupler waveguide design is illustrated in Figure 3. The figure shows how the acoustic waveguide is dimensioned and shaped so that it will pass through the entry port in the BMT outer housing, down through a narrow channel provided by NASA engineering, and then with a sharp bend in the tip of the waveguide, come into contact with the side of the outer race of bearing number 4. The coupler design itself required that the hardness of the acoustic waveguide be tempered to provide sufficient spring pressure against the side of the bearing outer race. This pressure should be in the neighborhood of 2 to 5 pounds load with a small contact point in order to get the contact pressure up to 5000 psi. When contact pressure is 5000 psi or greater, then adequate acoustic coupling exists between the two components.

The upper section of the hooked $A E$ coupler was designed to fit the standard compression fitting. This design was based on the standard design for the feedthrough and seal used in the BMT to withstand the pressure, the low temperature, and the possibility of ignition due to the iiquid oxygen environment. The acoustic waveguide diameter is reduced in the section that fits inside the BMT because the channel through which the acoustic waveguide must pass is narrow and it was necessary to provide adequate clearance so there is no possibility of the waveguide coming in contact with the sides of the channel. The waveguide then was hardened to provide sufficient pressure at the contact point. The contact pressure of the acoustic waveguide had to be carefully adjusted to avoid excessive preload. The tip of the acoustic waveguide was curved to provide a uniform contact surface between the t1p of the waveguide and the side of the number 4 bearing race. 


\subsubsection{Housing-Mounted Sensor}

The design concept of mounting the acoustic sensor on the outside of the BMT housing was deferred until the opportunity was presented for experimental measurements of the noise sources and attenuation through the material of the BMT housing. Evaluation of this method could not be carried further by simulation or mock-up because the individual contact areas and contact pressures between the components are critical, and the local noise sources are also important. The problem with mounting the acoustic sensor on the outside of the housing is that the sensor is exposed to all of the attendant noise sources including the noise from other bearings in the housing, noises of solenolds and valve actuation, and turbulence and cavitation noises of the flowing liquid in the housing. It is entirely possible that these extraneous noise sources would be much stronger than the low-level noise which is anticipated from the bearing when damage to the bearing first occurs.

\subsection{Onsite Evaluation of the BMT}

In order to have a clear understanding of the mechanism and the problems involved with installation of the $A E$ coupler in the BMT housing, components of the BMT were examined during a visit to the George C. Marshall Space Flight Center. The problems of access to the bearing races for the acoustic coupler were discussed with the test engineers and with the project monitor. It was determined that adequate space was available for the hooked waveguide to reach the outer race of bearing number 4. The possibility of alternative access for a straight waveguide through a ball pass counter port or a thermocouple port was discussed, but it was decided that the hooked waveguide should be implemented. The straight acoustic wavegulde approach was rejected because there was not sufficient room radially around the bearing to add another port similar to those used by the ball pass counter and the thermocouple probes. The information for design of the feedthrough and the seal was obtained from the instrumentation engineer on this visit.

SwRI also learned on this visit that NASA engineering anticipated that high-level turbulence and cavitation may be a problem in the BMT, and that it was very important to the test engineering to know if and when and under what conditions cavitation would occur. Based on these discussions, NASA and SwRI decided to conduct experimental acoustic measurements on the BMT when it was in operation in order to determine the actual noise levels experienced during the various operating conditions. It was decided then to complete the design of the hooked waveguide concept for the acoustic coupler and to bulld an experimental model of this concept for empirical evaluation on the BMT.

\subsection{Design of Hooked AE Coupler Waveguide}

The acoustic waveguide was designed with an enlarged body so that the coupler could be extended into the cavity of the BMT housing, providing support for the contact pressure between the tip of the acoustic 
waveguide and the side of the bearing race. The enlarged body of the acoustic coupler fits the standard 1/4-1nch diameter feedthrough seal assembly used on the BMT. The acoustic coupler total length is

7.25 inches, and the final 2 inches is reduced to a diameter of $1 / 8$ inch and bent to fit through the angled channel and around the corner of the bearing carrier so that only the tip of the waveguide comes in contact with the side of the bearing number 4 outer race. The acoustic coupler, after being bent to shape, is then heat-treated to provide the proper stiffness to apply pressure of a minimum of 5000 psi at the contact point. The tip of the acoustic waveguide is curved to a $1 / 16$ inch radius so that the contact point will be uniform regardless of the angle of contact with the side of the bearing race.

The top end of the acoustic coupler is tapered to a $1 / 8-1$ nch diameter to match the dimension of the piezoelectric element which forms the acoustic sensor at the end of the waveguide. The upper portion of the coupler is also threaded so that the assembly of the sensor housing can be made to the end of the wavegulde. Details of the acoustic emission sensor assembly mounted on the end of the waveguide are lllustrated in Figure 4 .

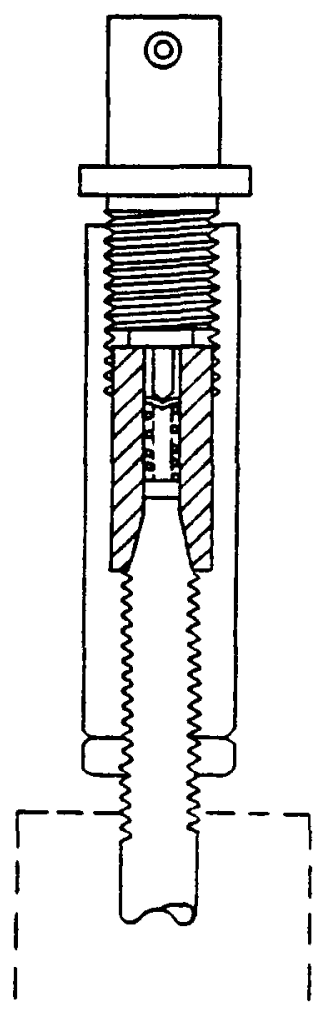

Figure 4. A Cross-Sectional View of the Acoustic Emission Sensor on the Hooked Acoustic Coupler. The standard coaxial cable connector provides both mechanical contact and electrical contact for the piezoelectric element which rests atop the tapered end of the threaded portion of the acoustic coupler. 
A standard BNC connector provides electrical connections to the acoustic sensor. The sensor is mechanically coupled to the waveguide tip by a spring-loading mechanism with spring pressure applied through the contact point of the BNC connector. Acoustic coupling between the sensor element and the waveguide tip is provided by low-temperature silicon grease.

The sensor design is capable of operating over a wide temperature range. Since the BMT housing itself will be at or near liquid oxygen temperature, it is assumed that the acoustic waveguide will be at a very low temperature as well.

Design sketches for the hooked $A E$ coupler waveguide are included in Appendix A.

\subsection{Evaluation of Hooked AE Coupler Waveguide}

The sensitivity and frequency response of the hooked waveguide acoustic coupler design were evaluated by comparison with a commercially available broadband acoustic emission sensor. The acoustic source used for this evaluation was a $0.5-\mathrm{mm}$ pencil lead break on a 10-inch thick steel block. The instrumentation system used for the evaluation and analysis of the acoustic waveguide is shown in Figure 5. Both the acoustic coupler and the commercial acoustic emission broadband sensor were placed in contact with the steel block. The commercial sensor used standard acoustic emission couplant, which is a viscous fluid, while the acoustic waveguide coupler used only the contact pressure. Contact pressure on the acoustic coupler was adjusted to 2 to 5 pounds to represent that which would be required on the BMT. Signals from the acoustic coupler and the broadband

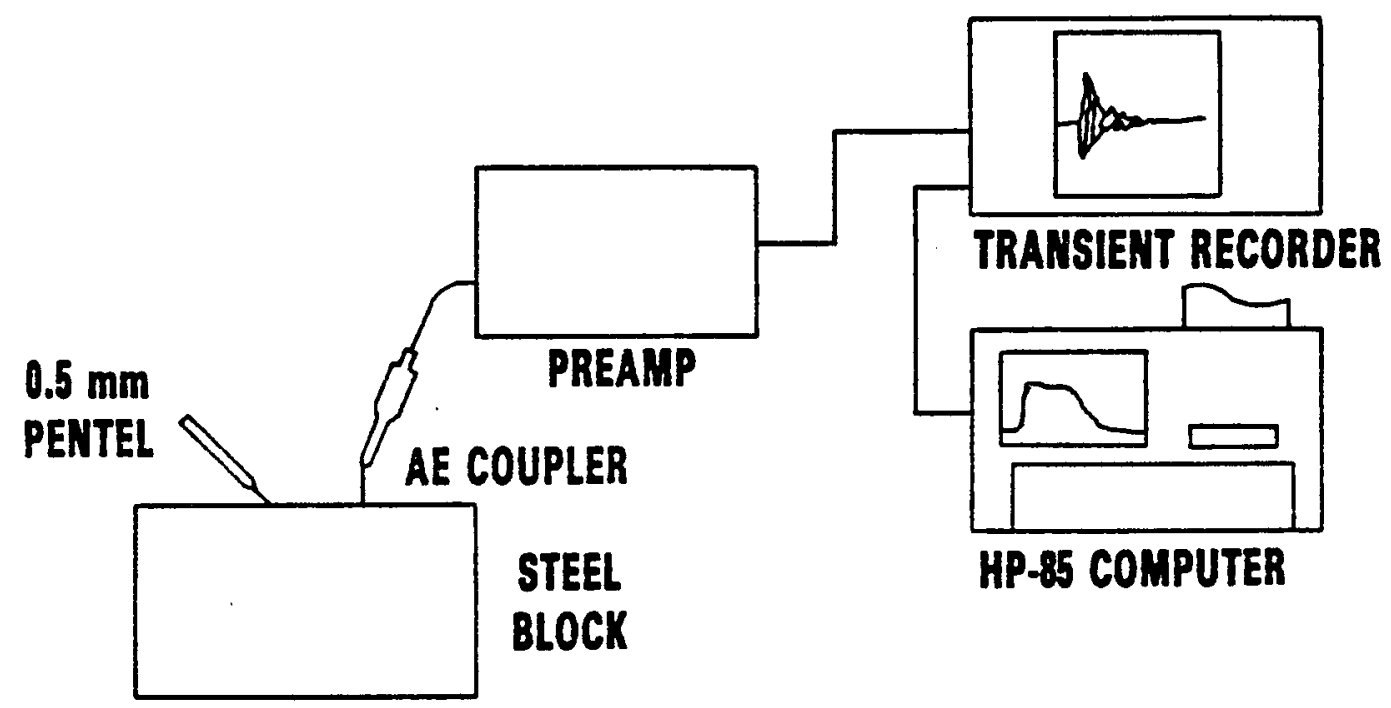

Figure 5. Block Diagram of the Acoustic Coupler Analysis Setup. The 0.5-mm Pentel pencil lead breaking on the surface of the steel block provides an impulsive acoustic source for analysis of the coupler sensitivity and frequency response. 
sensor were passed through a preamplifier and then into the transient recorder where the waveform from each was digitally recorded. Digitized waveforms were then subjected to Fourier analysis to determine the frequency spectrum.

Figure 6 is an illustration of the recorded waveform from the $\mathrm{AE}$ coupler. The initial impulse of the breaking pencil lead is illustrated by the first very sharp transition of the signal amplitude. In this case, it reaches a maximum amplitude in the negative direction. Vertical displacements of the surface of the seal block are coupled through the acoustic waveguide $A E$ coupler to the sensor. The coupler design and the small sensor dimensions ( $1 / 8$ inch diameter by 0.076 inch thick) reduce the sensitivity at frequencies below $100 \mathrm{kHz}$, but provide a broadband frequency response from $100 \mathrm{kHz}$ up to about $800 \mathrm{kHz}$. This frequency response is illustrated in Figure 7. For comparison purposes, the analog waveform and frequency response of a commercially available $A E$ sensor were also taken. The analog waveform for this commercial sensor is shown in Figure 8 . The duration of the initial impulse in this figure indicates that the bandwidth of the commercially available sensor is narrower than that of the AE coupler designed for the BMT. This is supported by the frequency response shown in Figure 9. In this frequency response, there is a strong peak in the neighborhood of $200 \mathrm{kHz}$, with the primary high sensitivity regions between 100 and $300 \mathrm{kHz}$.

In comparing Figure 6 and Figure 8, the amplitude sensitivity of the $A E$ coupler is approximately one order of magnitude or 10 times greater than that of the commercially available broadband sensor. A laboratory analysis of the sensitivity and the frequency response of the $A E$ coupler showed that it has the proper frequency range, that is, from $100 \mathrm{kHz}$ to $800 \mathrm{kHz}$, and it has adequate sensitivity to detect the noise in the bearings in the BMT. The working model of this design concept was taken to the NASA facility at the George C. Marshall Space Flight Center and fitted to the BMT in preparation for testing during operation of the BMT. As a part of this preparation, the design was also submitted to the test engineering section at the NASA facility for evaluation of the Impact of the $A E$ coupler on the operation of the BMT and assessment of the adequacy of the acoustic coupler design to withstand the turbulence and flow conditions in the cavity of the BMT. NASA test engineering concluded that the acoustic waveguide, being in the high flow and high turbulence region in the BMT cavity, would be subjected to severe vibrations which could possibly cause the tip of the waveguide to break off. Testing of the $A E$ coupler on the BMT was not permitted because of the possibility of damage to the BMT.

\subsection{Alternative Design Concept}

Since the hooked AE coupler could not be tolerated extending into the liquid oxygen flow, SwRI was asked to proceed with the alternative design concept of a straight acoustic coupler which would be inserted into an existing ball pass counter port or a thermocouple port. The resulting $A E$ coupler design is shown in Figure 10. 


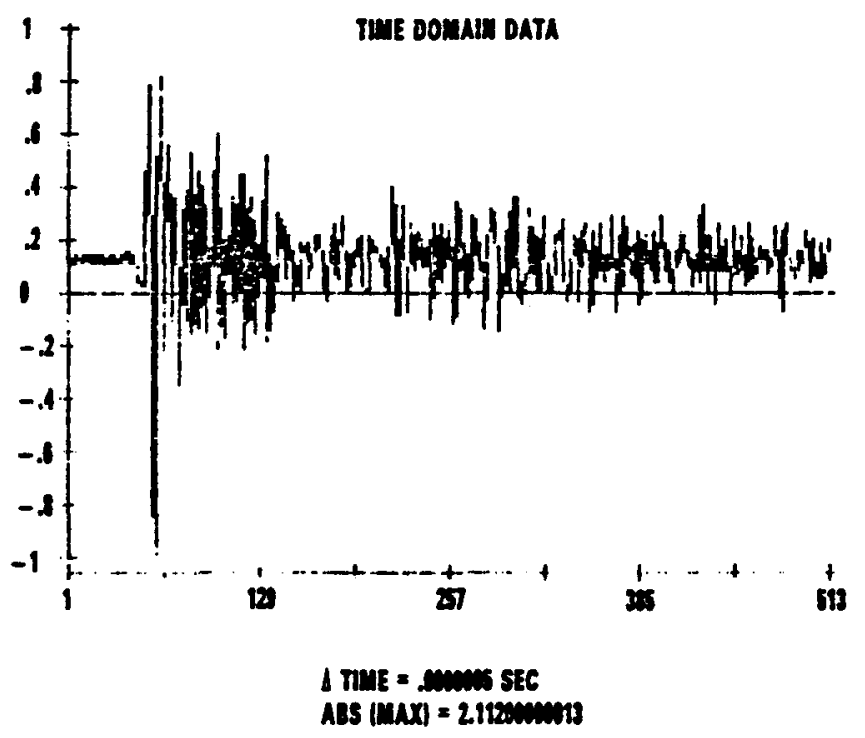

Figure 6. Time Domain Presentation of the Lead Break Signal from the SwRI Acoustic Coupler Output. The initial highamplitude, negative-going portion of this waveform represents the impulsive surface displacement caused by the pencil lead break. The time duration represented by this waveform is 256 microseconds, and the vertical scale is in percentage of the maximum amplitude.

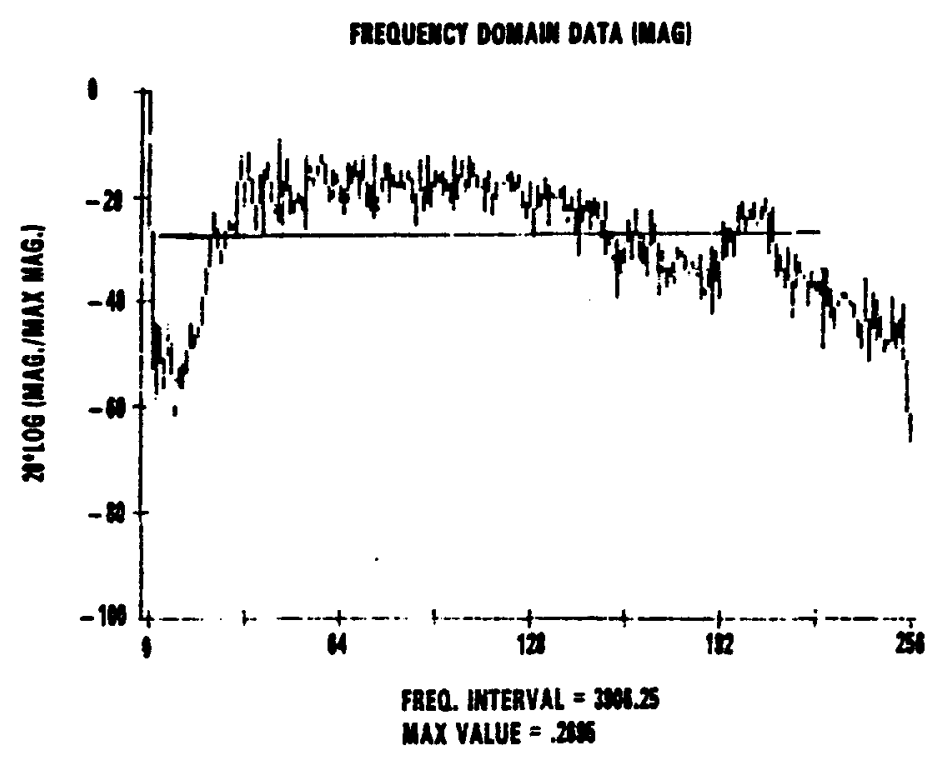

Figure 7. Frequency Response of the SwRI Acoustic Coupler. The magnitude of the frequency response over a range of 0 to $1 \mathrm{MHz}$ is shown in this logarithmic presentation. 


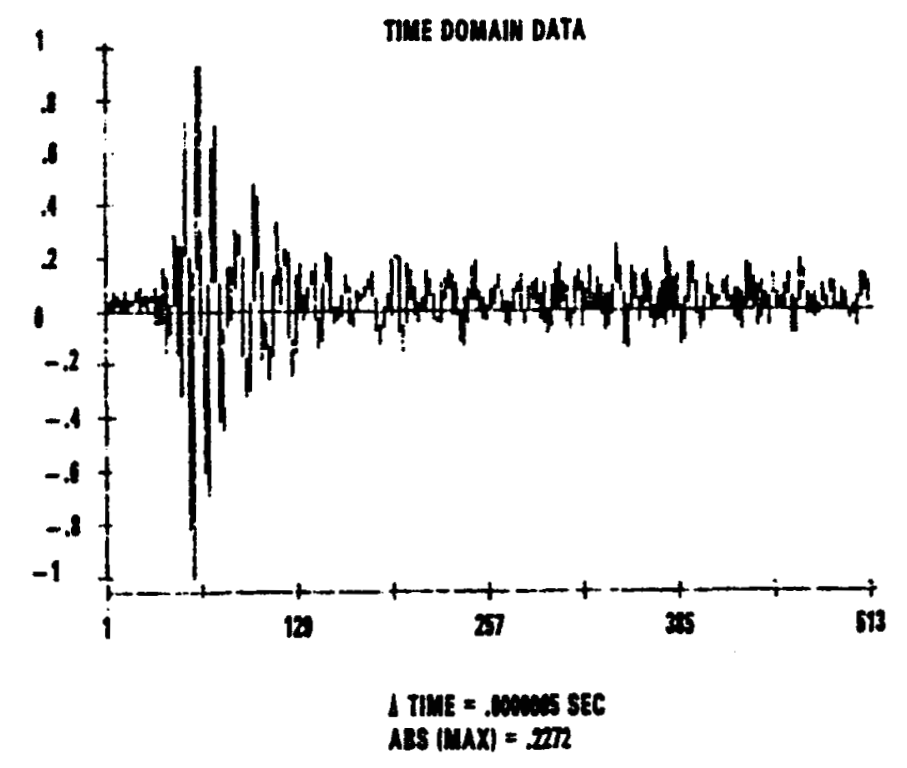

Figure 8. Time Domain Presentation of a Lead Break Signal from a Commercially Available Broadband Acoustic Sensor. The time base displayed is 256 microseconds, and the amplitude vertical scale is in percentage of the maximum value.

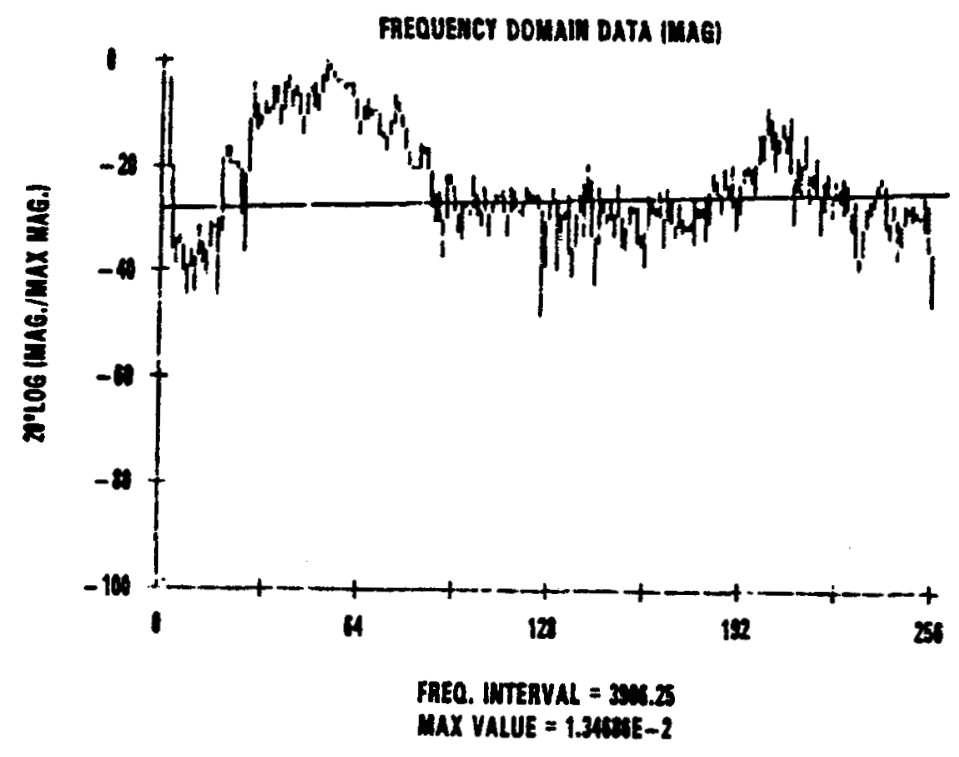

Figure 9. Frequency Response of a Commercially Available Acoustic Emission Sensor. The frequency range displayed is 0 to $1 \mathrm{MHz}$, and the vertical scale is logarithmic magnitude relative to the maximum value. 


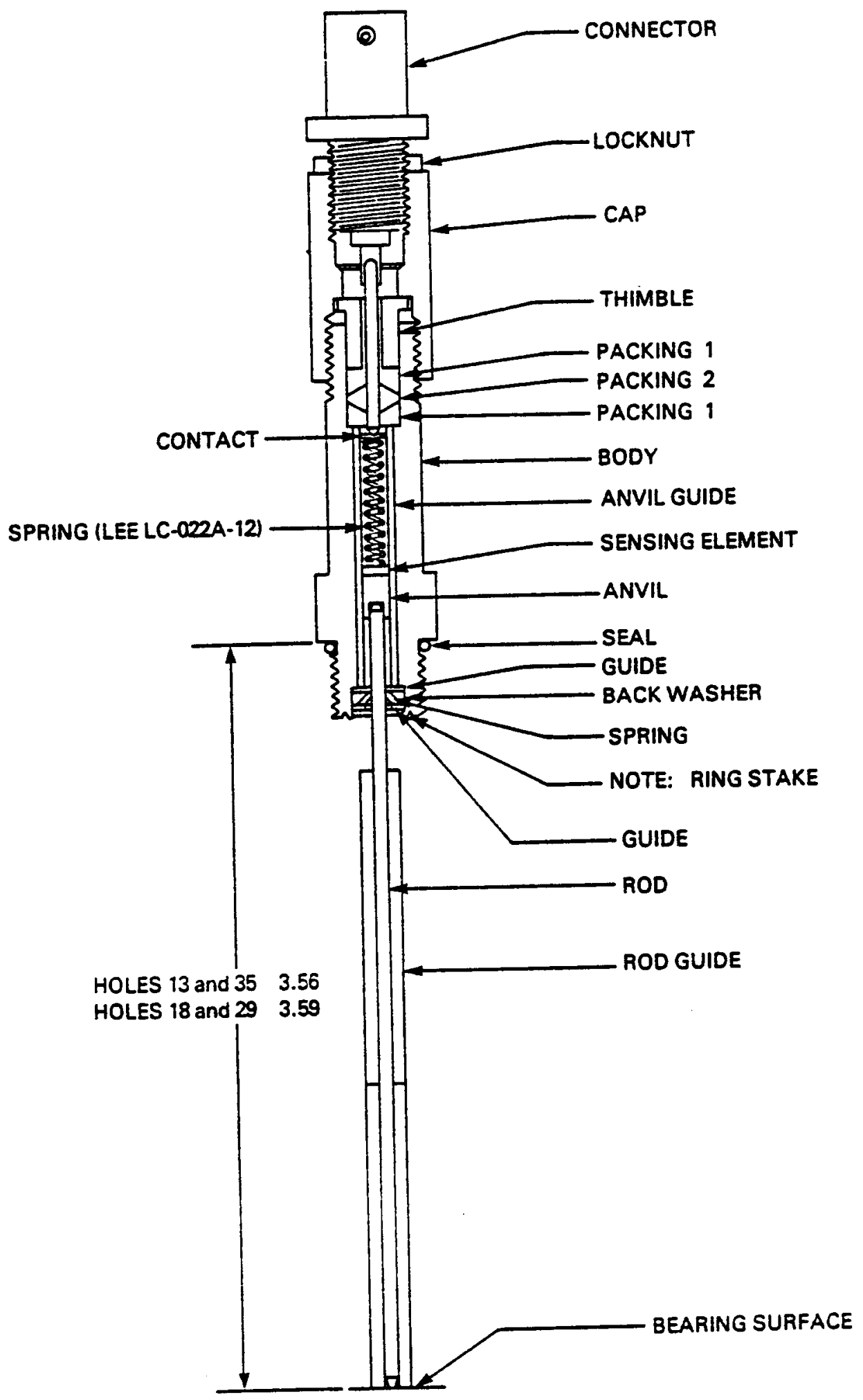

Figure 10. The Straight-Through Acoustic Coupler Assembly. This assembly is designed for insertion in the ball pass counter port or the thermocouple port. 
The straight AE coupler design is more complicated than the hooked waveguide coupler design because the feedthrough and seal assembly must make provisions for applying a constant load onto the acoustic coupler rod and maintaining constant acoustic contact between the plezoelectric element and the top of the acoustic coupler rod. This is accomplished by placing both the sensor and the acoustic coupler rod inside the pressure boundary of the BMT housing. The electrical connection to the coaxial cable connector at the top of the assembly is made through a solid rod which passes through the packing gland. This provides adjustment of the mechanical force which is applied through a compression spring to the plezoelectric sensing element and the anvil between the sensing element and the coupler rod, and to hold the rod in contact with the bearing surface. This design will maintain a constant contact pressure between the rod and the bearing surface over a wide range of temperatures.

In the feedthrough housing, the anvil guide, a Teflon tube, provides electrical insulation and acoustic isolation for the plezoelectric sensing element. Further acoustic isolation is provided by the rod guide, which prevents direct contact between the coupler rod and the narrow channel between the feedthrough and the bearing surface. The overall coupler design is made so that it can be used in elther the ball pass counter probe ports or the thermocouple probe ports. Since this design uses the same acoustic emission sensor as used in the hooked coupler design, it may be assumed that the sensitivity and frequency response characteristics of this new design will be simflar to those measured on the hooked design.

Design sketches for the straight-through $A E$ coupler waveguide are included in Appenaix B. 


\section{CONCLUSIONS}

Evaluation of three different design concepts for the acoustic coupler to be used on the bearing materials test facility led to the selection of a straight-through acoustic coupler which could be used in existing thermocouple or ball pass counter ports. The concept of using an acoustic sensor on the outside of the BMT housing to detect the sound transmitted from the bearing through the housing to the sensor was rejected because our analysis of this configuration indicated a strong likelihood that noises from extraneous sources such as turbulence, cavitation, and mechanical noises would prevent the detection of low-level noises due to damage of the bearing components. It was concluded that the hooked waveguide concept was not satisfactory on the basis of analysis by NASA test engineering which indicated that the acoustic coupler rod would vibrate and possibly bend or break in the high-level turbulence of the liquid oxygen in the BMT cavity. This engineering analysis concluded that the coupler should not be exposed directly to the flow of the liquid oxygen coolant. Therefore, the straight-through acoustic coupler designed to use existing thermocouple or ball pass counter ports was selected because this design can be applied to all four bearings in the $57 \mathrm{~mm}$ bearing materials tester and, in addition, the coupler will be protected from the coolant flow turbulence by the closed channel of the access port through the BMT housing to the outer surface of the bearing race. 


\section{RECOMMENDATIONS}

It is recommended that Phase II of the program be Implemented to evaluate the stralght-through acoustic coupler which is designed to fit into the ball pass counter or thermocouple ports in the BMT. A minimum of two prototype $A E$ couplers of this design should be fabricated for test and evaluation. Laboratory measurements should be made to verify the sensitivity and frequency response of the straight-through $A E$ coupler design, but it is most important to evaluate this coupler design on the operating BMT facility.

It is of utmost importance to determine experimentally the nolse levels involved in three particular conditions. The first is normal bearing operation under normal loads. The second is normal bearing operation under conditions of high turbulent flow of the liquid oxygen coolant. The third is normal bearing operation under conditions which cause cavitation of the coolant in the bearing housing.

Analysis of cavitation of the coolant is important for two reasons. First, the noise due to cavitation bubble formation and collapse produces a very broad-spectrum, high-amplitude noise which could mask or be confused with the noise of damage to the bearing. Second, cavitation can actually cause erosion and damage of the material if it occurs near the surface of the bearing race or the bearing balls.

The instrumentation setup recommended for use in the Phase II analysis of the acoustic coupler is shown in Figure 11. This block diagram 1llustrates the principal components of the acoustic coupler attached to the bearing tester and connected directly to the preamplifier which is located

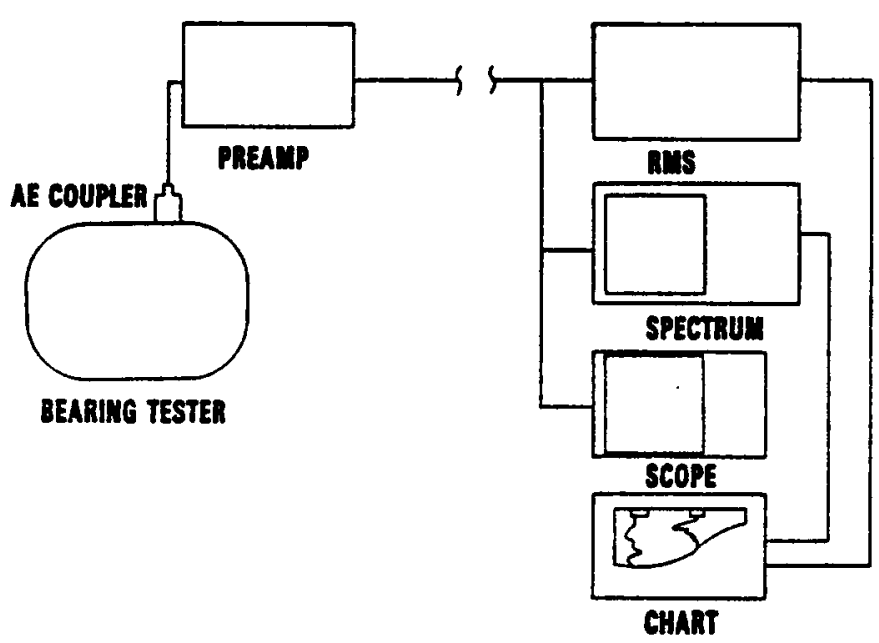

Figure 11. Block Diagram of the Acoustic Coupler Test Setup. This test setup is recommended for evaluation of the acoustic coupler on the bearing materials test facility to determine the character of noise under both normal and adverse operating conditions. 
at the site of the bearing tester and within a few feet of the acoustic coupler. The preamplifier should have an amplification of approximately $20 \mathrm{~dB}$ and should be capable of driving the long cable from the bearing tester location to the data analysis facility, which is more than 1000 feet away. At the analysis facllity, the output from the preamplifier can be divided between oscilloscope, spectrum analyzer, RMS voltage meter, and strip chart recorder. These instruments provide a real-time response for direct analysis, and their outputs may also be recorded for subsequent, more detailed analysis. The spectrum analyzer shown in Figure 11 may be replaced by a transient recorder which can be used to record specific waveforms, for example, the burst from cavitation or from acoustic emission signals produced by damage in a bearing component. The waveforms recorded on the transient recorder can then be used to obtain the spectrum analysis of the signals off-line by means of Fourler analysis.

Standard acoustic emission type instrumentation is not recommended for application on the BMT for this phase of the program because it is most important at this stage to analyze the character of the background noise associated with the BMT; that is, the noise of the flow conditions, the possibility of cavitation, and other extraneous noise sources. Thus, it is necessary at this stage to employ standard laboratory analysis type instrumentation. Once the character of the noise is known, then a particular acoustic emission instrument type or other electronic instrumentation can be spectfled to provide an early warning of incipient bearing fatlure in the BMT.

The recommended objective for Phase II is as follows: Fabricate two working models of the selected acoustic coupler design concept. Using this coupler design, record and evaluate the nolse from the 57-mm bearing materials test facility during both simulated and actual bearing test operations. These bearing tests, performed for the purpose of evaluating the acoustic coupler, should be conducted using liquid nitrogen as the lubricant and coolant in order that actual damaged bearings can be operated safely in the tester. 


\section{ORIGINAL PAGE IS \\ OF POOR QUALITY}

\section{APPENDIX A}

HOOKED AE COUPLER WAVEGUIDE DESIGN SKETCHES 


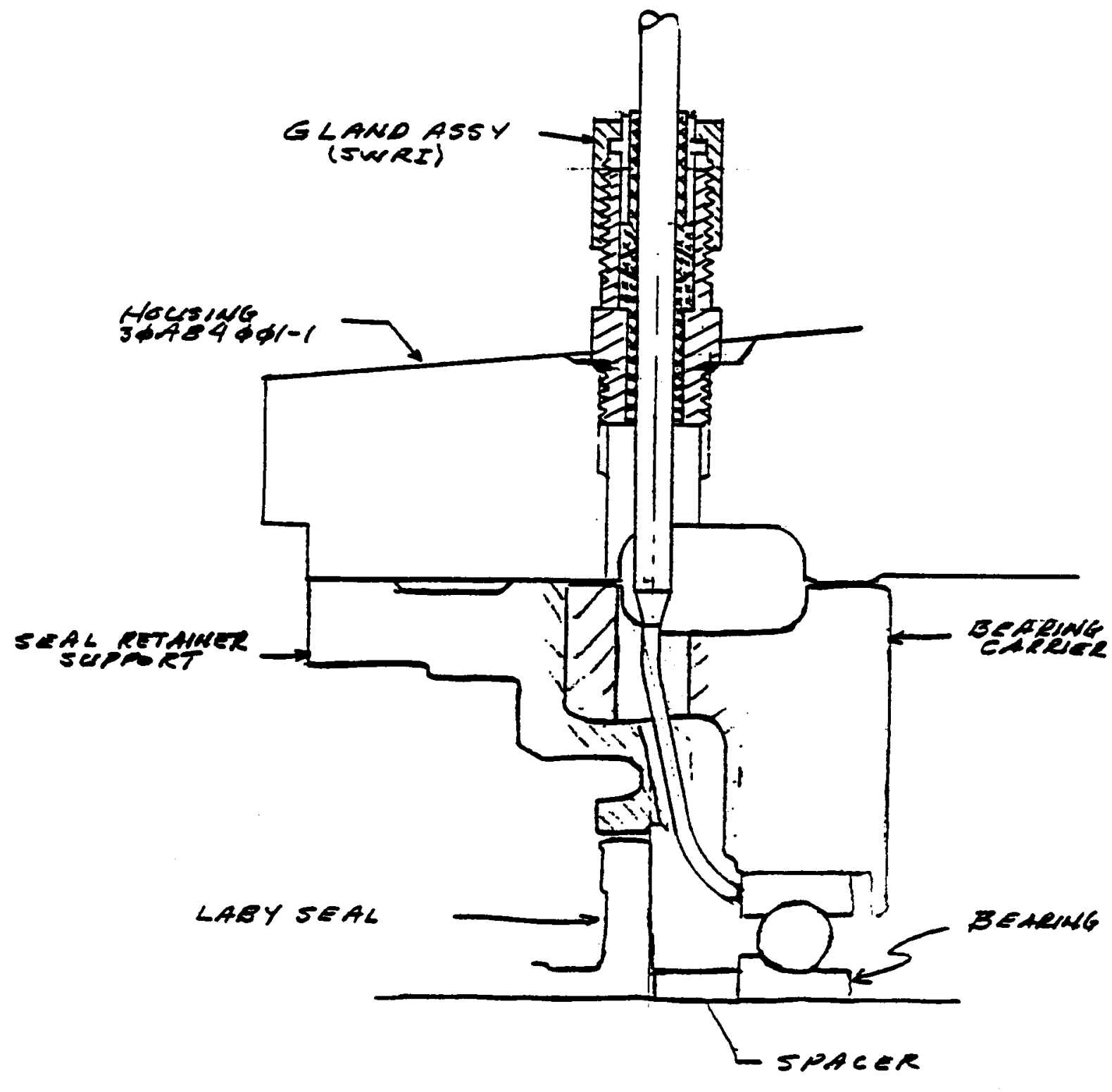

$3 / 10 / 03$ 


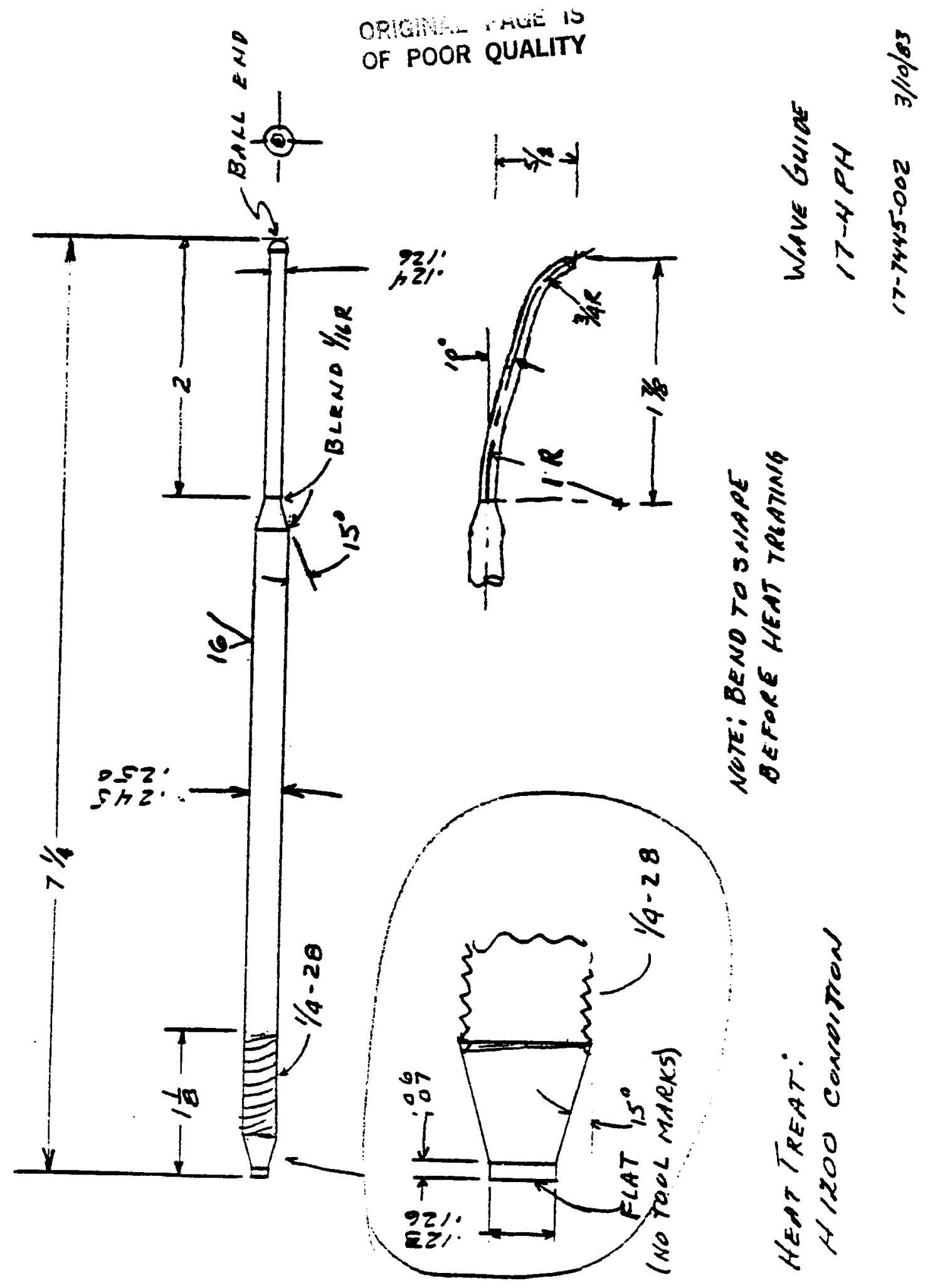




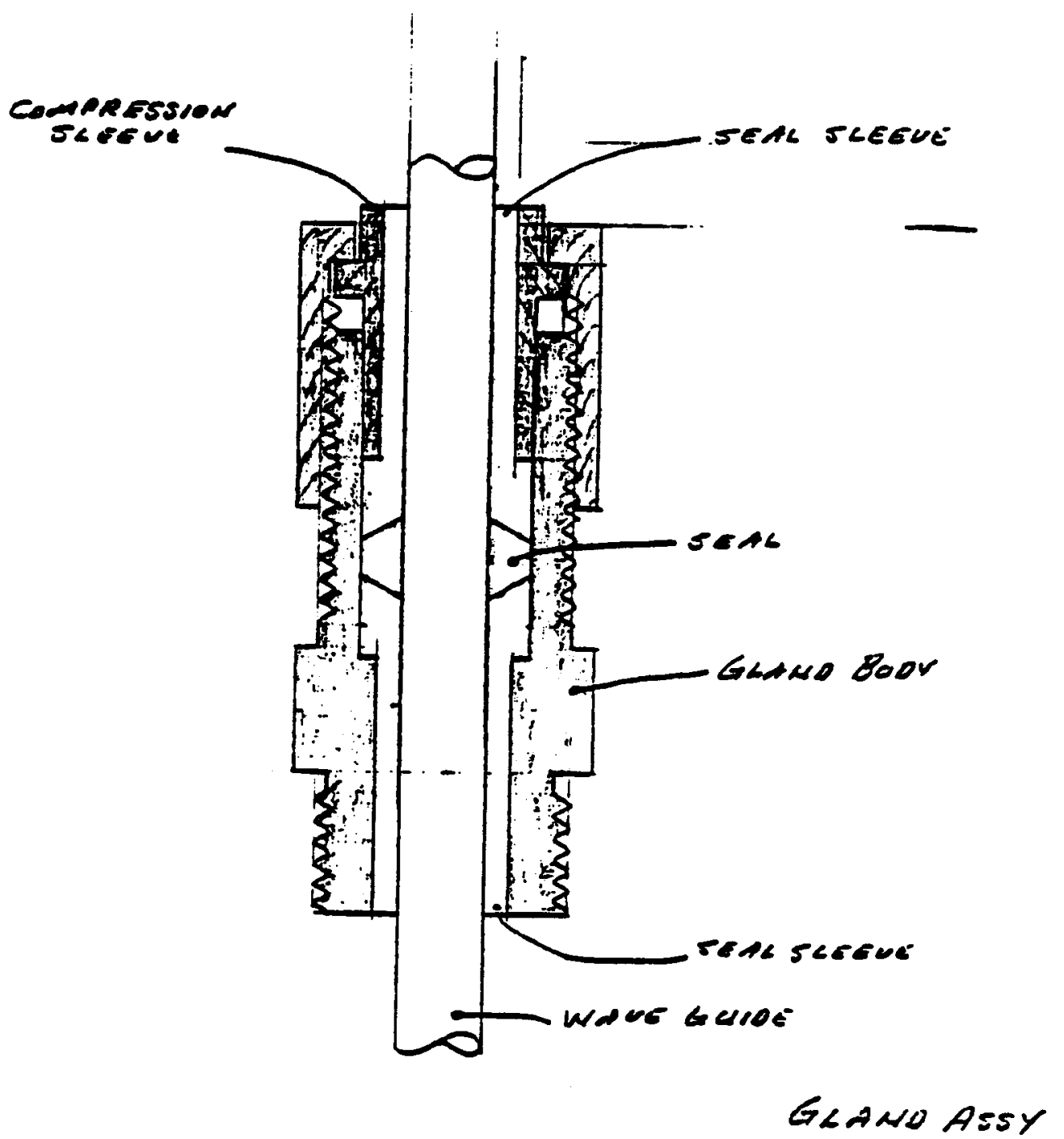




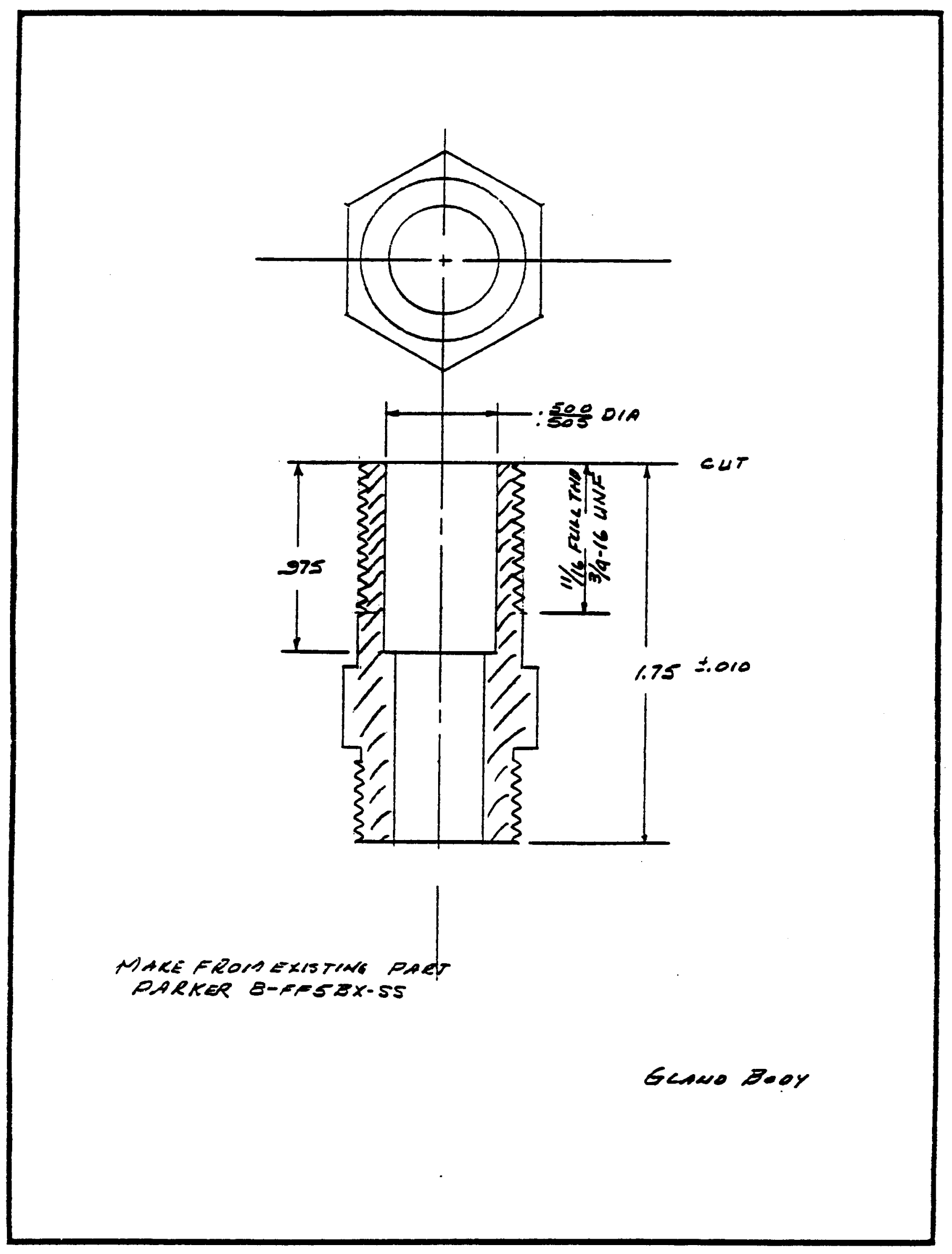




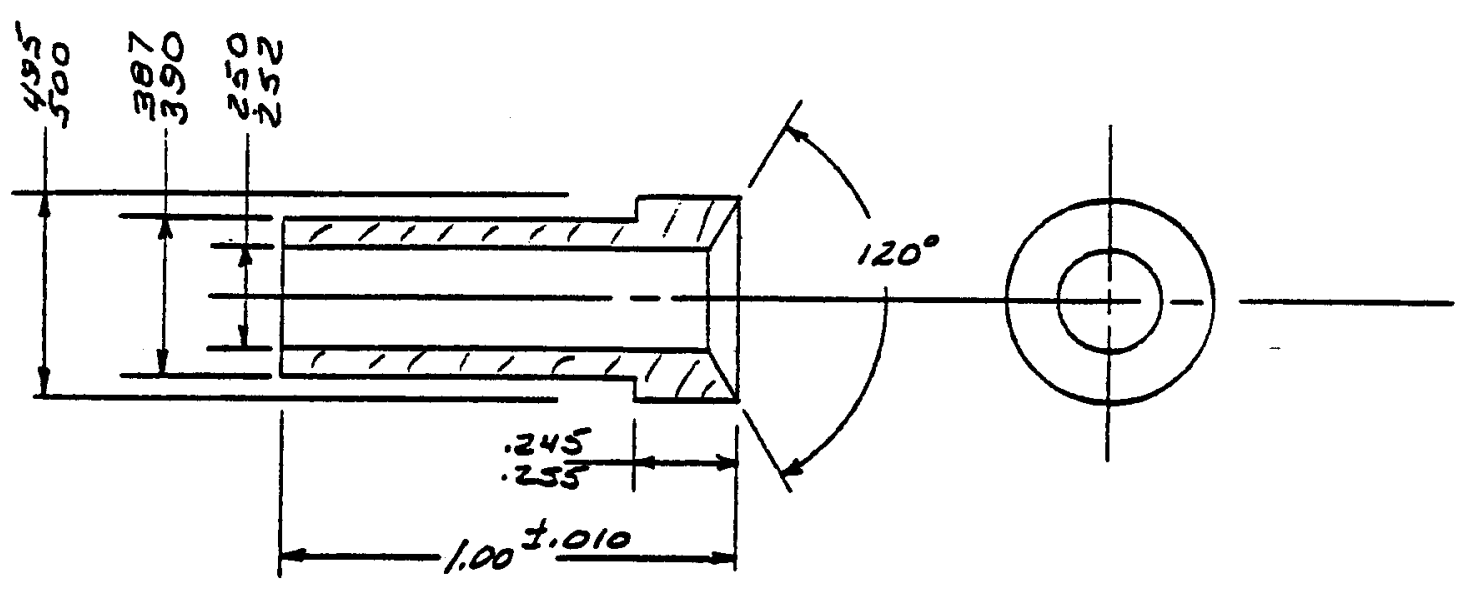

\footnotetext{
MATL: TFFLON

2 PEQO

sear SLeene
} 


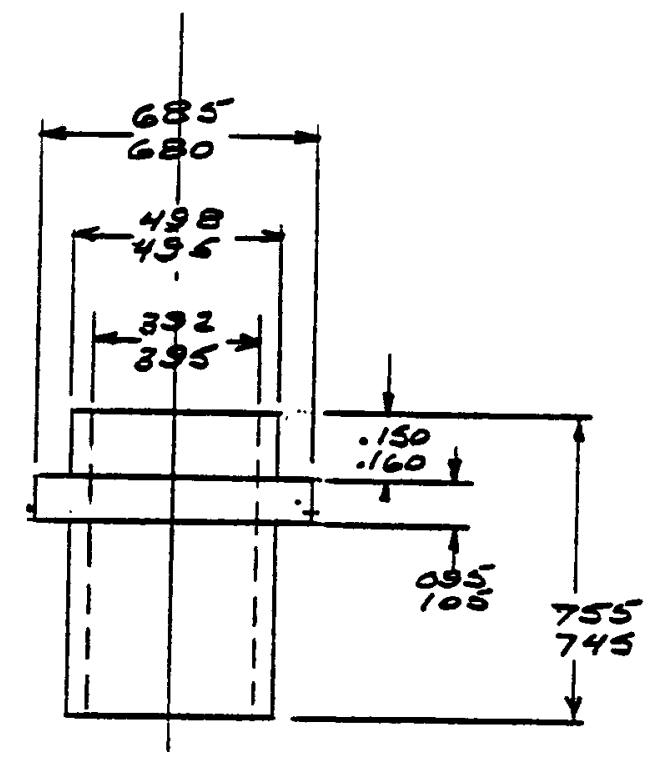

HATL: 303 stawless COMPRESION SLEEVE 

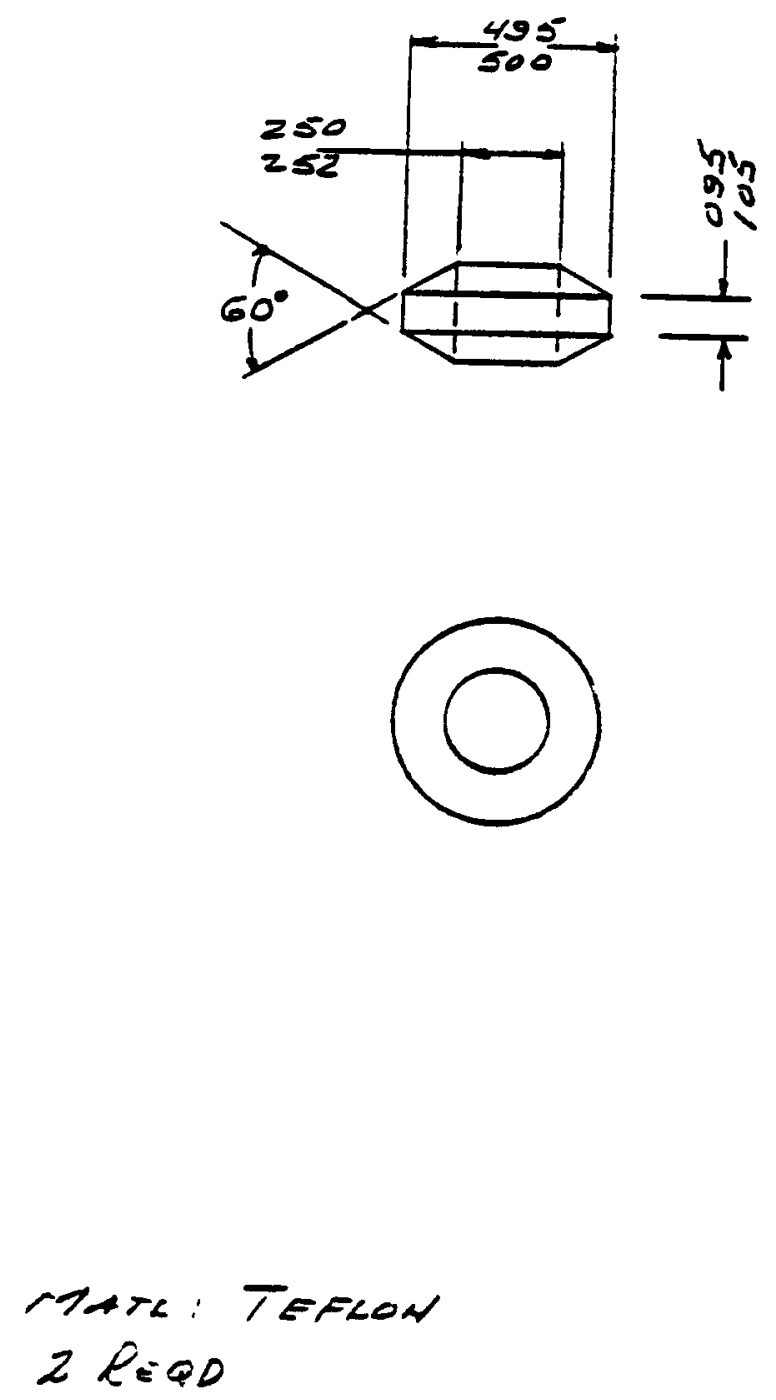

SEAL 

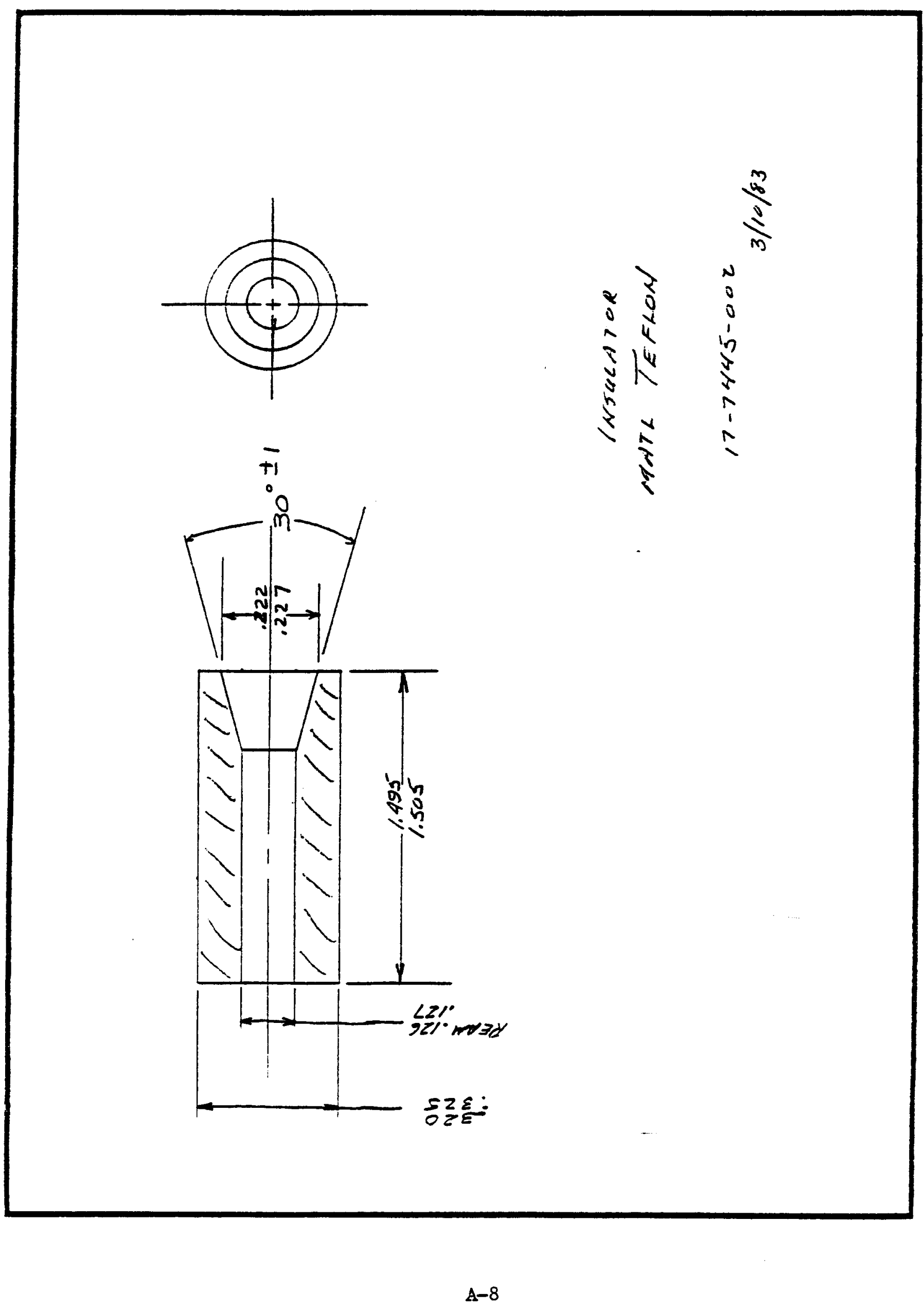

I
I
I 

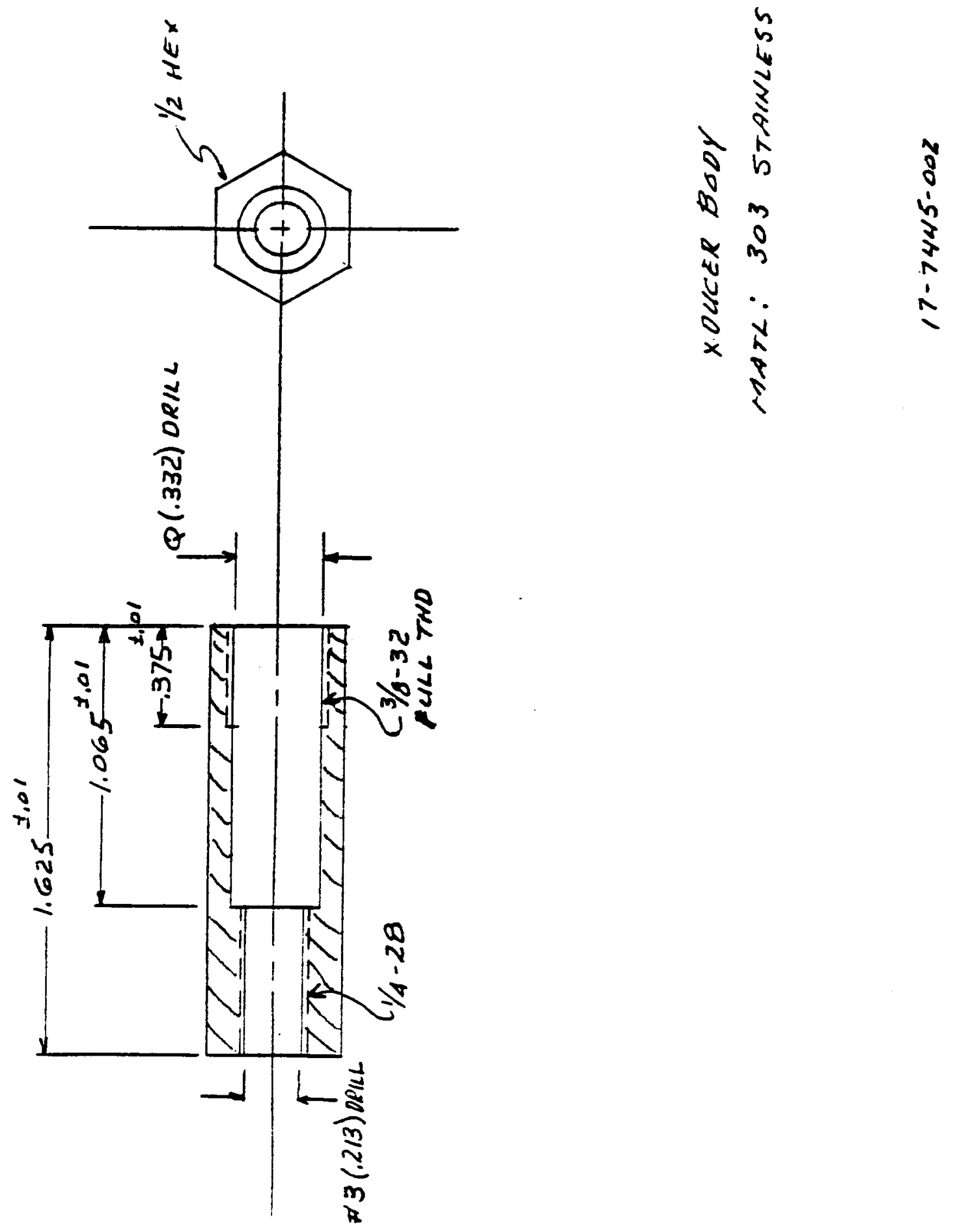

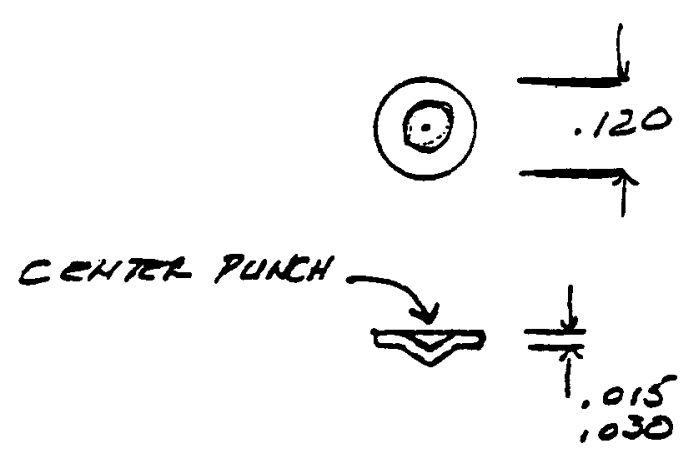

$$
\begin{array}{r}
\text { CONTHCT } \\
\text { BNA55 } \\
17-7445-002 \\
3 / 10 / 83
\end{array}
$$




\section{POPNAL PAGE IS \\ OF POOR QUALITY}

APPENDIX B

STRAIGHT-THROUGH AE COUPLER WAVEGUIDE DESIGN SKETCHES 
CRIGIYAL PASE IS

OF POOR QUALITY

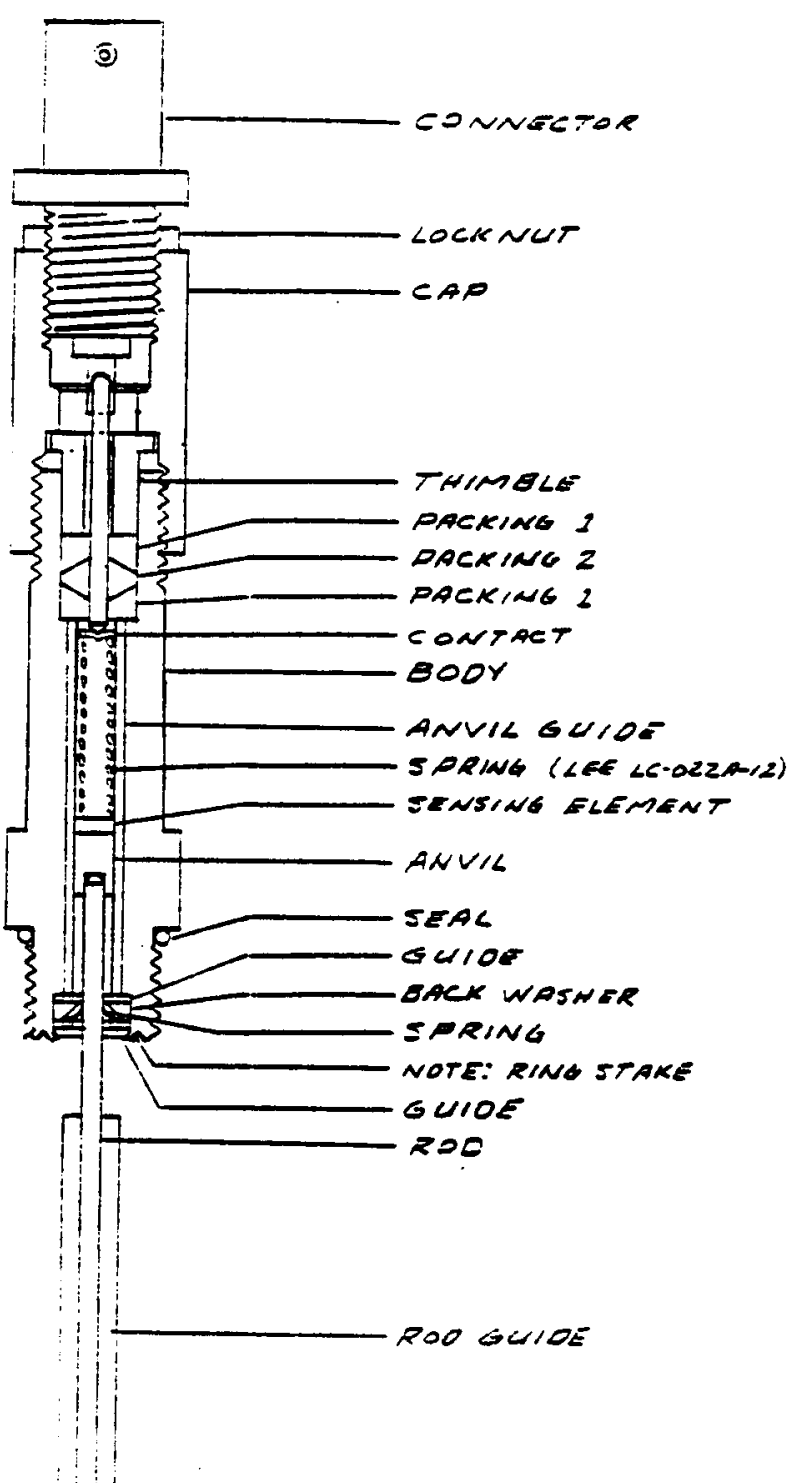

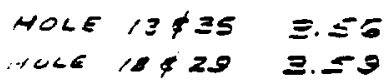
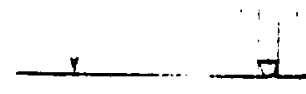

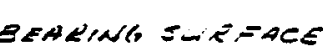

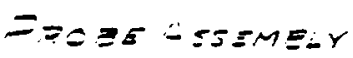

$$
\begin{aligned}
& =-7 \\
& \text { HeLE (3, } 2, \equiv \equiv \equiv \equiv
\end{aligned}
$$



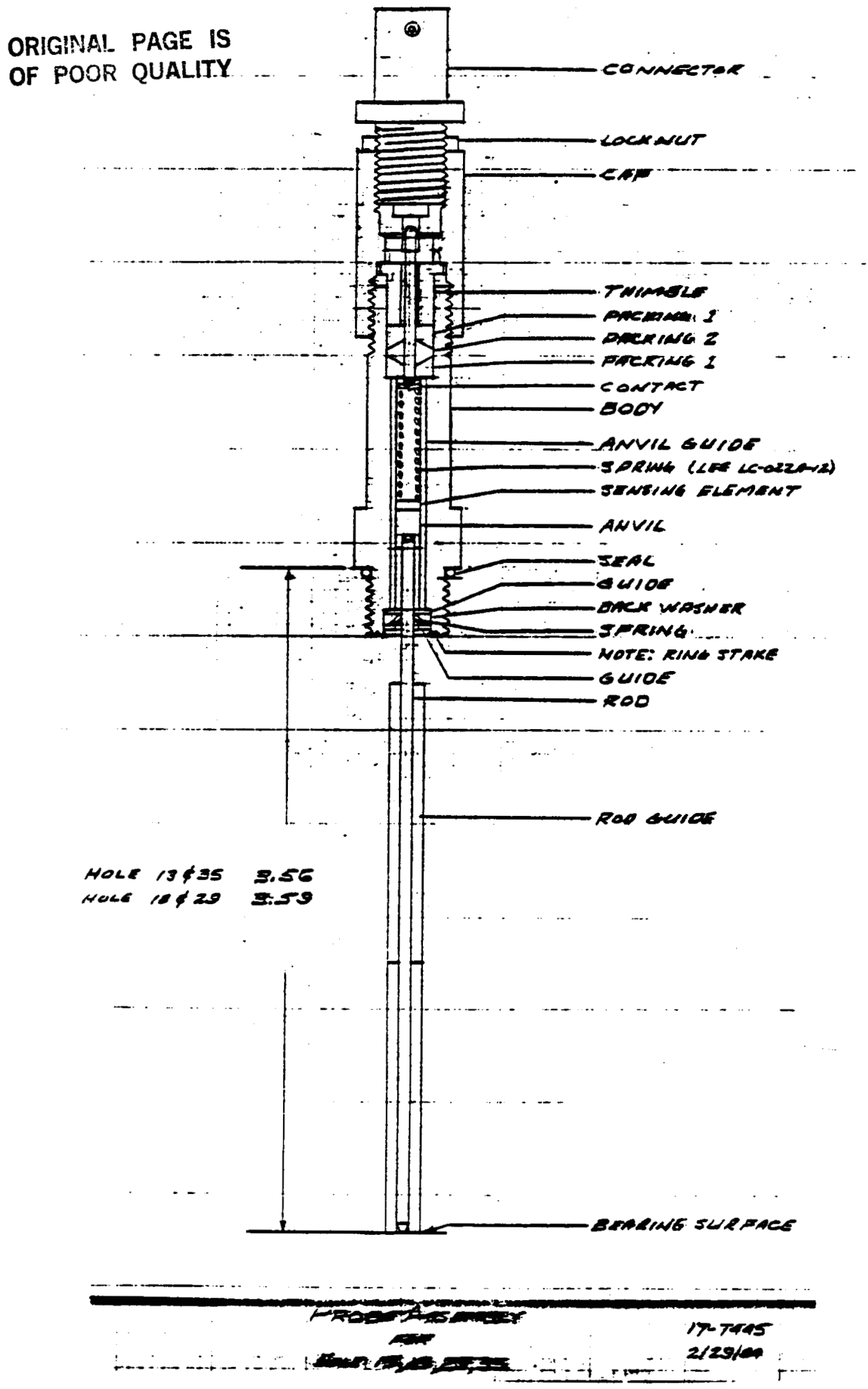


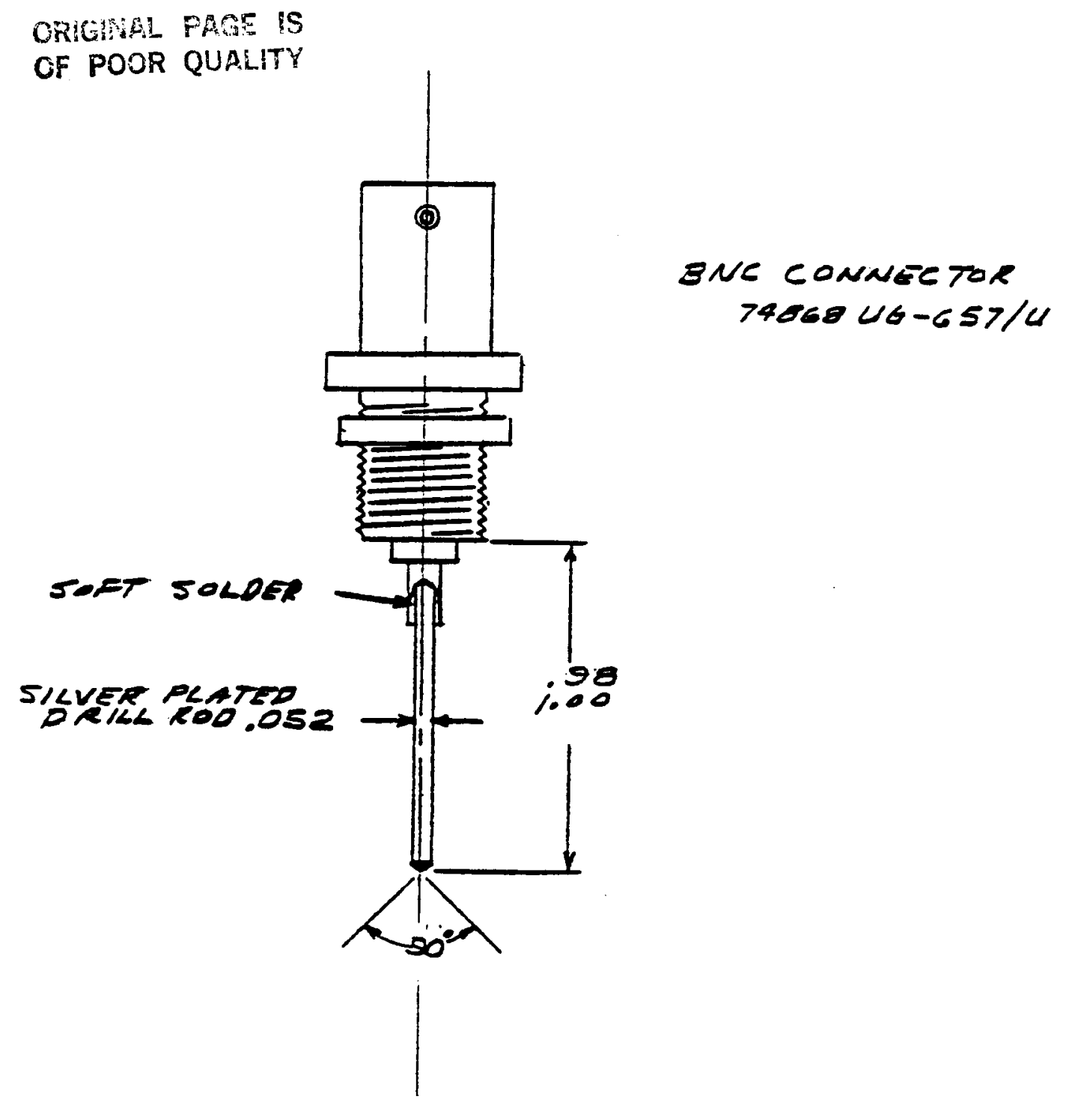

OF POOR QUALITY

CONNECTOR

$17-7445$
$2 / 29 / 04$ 

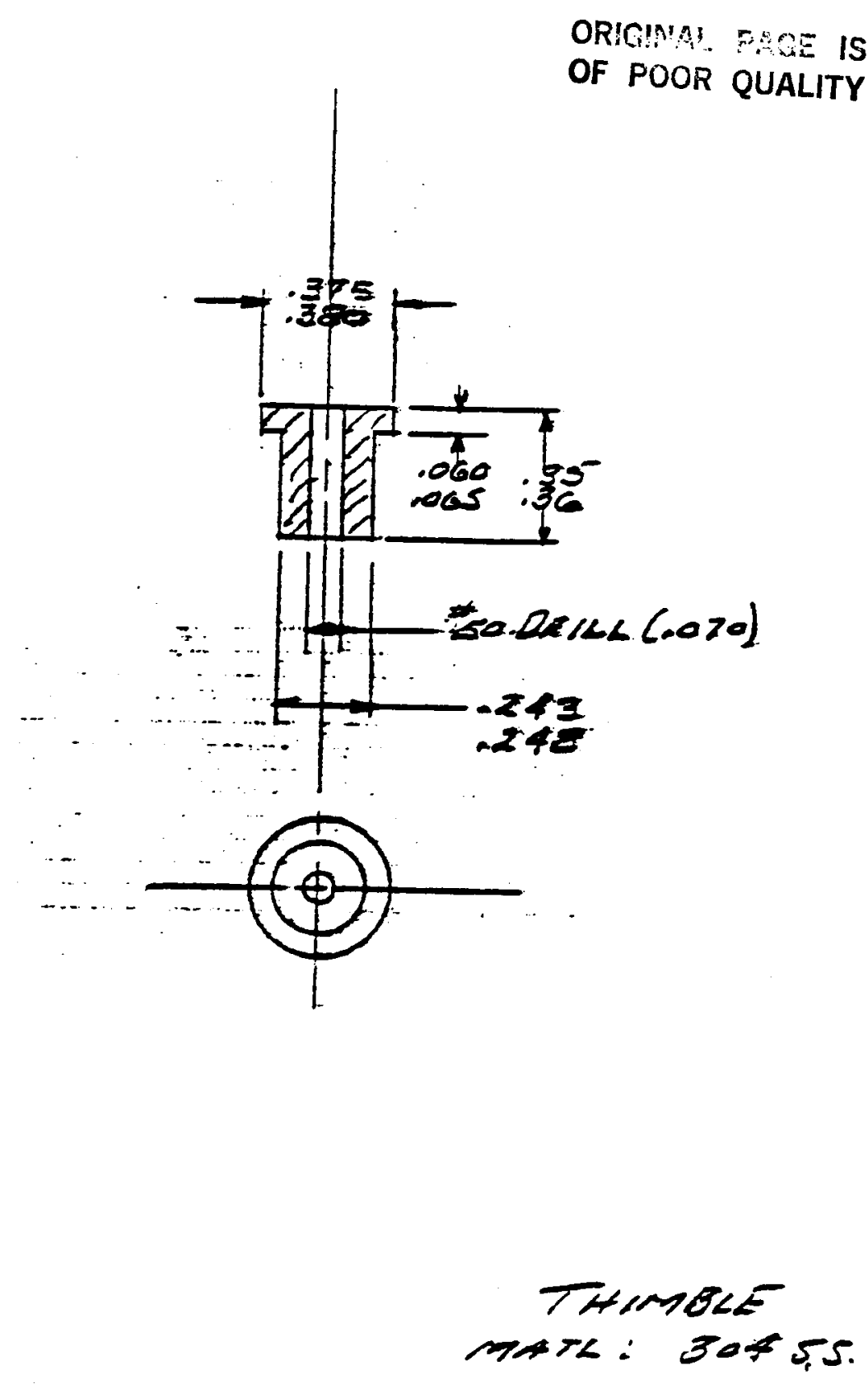

$1 T-7445$

$2620 / 04$ 

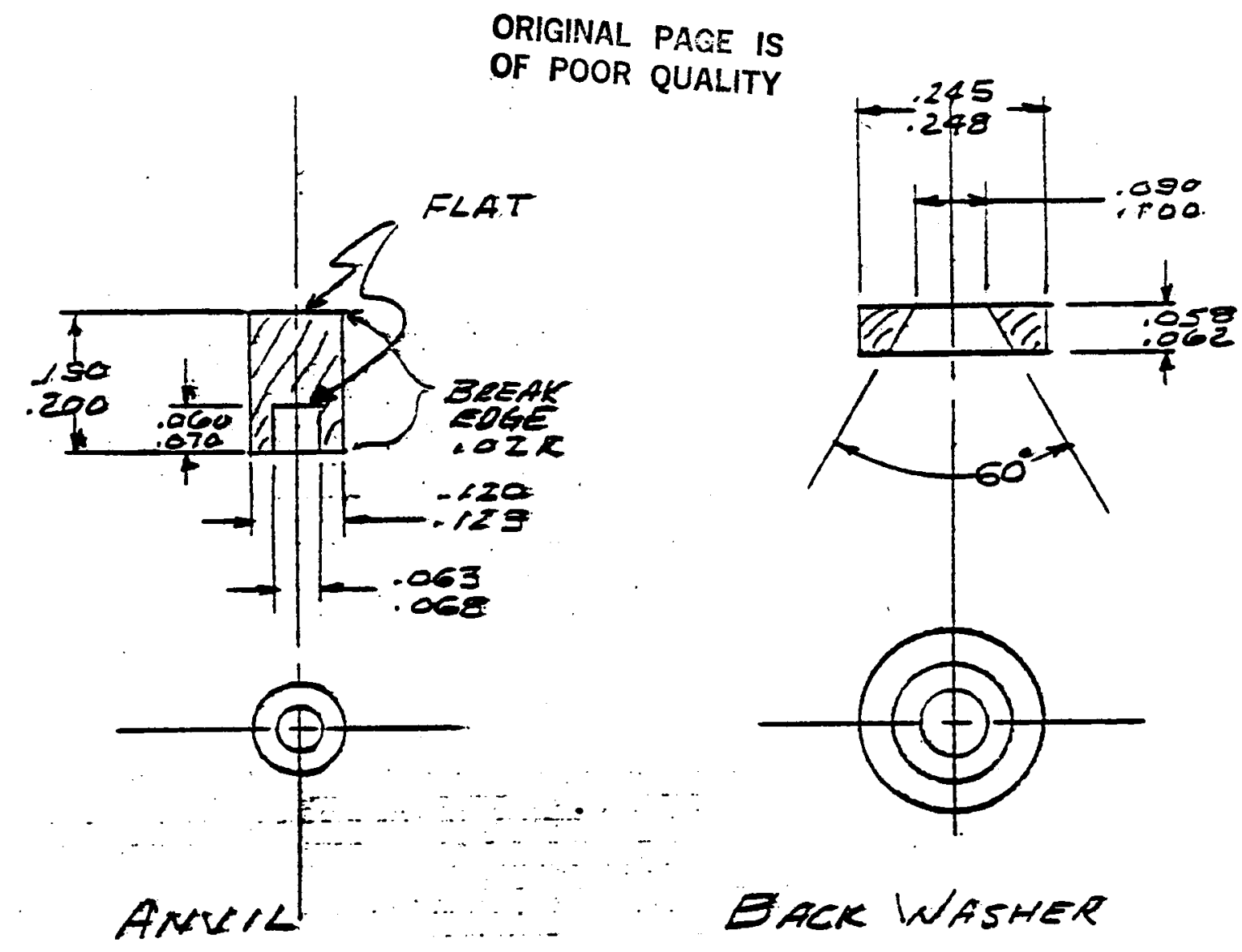

MATLE 30455

EACK WASHER ryara

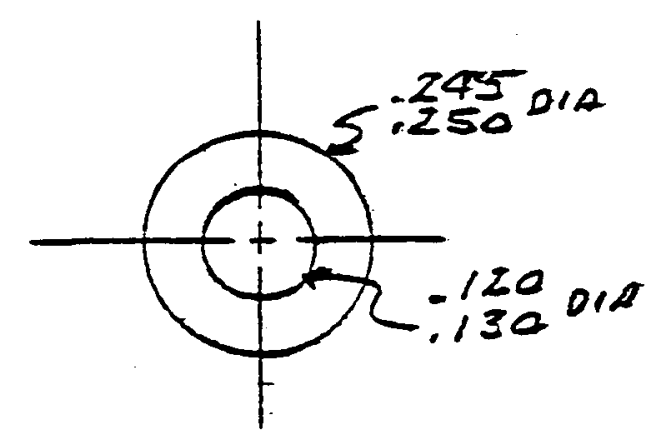

WASHER MATL: 30455

MATL: .020 30455

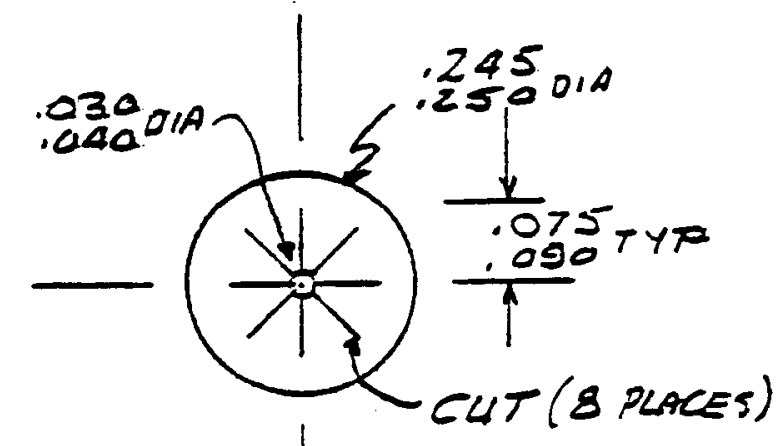




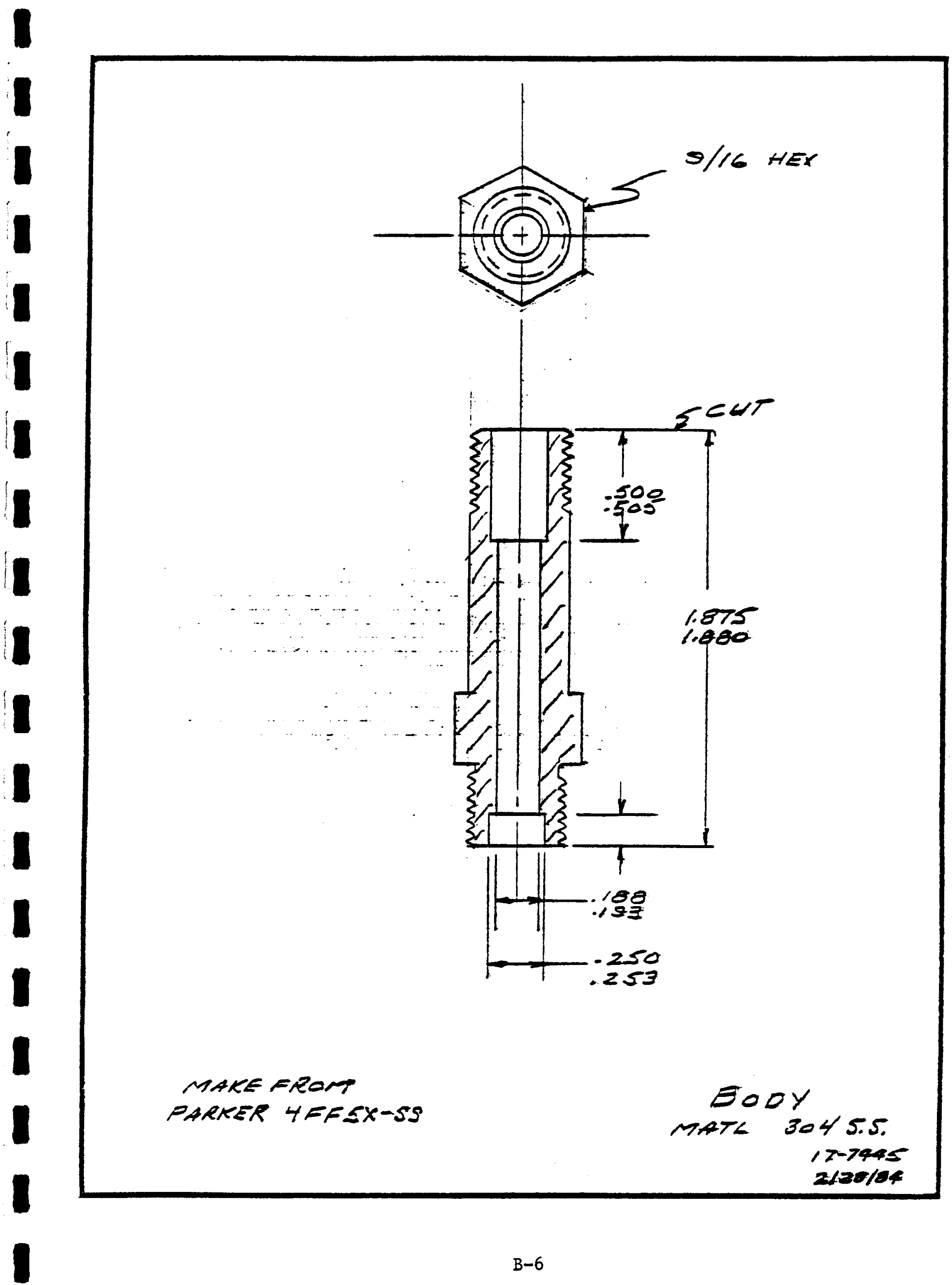




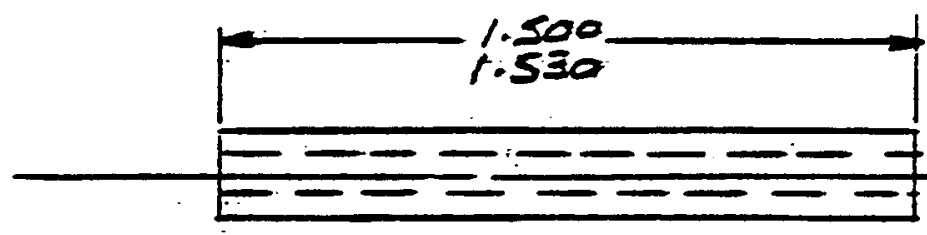

Ras Garoe

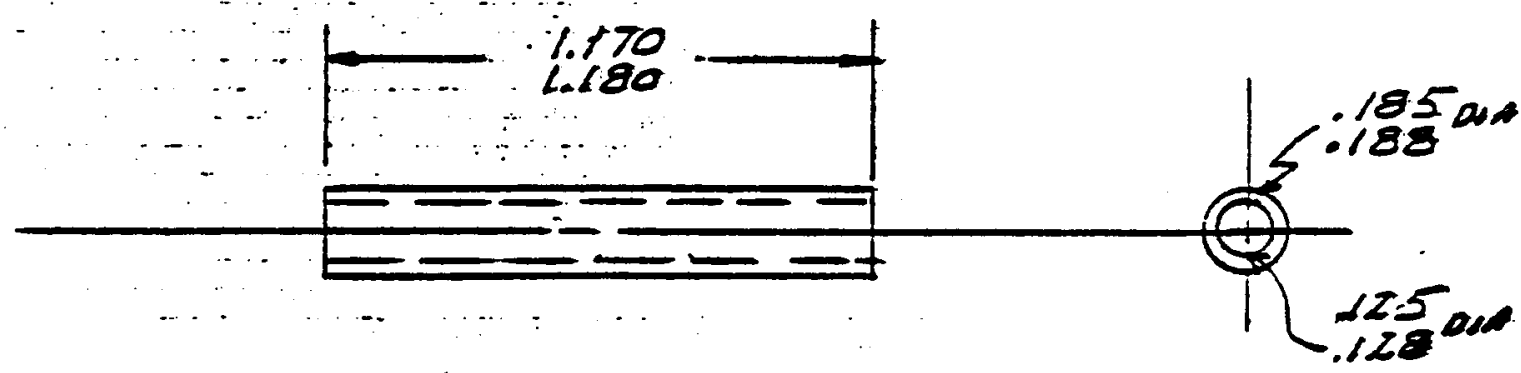

AMUIL GUIDE 


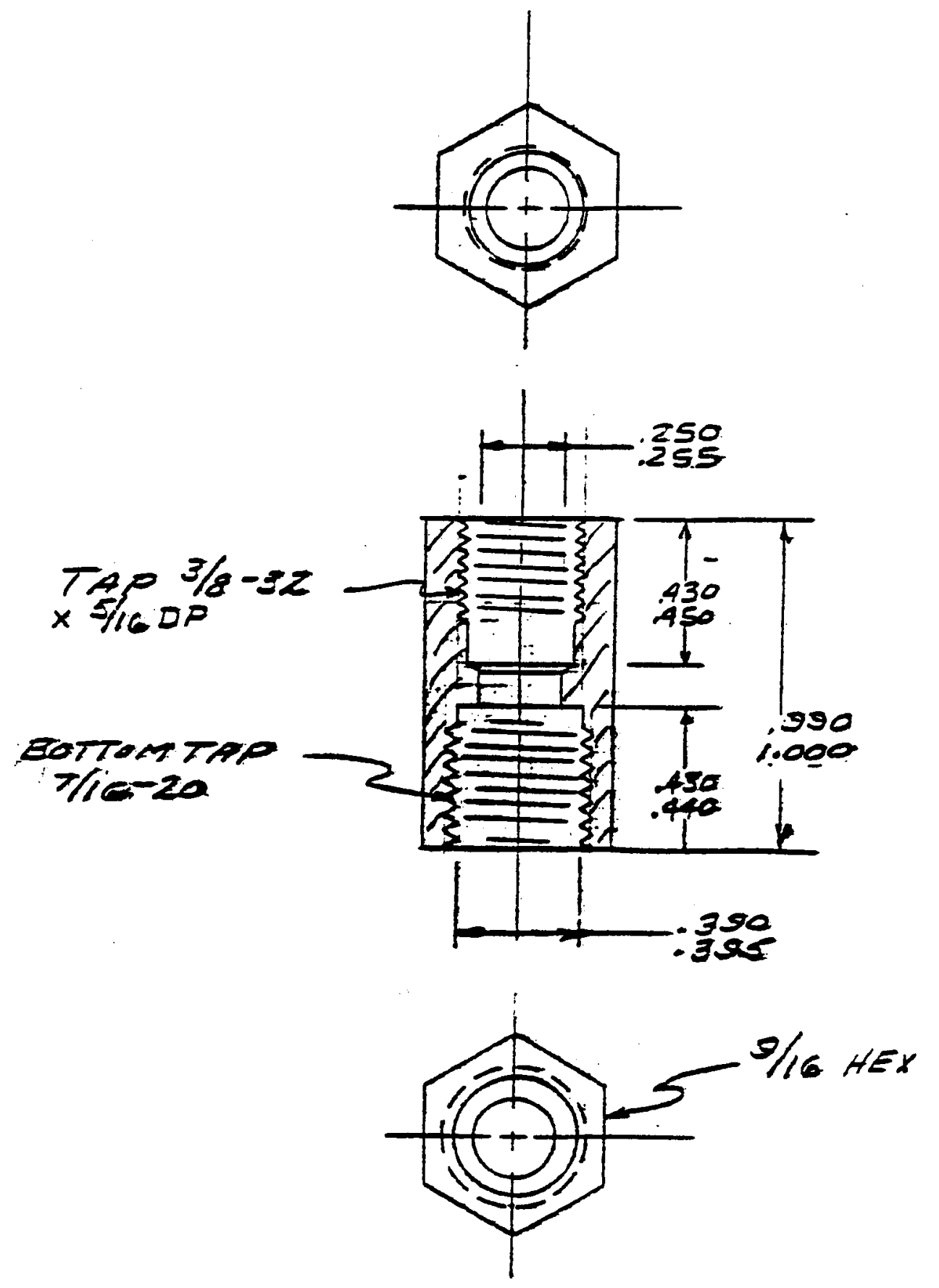

$$
\begin{aligned}
& \text { CAF } \\
& \text { MATL: 304 } \\
& 17-7445 \\
& 2 / 28 / 94
\end{aligned}
$$




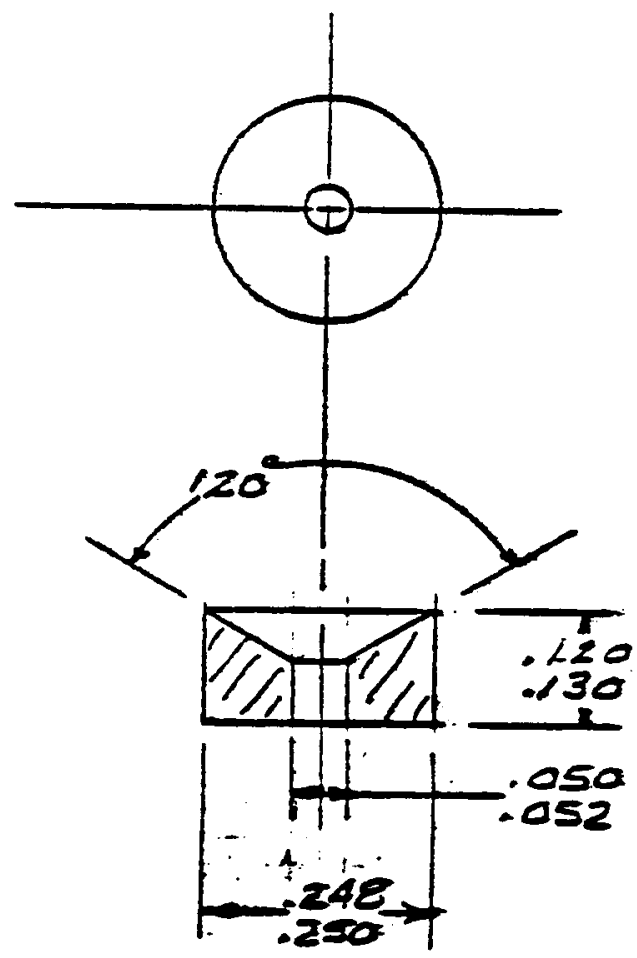

Packing I

ZREQO
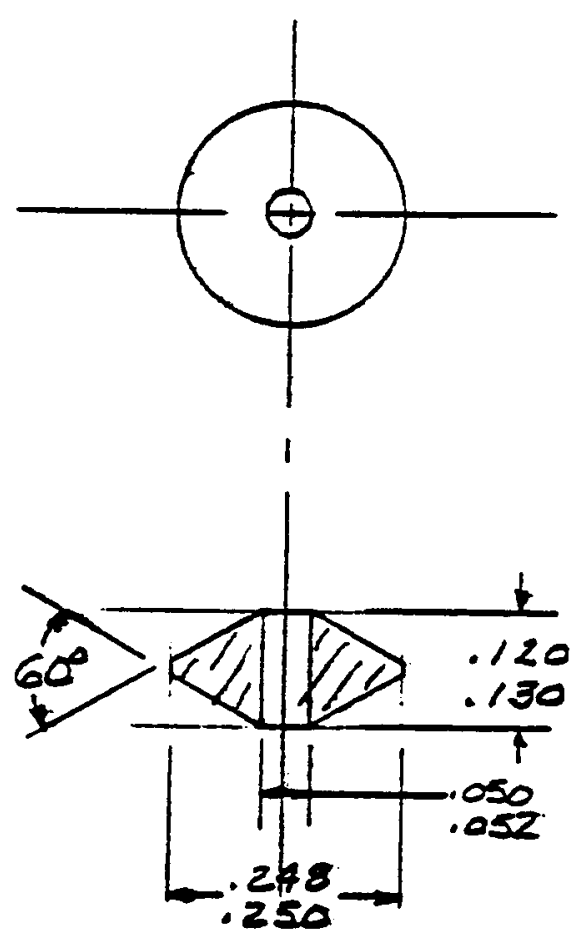

PACKING 2

I REPD

\section{MATL TEFLON}

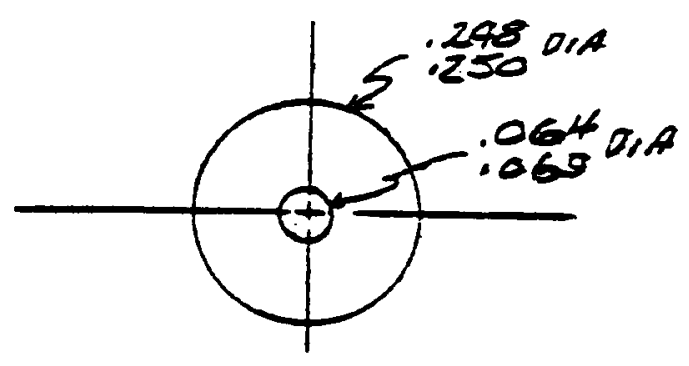

Guroe

.OZS THICK TEFLON 


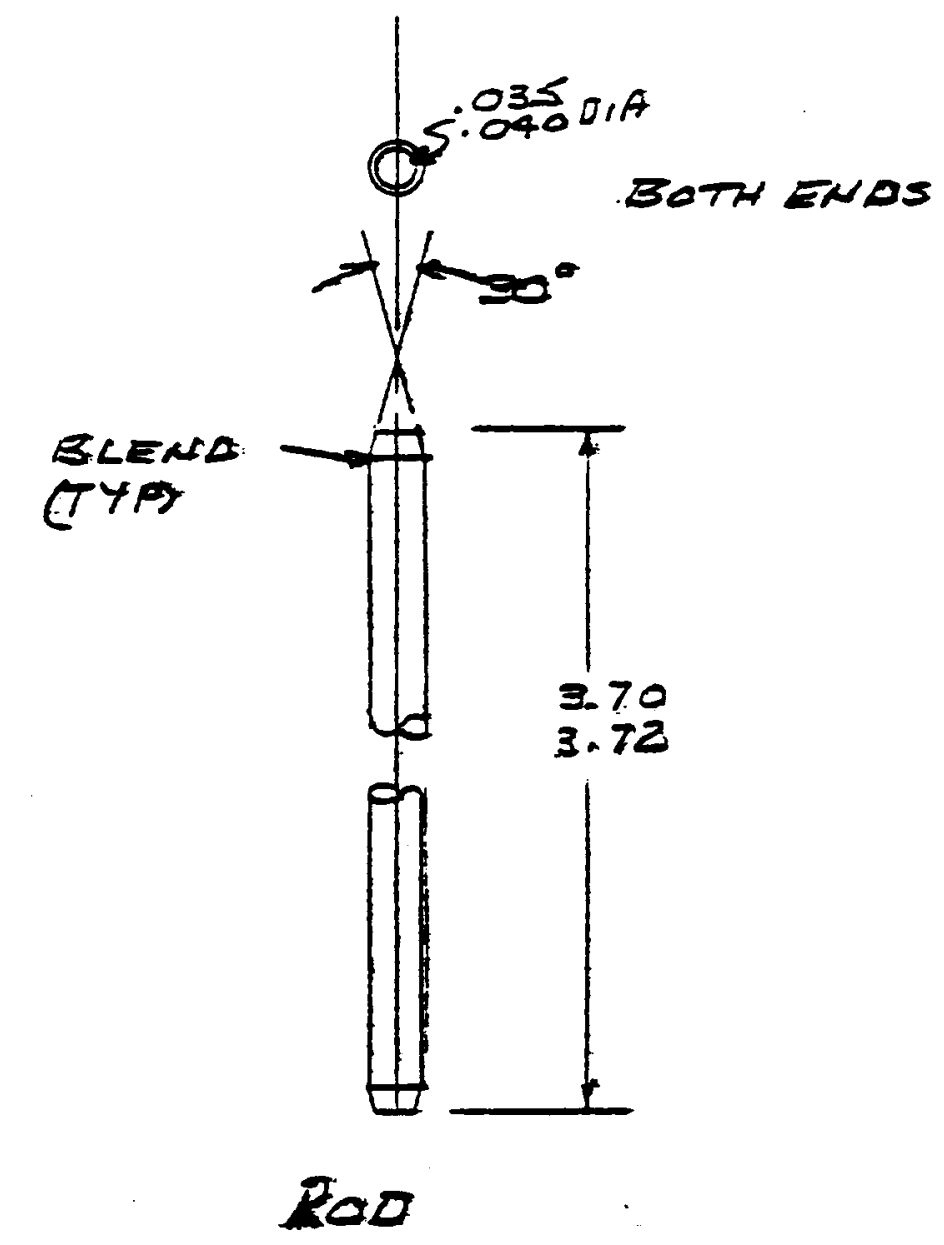

MATL: ZERG SHAPTIA S1-Z Bas $5 S$ 


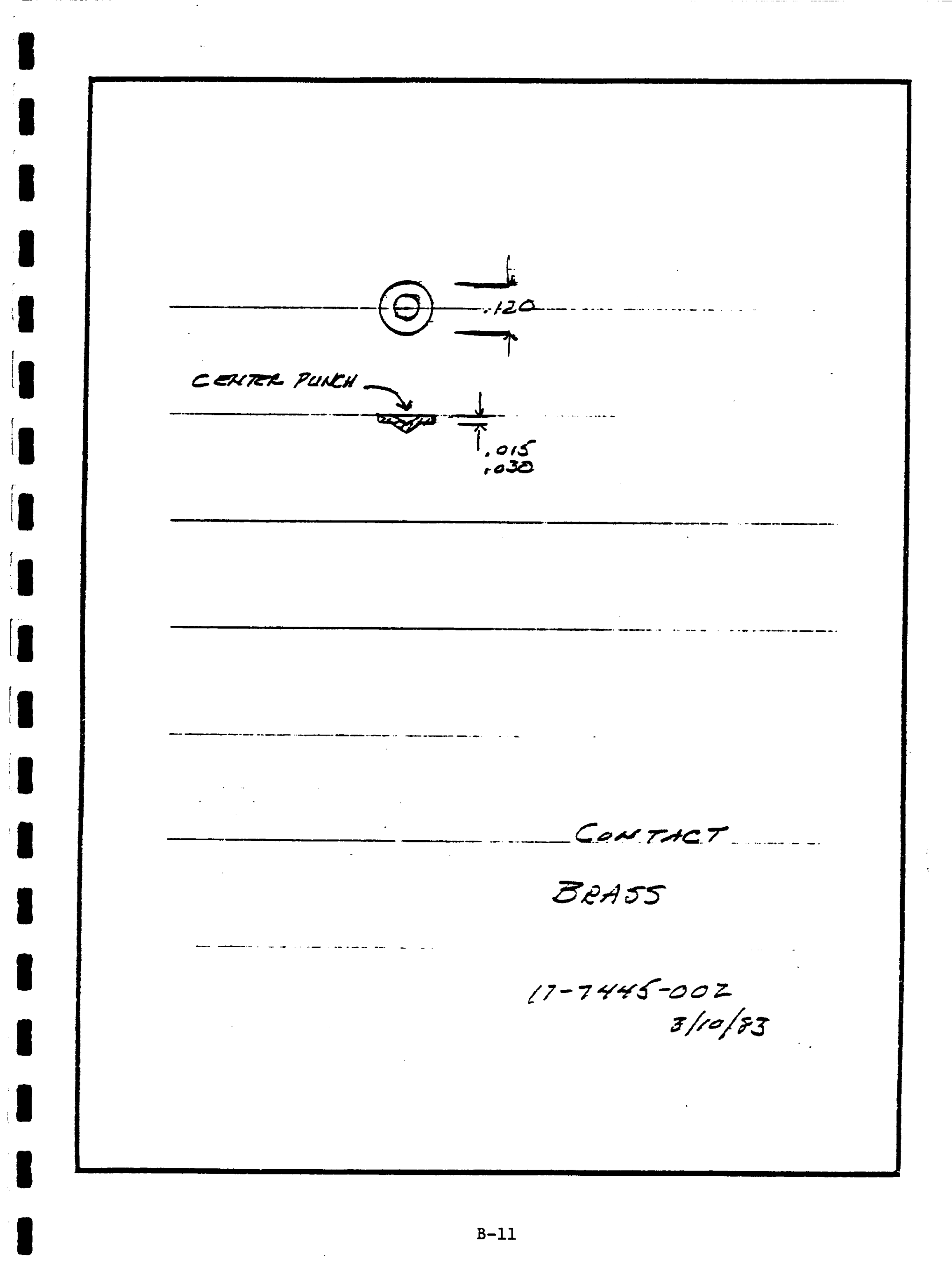




\section{ORIGINAL PAGE IS \\ OF POOR QUALITY}

\section{APPENDIX B}

\section{PHASE II FINAL REPORT*}

DEVELOPMENT OF AN ACOUSTIC MONITOR

TO DETECT INCIPIENT BEARING FAILURE

\footnotetext{
${ }^{*}$ Paper presented at 1986 Conference on Advanced Earth-to-Orbit Propulsion Technology, May 1986.
} 


\title{
DEVELOPMENT OF AN ACOUSTIC MONITOR TO DETECT INCIPIENT BEARING FAILURE
}

\author{
by \\ W1Illam D. Jolly \\ Institute ScIentist \\ W. R. Van der Veer \\ Staff Engineer \\ Southwest Research Inst1tute \\ John M. Knadler \\ Chief \\ NDE Branch \\ Marshall Space Flight Center
}

ABSTRACT

Bearings in liquid-oxygen turbopumps are cooled and lubricated by the liquid oxygen. It is 1mperative that damaged bearings, which generate heat, not reach kindling temperature because of the volatility of the oxygen. Acoustic monitoring of bearings, a method widely used to detect bearIng fallure under less exotic operating conditions, was considered for turbopump bearing monitoring. Results of recent tests of a prototype acoustic emission (AE) coupler on the Marshall Space Flight Center's Bearing Materials Test (BMT) Fac1lity indicate that acoustic monitoring can be performed in the high-noise, cryogenic environment of the BMT. This paper reviews the development of two prototype AE coupler mechanisms and presents test results on the selected design. 


\title{
1. INTRODUCTION
}

\author{
ORIGINAL PAGE IS \\ OF. POOR QUALITY
}

icoustic surveillance of rotating element bearings goes back to the time when man first learned that if he stopped and greased the squeaking wheel on his wagon, the axle and the hub would not catch fire. The problems now being experienced with rocket-engine turbopump bearings have taken us full circle. Now it is the liquid oxygen that ignites the exotic steels in the turbopump bearings when a bearing begins to fail. There is little resemblance between the exotic device illustrated in Figure 1 and the hub of a wheel on a prairie schooner, but the problem is the same. Friction produces heat, and heat in the presence of fuel and oxygen causes fire.

In response to the problem, the National Aeronautics and Space Administration (NASA) instigated a project aimed at development of an acoustic method of detecting incipient failure in the bearings of the NASA bearing materials tester (BMT). The goal was to obtain sufficient warning to prevent overheating to the point of ignition of the steel in the bearings by combination with the liquid oxygen. The NASA facility

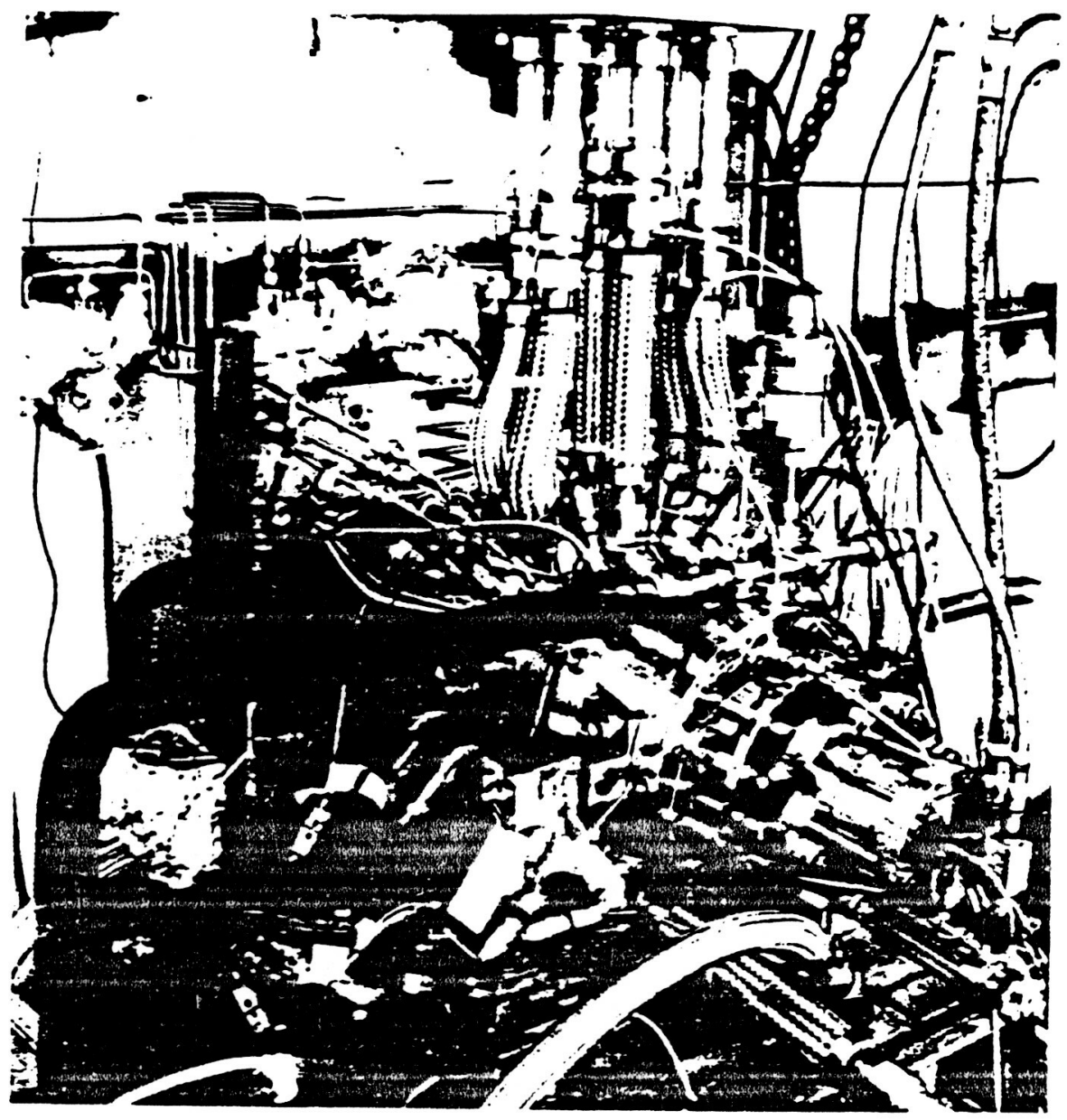

Figure 1. Bearing Materials Tester : lounted on a Test Stand for a Bearing Test 
tester tests new materials and new bearing designs for the bearings of turbopumps used to supply liquid oxygen and fuel to rocket engines. Success in this project will lead to development of a bearing monicor for rocket-engine turbopumps.

The turbopumps and the BMT use liquid oxygen as both a lubricant and a coolant for the bearings. In order to provide cooling and lubrication, the liquid oxygen is pumped through the bearing assemblies at a pressure of up to 500 psi. This environment provides severe operating conditions for the bearlngs as well as for acoustic surveillance of the bearings.

Design concepts were evaluated for mechanisms capable of coupling the acoustic noise from the bearings in the BMT to an extermally mounted acoustic sensor. Figure 2, a cross-sectional view of the BMT, shows the location of the shaft and the bearings and illustrates the problem of access to the bearing race through the housing and the bearing carrier.

The design concept first developed was an acoustic coupler for the 57-mearing test facility using an access port located adjacent to the No. 4 bearing. The channel from the access port to the outer race of the No. 4 bearing was narrow and angled from the access port into the bearing. This required the design of an acoustic waveguide with a

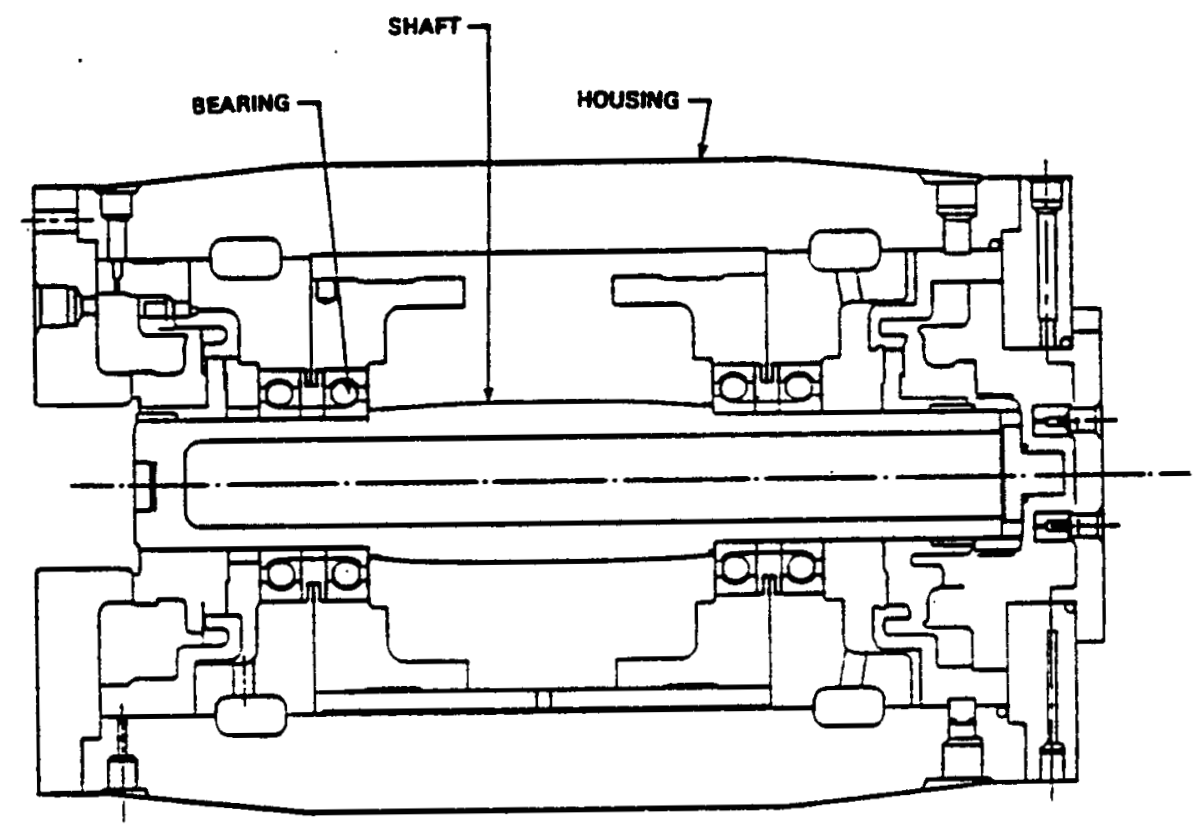

Figure 2. A Cross-sectional View of the Bearing Materials Tester Showing the Shaft and the Location of the Four Bearings, and Their Carriers 
bend and then a sharp hook at the end of it, as illustrated in Figure 3 . One inherent problem with this design was that noise from sources such as turbulent flow of the liquid oxygen and possible cavitation of the liquid oxygen could mask the low-level signals from a damaged bearing. A secondary problem was with the designated access port. The acoustic waveguide had to pass through the stream of oxygen flow, unshielded, on its way from the outer housing of the BMT to contact the race of the No. 4 bearing. This exposure to the flow of the liquid oxygen and, in particular, the turbulence in the area could lead to vibrations and perhaps even liftoff of the contact point of the acoustic coupler. Either of these effects would interfere with the detection of noise from the bearing. The hooked waveguide design concept was, therefore, rejected in favor of a straight-through design that contacted the outer bearing race through a thermocouple port or a ball-pass counter port.

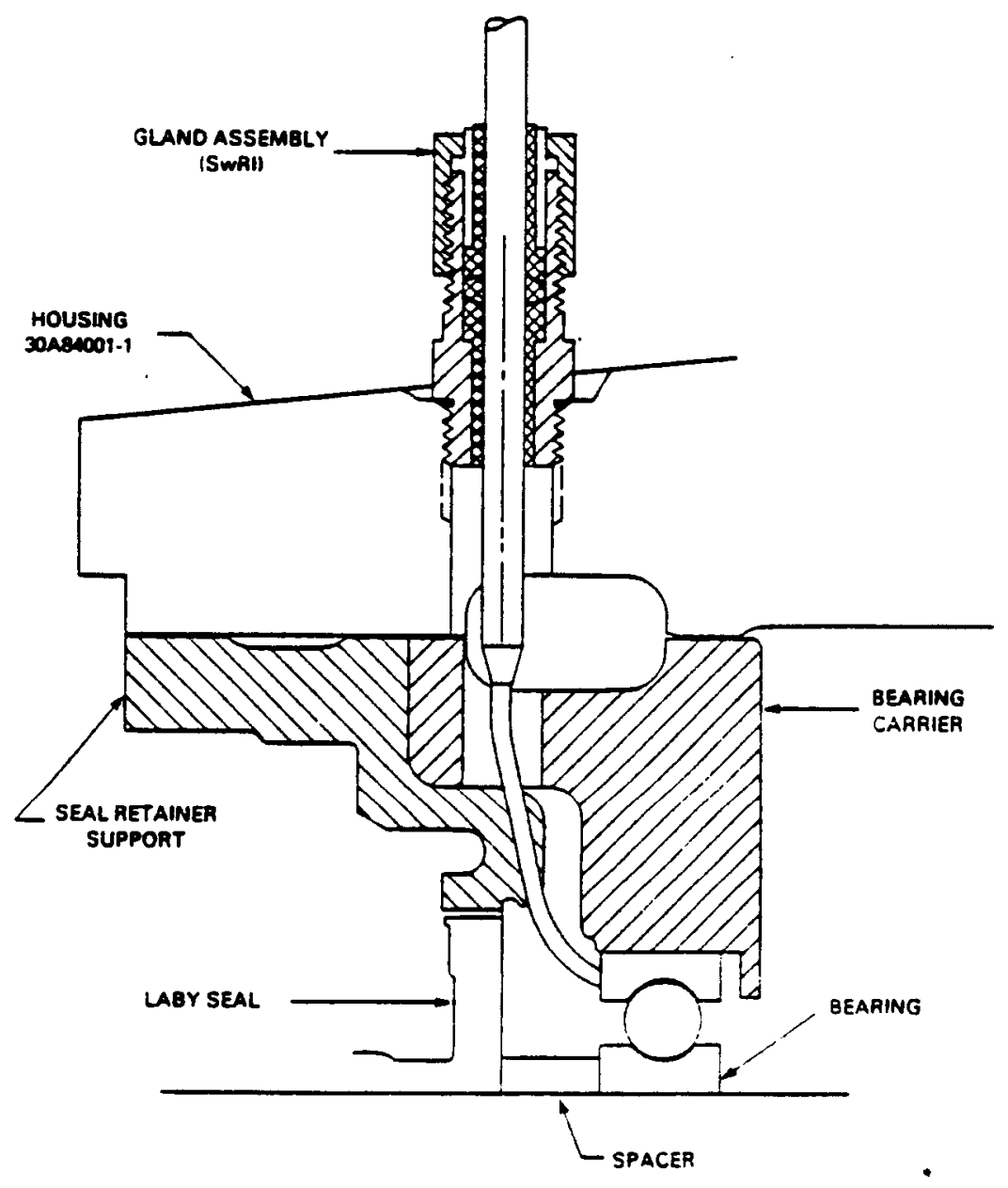

Figure 3. Prototype 1, the hooked acoustic coupler. The coupler is shown installed in the bearing materials tester. The small end of the coupler is in contact with the outer race of the No. 4, bearing. 
This paper briefly reviews the techniques of acoustic bearing monitoring, discusses the acoustic coupler design selection, and presents experimental results obtained with the selected straight-through coupler design from bearing test runs on the BMT.

\section{TECHNICAI DISCUSSION}

Acoustic surveillance of rotating equipment bearings is in general use today. Motors and pumps for critical applications are commonly supplied with acoustic bearing monitors in place. Application of acoustic surveillance to turbopump bearings and to the BMT facility to detect incipient failure in the bearings is unique only in that the liquid oxygen and its high flow rates provide a severe environment in which to detect acoustic noise due to bearing damage.

The detection of bearing noise due to damage or overheating of the bearings in the BMr would be straightforward except for the fact that the liquid oxygen flowing through the bearing assemblies generates noise due to turbulence and cavitation. Turbulence noise is usually in a frequency range below $100 \mathrm{kHz}$ while cavitation noise may extend to frequencies as high as 1 MAlz. Another source of noise is mechanical noise in the system; that is, nolses from other bearings, valves, actuators, and solenoids. These mechanical noises also are in the frequency range below $100 \mathrm{kHz}$.

Based on our experfence, the project team selected a frequency range for acoustic monitoring of $200 \mathrm{kHz}$ to $1 \mathrm{MHz}$ on the assumption that most of the necessary information would be in that frequency range. The solution to the basic problem of turbulent flow noise lies in the selection of a frequency band where the turbulence nolse is minimized and the bearing damage noise is maximized. Usually the desired frequency band lies above $100 \mathrm{kHz}$ and below $1 \mathrm{MHz}$ because turbulent flow no1se, being related to the flow velocity and the physical dimensions of the mechanical components, resides in the lower frequencies below $100 \mathrm{kHz}$.

Cavitation, on the other hand, involves the formation and violent collapse of tiny vapor bubbles, which generate acoustic transients having a broad frequency spectra extending to more than 1 MHz. Cavitation in the BMT could be of sufficient intensity to mask the changes in bearing nolse being sought. The bearing noise signature will change because of a damaged bearing ball or overheating of the bearing due to general surface damage. Initially, the change in bearing noise will be on the order of a few percent; but as the damage to the bearing accumulates, the noise will increase to a few hundred percent of the noise of a normal bearing. Cavitation noise, however, may be on the order of 500 to 1000 percent of the normal bearing noise.

It is fortunate that an acoustic bearing monitor can detect and identify cavitation because cavitation can cause erosion and pilting in both the bearing race and the bearing balls. 


\section{Initial Design Concedts}

Three possibilities were considered for coupling the acoustic noise from the bearing to the environment outside the BMT housing. The first concept was to use the BMT housing itself as the acoustic coupler, since the outer race of the bearings was in intimate mechanical contact with the BMT housing. The second concept was the hooked acoustic emission (AE) coupler waveguide, which contacted the surface of the side of the outer race of bearing No. 4. It then would couple the sound from that point directly to a sensor mounted on the opposite end of the waveguide outside the BMT housing. The third concept was that of a straight waveguide passing through a ball-pass counter port or a thermocouple port.

Housing-Mounted Sensor. The design concept of mounting the acoustic sensor on the outside of the BMT housing was rejected because the individual bearings could not be identified and because the sensor would be exposed to all of the attendant noise sources including the noise from other bearings in the housing, noises of solenoids and valve actuation, and turbulence and cavitation noises of the flowlng liquid in the housing.

Hooked AE Coupler Waveguide. The hooked AE coupler waveguide design is illustrated in Figure 3 . The enlarged body of the acoustic coupler fit the standard 1/4-inch diameter feedthrough seal assembly used on the BMT. The coupler's total length was 7.25 inches, with the final

2 inches reduced to a diameter of $1 / 8$ inch and bent to fit through the angled channel and around the corner of the bearing carrier. Then only the tip of the waveguide came in contact with the side of the bearing No. 4 outer race.

After being bent to shape, the coupler was heat-treated for proper stiffness to apply pressure of a minimum of 5000 psi at the contact point. The tip of the acoustic wavegulde was machined to a 1/16-inch radius for uniform contact with the side of the bearing race. Details of the acoustic emission sensor assembly mounted on the end of the waveguide are illustrated in Figure 4. The sensor was acoustically coupled by low-temperature silicon grease and mechanically coupled to the waveguide tip by a springloading mechanism through the contact point of the BNC connector.

The working model of this design concept was fitted to the BMT, and the design was submitted to the test engineering section at the NASA facility for (1) evaluation of the impact of the $A E$ coupler on the operation of the BMT and (2) assessment of the adequacy of the acoustic coupler design to withstand the turbulence and flow conditions in the cavity of the BMT. NASA test engineering concluded that the acoustic waveguide, being in the high flow and high turbulence region in the BMT cavity, would be subjected to severe vibrations which could possibly cause the tip of the waveguide to break off. Testing of the hooked $A E$ coupler on the BMI was not permitted because of the possibility of damage to the BMT. 


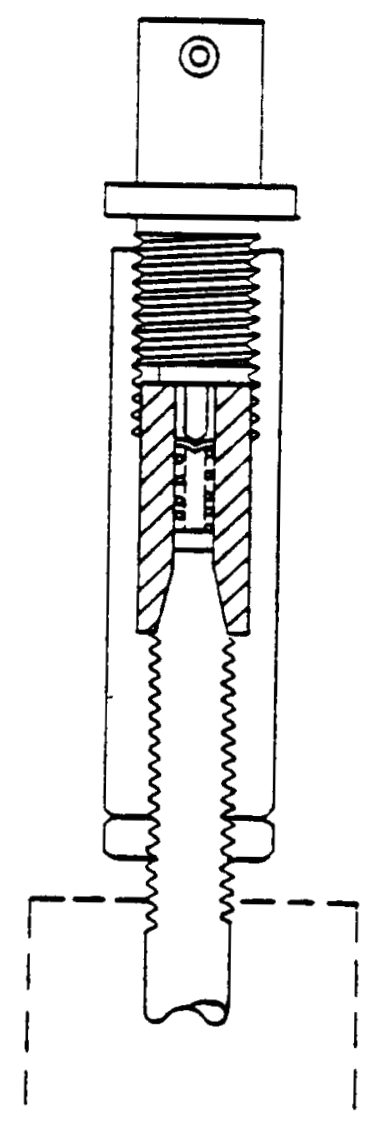

Figure 4. A cross-sectional view of the acoustic emission sensor on the hooked acoustic coupler. The standard coaxial cable connector provides both mechanical and electrical contact for the piezoelectric element placed on top of the tapered end of the threaded portion of the acoustic coupler.

\section{Straight-Through Acoustic Coupler}

Since the hooked $\mathrm{AE}$ coupler extending into the liquid oxygen flow could not be tolerated, the alternative design concept, a straight-through acoustic coupler for insertion into an existing ball-pass counter port or a thermocouple port, was implemented. The resulting $A E$ coupler design is shown in Figure 5. This design was not developed initially because it would displace a thermocouple or ball-pass probe or require additional ports in the BMT.

The straight AE coupler design is more complicated than the hooked waveguide coupler design because the feedthrough and seal assembly must provide for (1) applying a constant load onto the acoustic coupler rod and (2) maintaining constant acoustic contact between the piezoelectric element and the top of the acoustic coupler rod. These are accomplished 


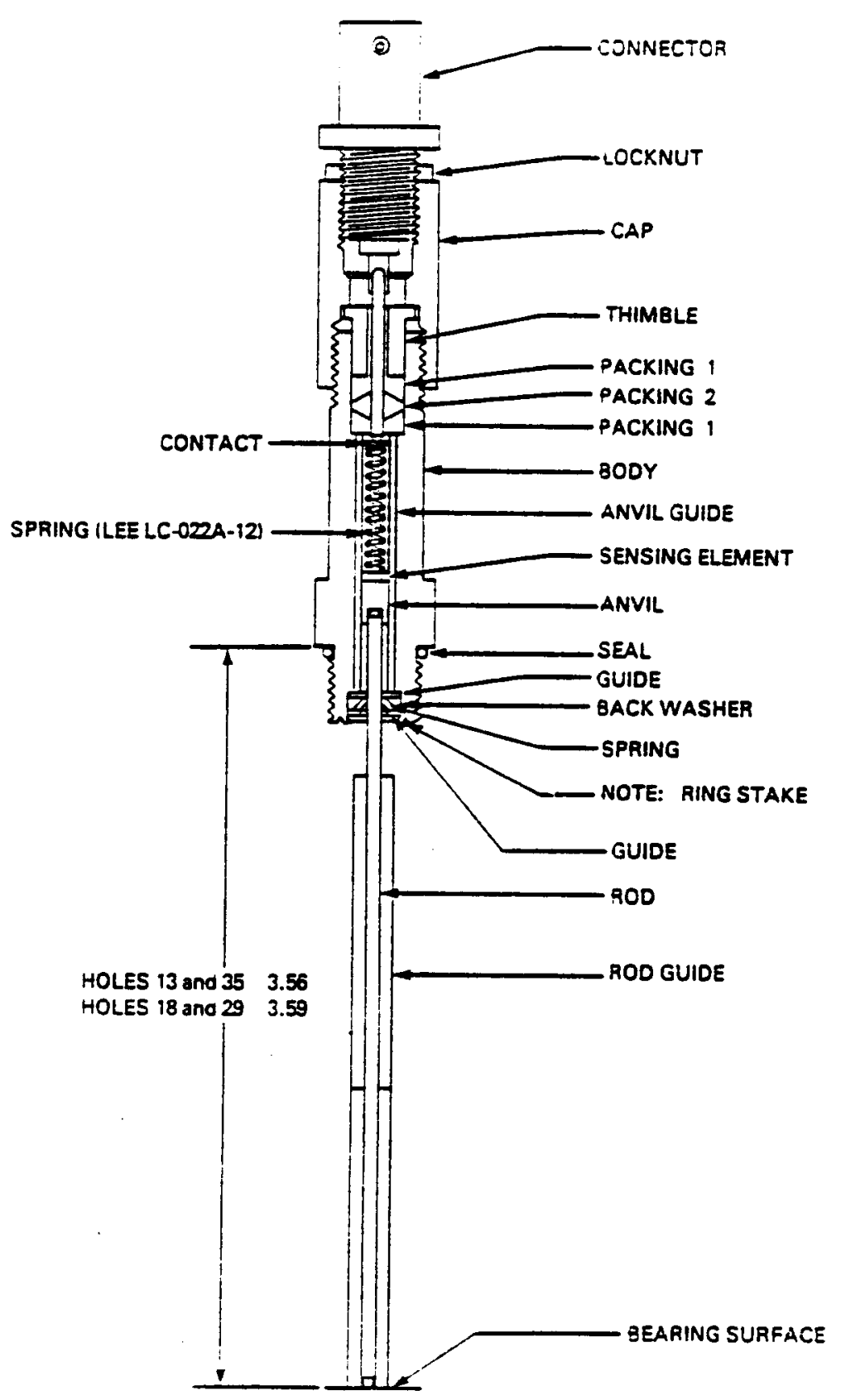

PROBE ASSEMBLY FOR HOLES 13.18 .29 , and 35

Figure 5. The second prototype, a straightthrough acoustic coupler assembly. This assembly is designed for insertion in the bal1pass counter port or the thermocouple port. 
by placing both the sensor and the acoustic coupler rod inside the pressure boundary of the BNT housing. The electrical connection to the coaxial cable connector at the top of the assembly is made through a solid rod passing through the packing gland. The assembly provides adjustment of the mechanical force, which is applied by a compression spring through the piezoelectric sensing element to hold the rod in contact with the bearing surface. The design provides for a constant contact pressure between the rod and the bearing surface over a wide range of temperatures.

In the feedthrough housing, the anvil guide (a teflon tube) offers electrical insulation and acoustic isolation for the piezoelectric sensing element. Further acoustic isolation is given by the rod gulde, which prevents direct contact between the coupler rod and the narrow channel between the feedthrough and the bearing surface. The overall coupler design is made so that it can be used in either the ball-pass counter probe ports or the thermocouple probe ports. It also uses the same $A E$ sensor that was used in the hooked coupler design.

\section{EVALUATION OF ACOUSTIC COUPLER}

Evaluation of the final prototype acoustic coupler design was conducted on the BMI during the first full-speed test of a new test module built for investigation of bearing failure mechanisms. As this BMT was designed for operation with liquid nitrogen in place of liquid oxygen, it is possible to safely operate with damaged bearings.

This section describes the test setup, instrumentation for evaluation of the acoustic coupler, and analysis of the results from BNT test No. 3 .

\section{Test Setup}

The straight-through acoustic coupler design was evaluated on the BMI in September 1985. The evaluation was carried out on test No. 3 of the BMT, as shown set up in Figure 6 . The acoustic coupler installed in port No. 29 is indicated on the lower left corner of the photograph. Port No. 29 is a thermocouple port on bearing No. 3. The preamplifier for the acoustic coupler was mounted nearby, but away from the tester a sufficient distance to avoid the cold and frosting conditions that occur during the resting. The acoustic signal output from the pream plifier was then connected into the test-stand instrumentation cabling leading to the data acquisition station 1200 feet away. The preamplifier was battery powered in order to isolate the preamplifier circult from the possibility of ground currents in the test-stand power-suppiy system. The 12-volt battery was sufficient to power the preamplifier continuously for up to 20 hours. The acoustic coupler was installed so that contact pressure of 2 to 5 pounds was provided between the acoustic coupler tip and the outer race of the No. 3 bearing. 


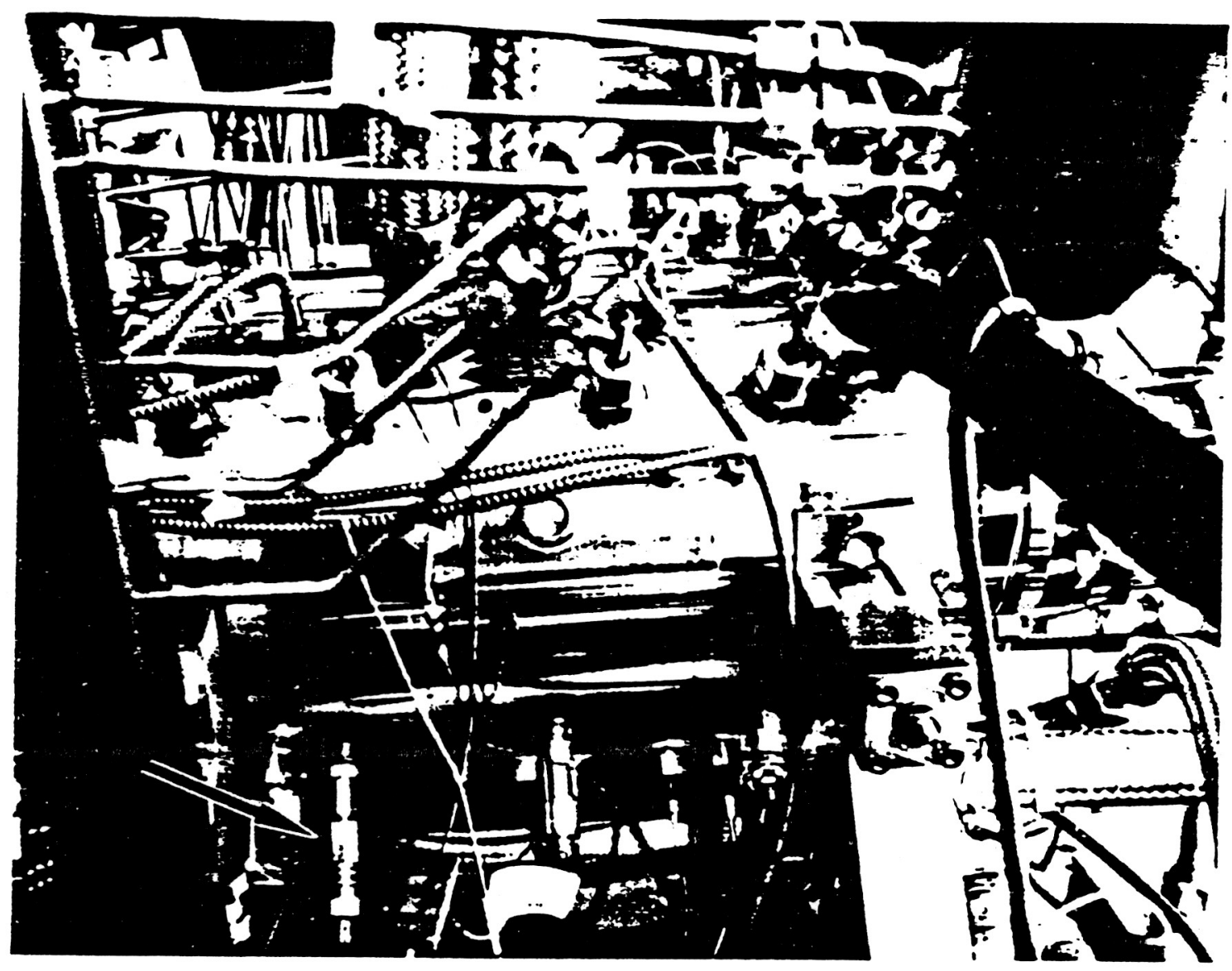

Figure 6. Bearing Materials Tester Showing Installed AE Coupler in Port No. 29 at Bearing No. 3

Instrumentation

A block diagram of the AE coupler instrumentation at the data acquisition station is shown in Figure 7. The signals from the acoustic sensor were coupled to the input of the preamplifier, which provided $22 d B$ of gain, and included a bandpass filter for a frequency range from $200 \mathrm{kHz}$ to $1 \mathrm{MHz}$. The preamplifier had sufficient power to drive the 1200 feet of coaxial cable between the test stand and the data acquisition station.

In the data acquisition station, two amplifiers, an HP-465A and an HP-461A, were connected to the signal cable from the preamplifier. The $\mathrm{HP}-461 \mathrm{~A}$ preamplifier was set to a gain of $20 \mathrm{~dB}$, and its output was connected to the MSFC data acquisition system. There the signals from the acoustic coupler were digitized and recorded in the standard VSFC data format. The UP-465A amplifier was also set to $20 \mathrm{~dB}$ gain, and its output was connected to SwRI instruments consisting of an $\mathrm{HP}-3400 \mathrm{C}$ RMS voltmeter and a Nicolet $204 \mathrm{~A}$ digital oscilloscope. The RMS voltmeter provided a continuous output level indication of the full bandwidth 
from the acoustic coupler through the preamplifier. The Nicolet digital oscilloscope was used to record waveforms on a floppy disk waveforms at intervals throughout the test.

During the 1nitial 1nstrumentation setup and checkout, the final amplifier (EP-465, BP-461) gain at the data acquisition station was inttially set to $40 \mathrm{~dB}$; however, it was found after the test serfes was initlated that the optimum setting for the gain of these final amplifiers was $20 \mathrm{~dB}$. In this configuration, as shown in Figure 7,42 dB was gained overall between the acoustic sensor in the $A E$ coupler and the instrumentation. At the total gain of $42 \mathrm{~dB}$, the maximum amplitude of the s1g nals recorded throughout the test did not exceed 2 volts peak to peak. This instrumentation setup was then used to monitor the response of the acoustic coupler during test No. 3 of the BMT.

The response of the coupler as indicated by the RMS voltmeter is recorded chronologically in Figure 8. This test was interesting because 1t 1nvolved three startups and shutdowns. In the 1nitlal two startups, the BMT was turned up to more than 18,000 rpm. The final stage of the test of the BMT was run at 30,000 rpm for more than 2 minutes.

Referring to Figure 8, the 1nitlation of the test at 11:05 on September 19 shows the response of the acoustic coupler as the chilldown of the tester began. Chllldown involved venting liquld nitrogen through the BMT at a lowered volume in order to cool the tester to near the liquid nitrogen temperature. This was done in preparation for the full flow, established when the BMT shaft begins to turn. The BMT consisted

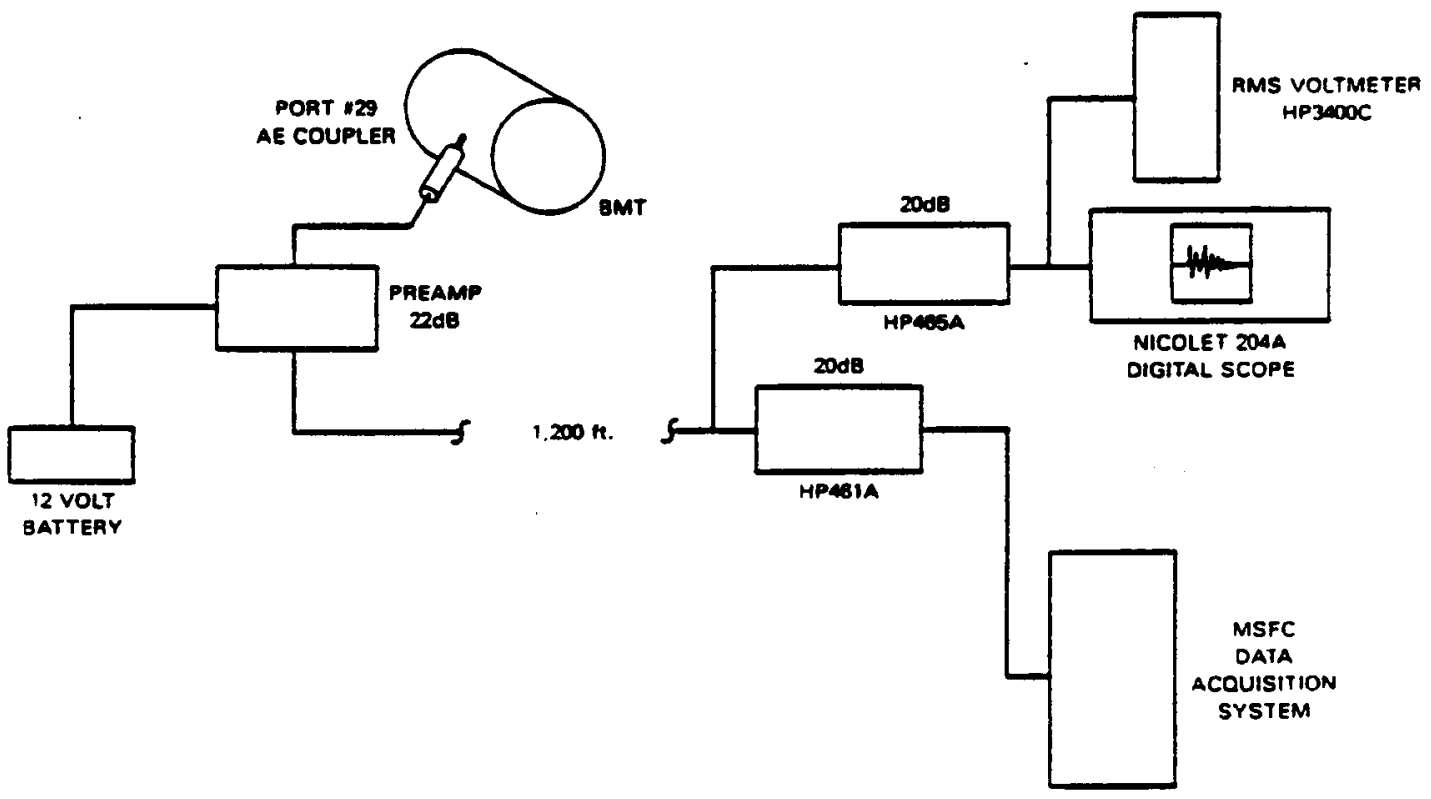

Figure 7. Block Dlagram of Instrumentation Used to Evaluate the $A E$ Coupler at the Marshall Space Flight Center 


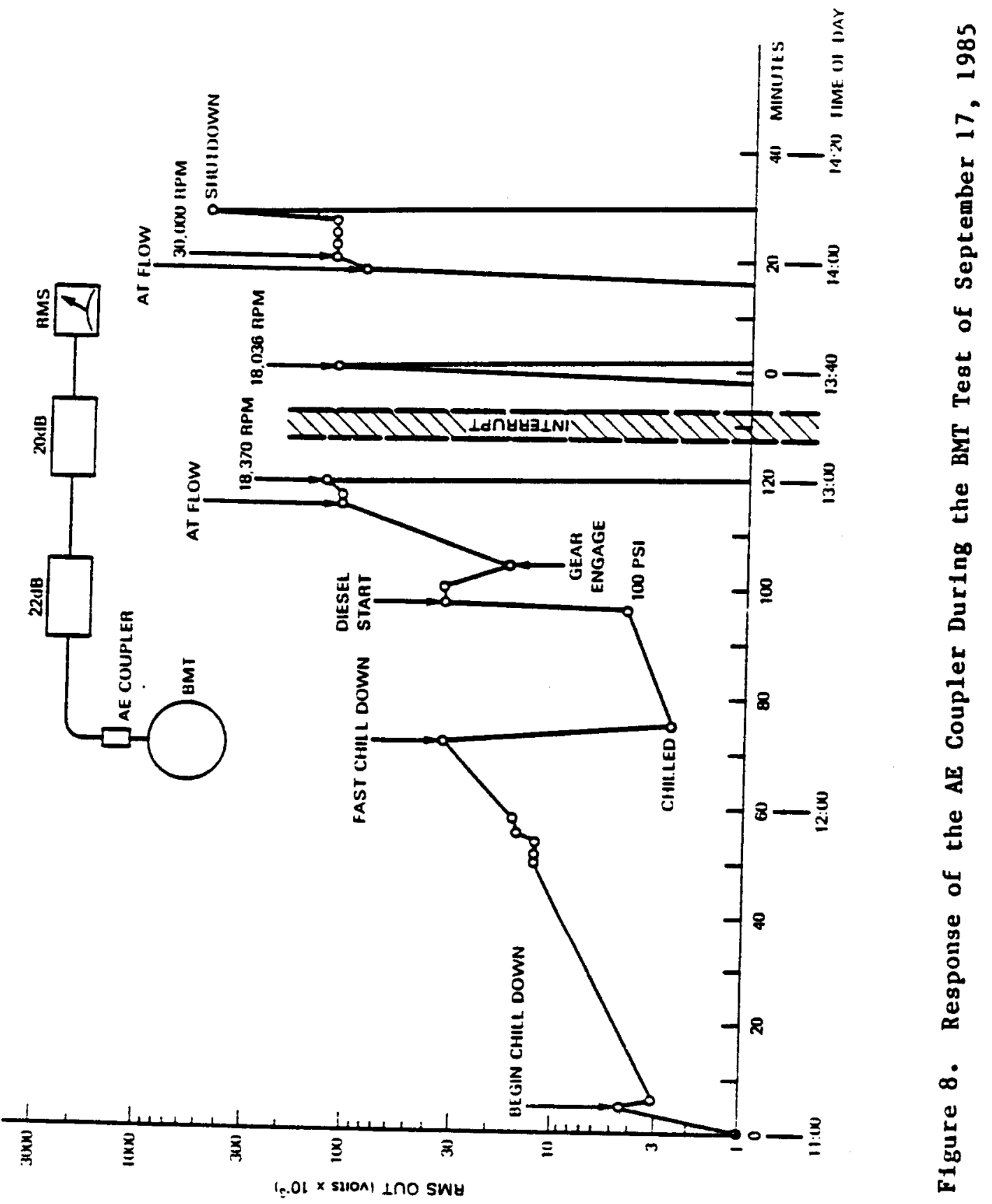


primarily of a shaft and four bearings turned by a diesel engine through a hydraulic transmission.

The stages of the test consisted of chilldown, engine start, engagement of the bearing shaft, and then increase in $r$ pm of the bearing shaft unt1l the desired speed was reached. FIgure 8 shows that the RMS output level 1ncreased rather steadily as the chilldown progressed. This was thought to be due to liquid nitrogen boiling in the BMT. Immediately after the fast chilldown was completed and the rate of cooling. reduced, the noise level fell to approximately the same level as at the beginning of the test.

The next erent in the test was the ralsing of the nitrogen pressure to 100 psi; that 1s, to establish an initial flow condition through the BII so that the englne could be started and the bearlng shaft engaged for rotation. A considerable increase in the RMS level was noted as the diesel was started. Th1s level dropped significantly, however, when the gear was engaged, and increased again when the flow of liquid nitrogen was increased to the full flow condition required for the test. When the BMT shaft was turned up to $18,370 \mathrm{cpm}$, the nolse level 1ncreased only slightly, Indicating that the mechantcal noise associated with the normal rotation of the bearing shaft was only a small por tion of the total background notse. The sources of background noise were the mechanical noise coming from the diesel engine, noise from the hydraulic transmission, and nolse from the nttrogen flow.

The second startup of the BMT occurred at 1340 hours, and its record illustrated the repeatability at 18,000 rpm as the RMS amplitude of the noise was approximately the same as that of the initial startup. The final test started shortly before 1400 hours. Durlng this test, the shaft speed of the BMI was Increased to the full test speed of $30,000 \mathrm{rpm}$. The noise level in the at-flow condition and the noise level at full $\mathrm{Tpm}$ differed by about 10 percent. This again polnts out that the mechanical noise associated with turning the bearing shaft is small compared to the other nolse sources in the bearing tester. Those noise sources are from the flow, englne, and transmission. At the end of this test when the BMI was shut down, the noise level increased about 20 percent. This increase was not understood; however, it is assumed to be a result of instabllities in the mechanical components as well as an increase in turbulence in the flow as the liquid nitrogen was throttled.

The acoustic coupler and its preamplifier remained at the test site for subsequent BMT tests during which the output from the coupler was recorded on the MSFC data acquisition system. Figure 9 1llustrates the record from a portion of test No. 6, conducted on November 3 . This record Indicates that (1) the nolse level recorded by the MSFC data acquisition system is similar to that recorded with SwRI Instrumentation and (2) the noise level from bearing No. 3 does not change appreclably from test to rest. Another encouraging report feature is that the noise level throughout the test was sufficlently uniform so that a change of 

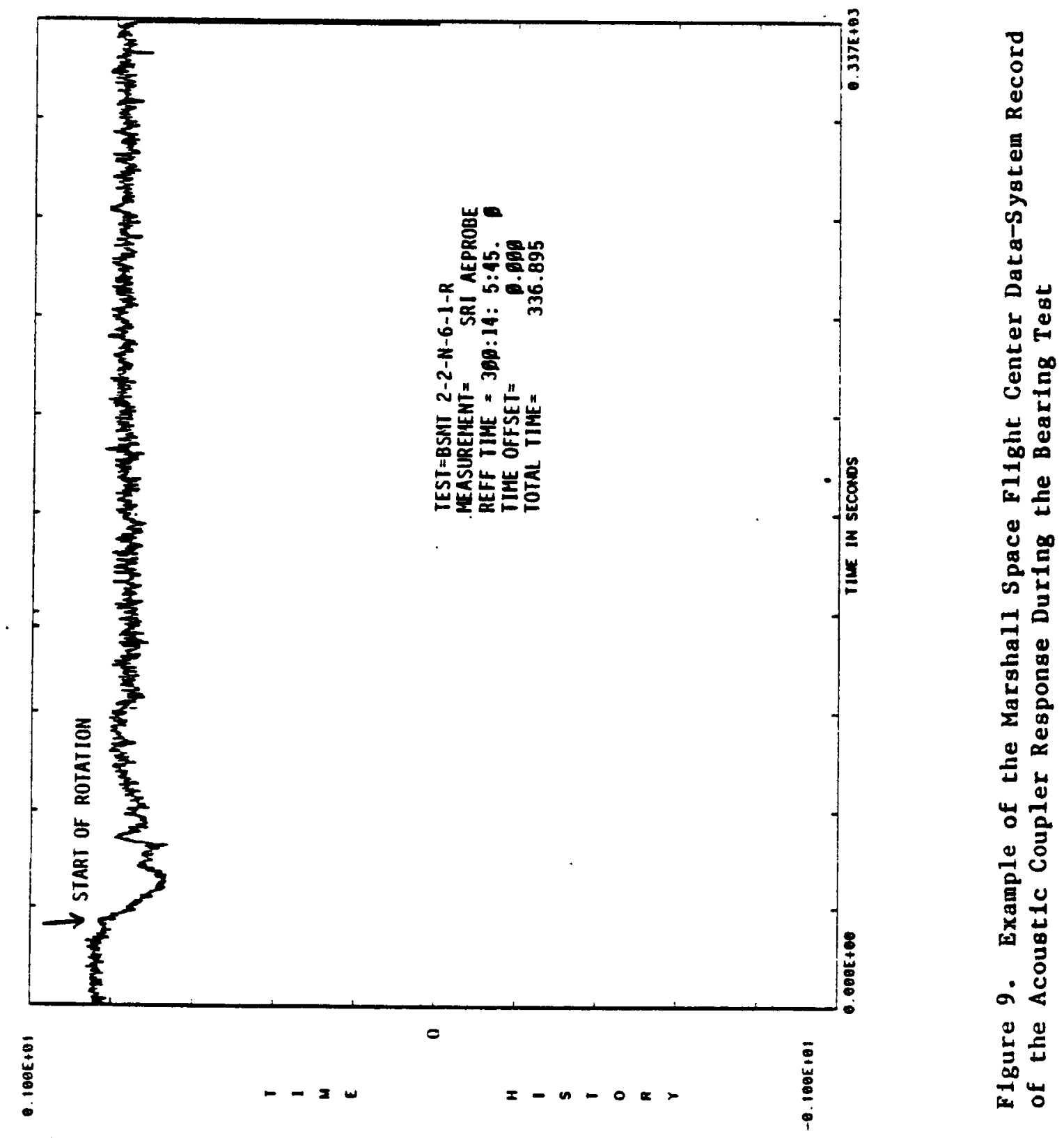
only a few percent in the average noise level could be detected. This means that a small increase in notse due to roughness of the bearing could be detected during a bearing test.

\section{Analysis of Data from Test No. 3}

The coupler data digitized on floppy disk by the N1colet 204A digital oscilloscope were subsequently analyzed in order to evaluate the frequency response throughout the test. A standard waveform analysis package was used to perform the fast Fourler transformation on the recorded Waveforms and also to reproduce the time-domaln waveform. F1gure 10 1llustrates the frequency-domain and time-domain data from the post-test calibration check on the acoustic coupler.

Th1s calibration check consisted of a sharp impulsive signal generated by a $0.5 \mathrm{~mm}$ pencil-lead break (Bsu-NIelsen source). While the amplitude of this signal input is very small compared to the continuous nolse generated by the BMT, it does provide a broad spectrum signal and a reasonably unfform signal amplitude for verifying the proper function of the acoustic coupler and the preamplifier. The signal indicated in F1gure 10 had a maximum peak-to-peak amplitude of $83 \mathrm{mV}$, and the frequency response extended to a little above $700 \mathrm{kBz}$ with one dip in the spectrum at about $350 \mathrm{kHz}$. The lower end of this frequency-domain plot shows the effect of the high-pass filter in the preamplifier, which is set at a cutoff frequency of $200 \mathrm{kHz}$.

In Figure 11, the frequency and time-domatn data are shown for a waveform segment recorded at full coolant flow, but prior to beginning of the shaft rotation. The primary response was slightly above $200 \mathrm{kHz}$, and the response of the flow nolse above $300 \mathrm{kHz}$ was very low. This Indicates that ( 1 ) the noise was primarily due to turbulence in the flow and (2) no evidence of carltation was indicated in the flow. As shown on the figure, the record was taken with a final amplifier gain of $40 \mathrm{~dB}$. This was imnediately prlor to reducing the gain to $20 \mathrm{~dB}$ for the remainder of the test. At $40 \mathrm{~dB}$, the maximum amplitude indicated here was 5.59 volts. When we rescaled to correspond to a 20-dB gain, this maximum amplitude would reduce to 0.559 volt.

Figure 12 shows the change in amplitude and spectrum regarding frequency-domain and time-domain data when the tester was turned to its full 30,000 rpm. Interestingly, the maximum signal amplitude increased to only 0.616 volt compared to 0.559 under the full flow condition. The frequency-domain data indicated that the noise in the higher frequency region had 1ncreased slightly in proportion to the notse in the 200-kHz turbulence peak; however, there was still no Indication of the possiblilty of cavitation in the flow. Additionally, no indication appeared of continuous high-frequency noise which would be associated with a damaged or roughened bearing. 


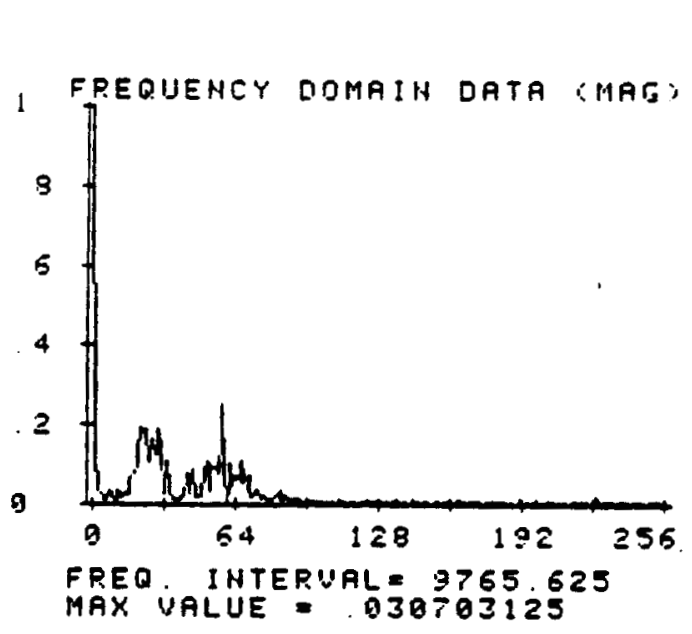

Diek $17 /$ rrack $2 / Q 1$ $\star 20 \mathrm{~dB}$ gain

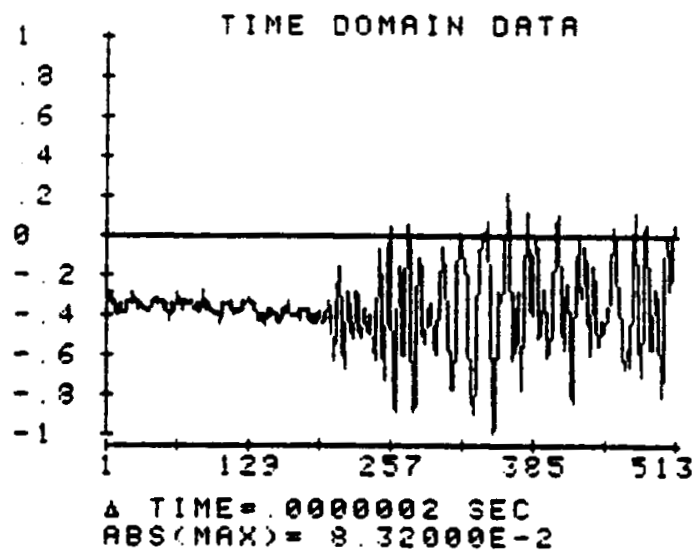

Salple Rate - 200 neac

F1gure 10. Frequency Spectrum and Waveform of the Post-Test Calibration Check on the AE Coupler

40 dB gata

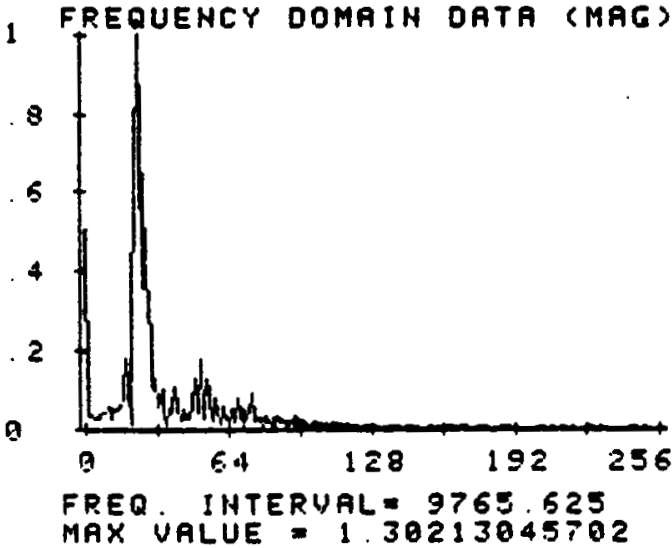

DLak 6/Track $8 / Q 2$

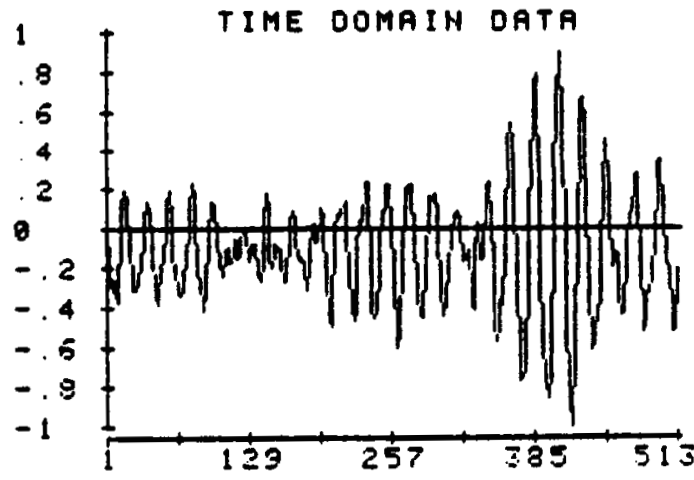

- TIME $=0909002$ SEC ABS $(M A X)=5.59999999956$

Safiple Rate - 200 naec

Figure 11. Frequency Spectrum and Waveform from Iiquid Nitrogen F low of Test No. 3 
๓20 dB ge1n

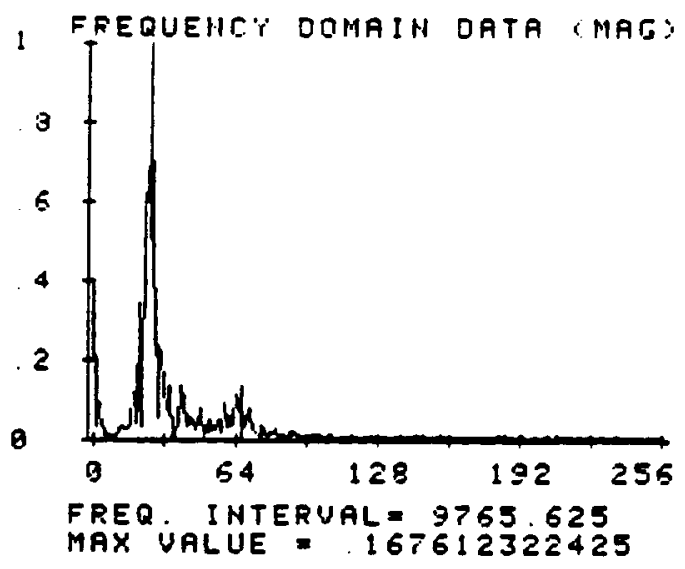

D1sk 12/Track 5/Q1

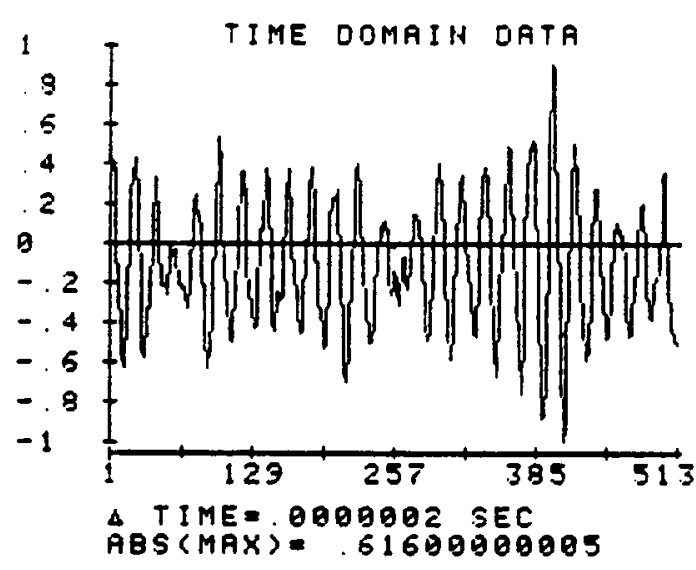

Sample Rate -200 asec

F1gure 12. Frequency Spectrum and Waveform of the Acoustic Coupler Response During Shutdown from Test No. 3

Data recorded during the shutdown sequence and presented in Figure 13 showed a high increase in the amplitude and the presence of highfrequency components in the frequency-domain data. The time-domain data Indicated that the peak-to-peak amplitude increased by more than a factor of 2; and the frequency-domain data indicated that very highfrequency components, particularly above $600 \mathrm{kHz}$, were present that were not notlced before. The high-frequency components could be indicative of cavitation during the shutdown sequence or a change in mechanlcal notse when the load on the transmission was reversed. Th1s cond1t1on was particularly difficult to expla1n, since it did not appear on the data recorded from subsequent tests.

The visual examination of all four bearings following test No. 3 indicated that no noticeable bearing damage occurred on any of the four bearings during this test. During subsequent tests, visible damage was reported on bearing No. 2. The analysis of the acoustic coupler response from the subsequent tests, however, did not indicate an increase in the nolse level. This is encouraging because the acoustic coupler mounted on bearing No. 3 should not detect nolse from bearing No. 2 .

Analysis of data recorded from test No. 3 and a comparison with data recorded by the MSFC data acquisition system indicated that the acoustic coupler as tested was operating in a frequency range where it would be posaible to detect an increase in nolse due to wear or damage to a bearing. In addition, the acoustic coupler clearly was able to withstand the cryogenic temperatures and mechanical vibrations associated with the BMT, since it performed satisfactorily on several consecutive test runs of the BMT. 

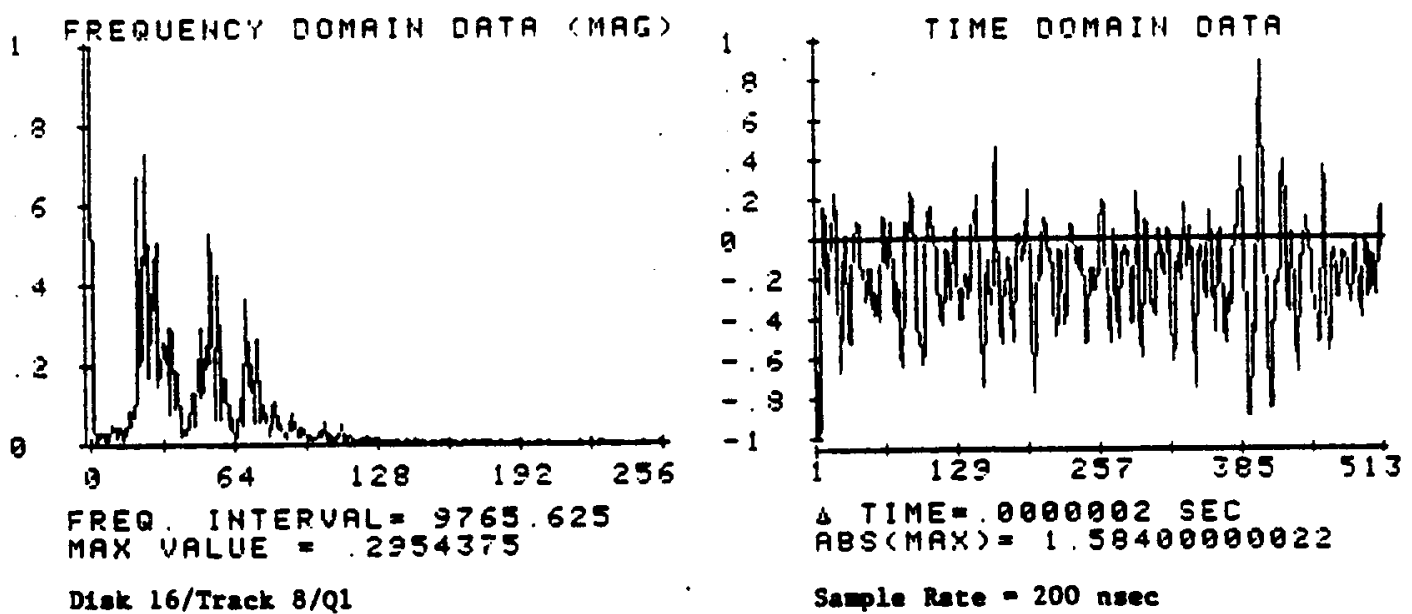

Figure 13. Frequency Spectrum and Waveform of the Acoust1c Coupler Response During Shutdown from Test No. 3

Figure 14 illustrates the condltion of the BMT imediately following test run No. 3. The preamplifier was mounted a sufficient distance away from the BMI to avold the cold and frost that occur directly on the BMT. The acoustic coupler was subjected to the cold and frost, but this did not caused deterforation of the acoustic coupler response.

In summary, the testing of the acoustic coupler on the BMT at Marshall Space Flight Center was successful. It demonstrated that the acoustic coupler design was within the nominal operating range.

\section{CONCLUSIONS AND RECOMENDATIONS}

From the results of laboratory tests and tests on the BMT at the Marshall Space Flight Center, the acoustic coupler design proved to be satisfactory for monitoring the cryogenic bearings during testing on the BMr. Further, the design of the acoustic coupler, its frequency range of detection, the dynamic noise range, and the selected gain of the ampliffer were such that the detection of increased bearing noise due to worn or damaged bearings was possible. No conclusion can be reached about the effect of cavitation, since cavitation was not detected durlng these tests; however, it may be assumed that cavitation would override the mechanical notse from the bearlings and prevent the possibility of detecting bearing damage. Since this inltial test of the prototype acoustic coupler was successful, we recommend that acoustic couplers be installed on all four bearings in the BMT so that direct comparisons can be made among them. This compar1son will allow us to fully evaluate the sensitivity of the acoustic coupler for detection of bearing damage. 


\section{ORICNAL PAGE 10 \\ Of. POOR QUARTH}

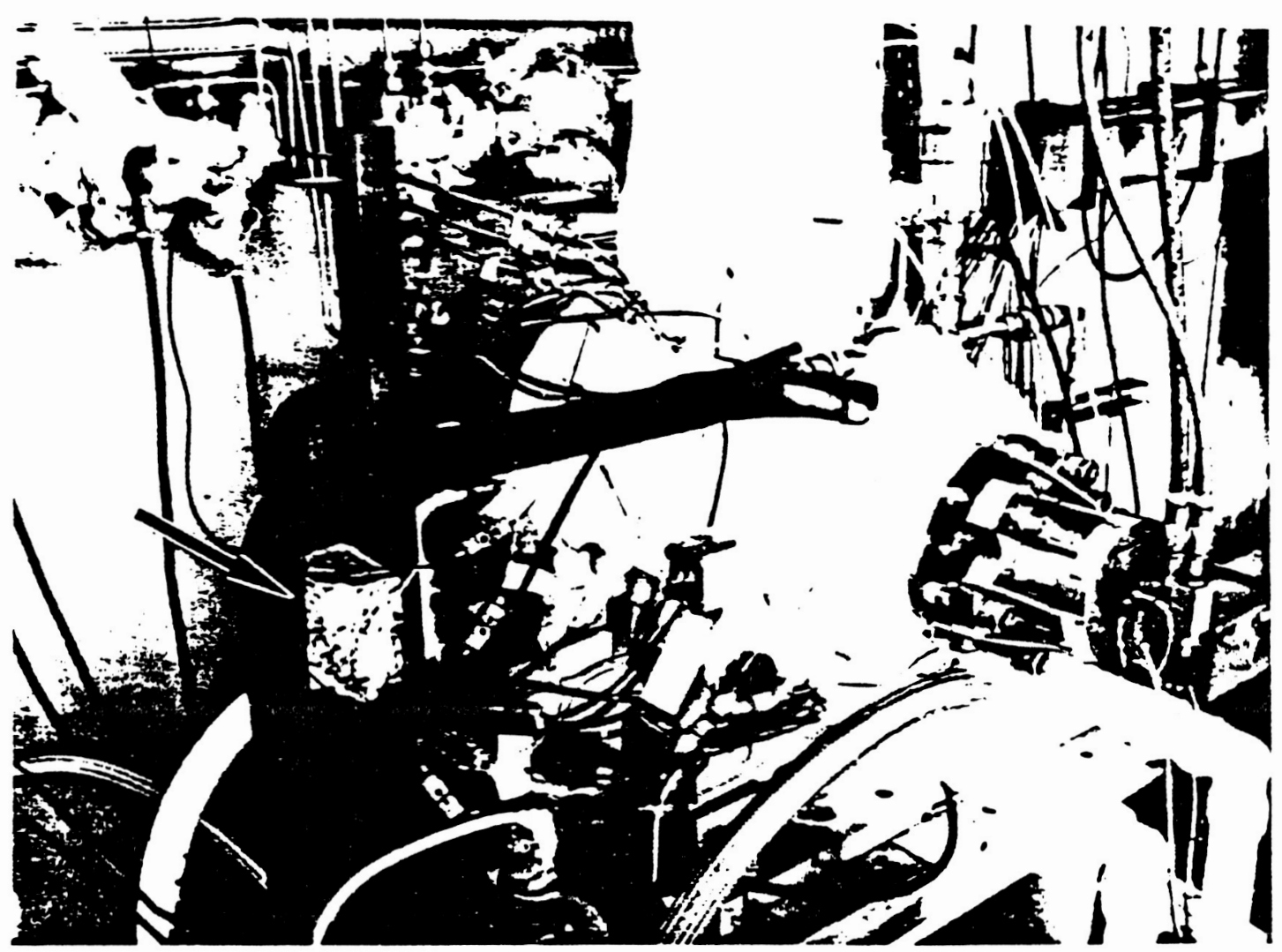

- Figure 14. Frost-Covered Bearing Materials Tester Immediately After Completion of a Bearing Test 